Participatory Mapping of Regional Food Assets using VolunteERED GEOGRAPHIC INFORMATION SYSTEMS

\author{
by \\ Victoria Fast \\ B.A. Honours Human Geography, Brock University, 2007 \\ M.A. Geography, Brock University, 2011 \\ A dissertation presented to Ryerson University \\ in partial fulfillment of the \\ requirements for the degree of \\ Doctor of Philosophy \\ in the program of \\ Environmental Applied Science and Management
}

Toronto, Ontario, Canada, 2015

(C) Victoria Fast, 2015 


\section{AUTHOR'S DECLARATION FOR ELECTRONIC SUBMISSION OF A DISSERTATION}

I hereby declare that I am the sole author of this dissertation. This is a true copy of the dissertation, including any required final revisions, as accepted by my examiners.

I authorize Ryerson University to lend this dissertation to other institutions or individuals for the purpose of scholarly research.

I further authorize Ryerson University to reproduce this dissertation by photocopying or by other means, in total or in part, at the request of other institutions or individuals for the purpose of scholarly research.

I understand that my dissertation may be made electronically available to the public. 


\section{Abstract \\ Participatory Mapping of Regional Food Assets using Volunteered Geographic Information Systems}

Degree: PhD, Environmental Applied Science and Management

Year and Institution: 2015, Ryerson University

Name of Graduate: Victoria Fast

Local food systems are increasingly being studied in response to the threats imposed on global agri-industrial food systems. Central to local food is the community who is imagining and implementing diverse and hyper-local food assets, which are making a significant, but largely unknown, contribution to food security, resiliency, and sustainability. It is important to align these assets with broader regional food policies, programs, and regulations. However, there are few mechanisms to engage stakeholders or share local information. One possible mechanism to learn about local food assets is volunteered geographic information (VGI); a phenomenon that blends crowdsourcing, citizen science, and online mapping. It is currently being studied for its ability to engage and gather information from diverse and under-represented groups.

This policy-relevant research investigates how VGI can support greater engagement and knowledge sharing across diverse food stakeholders. To achieve this objective, the VGI system framework is established to study the processes that support the creation of VGI. Next, the new era of food mapping, dubbed Food Mapping 2.0, is investigated to understand the impact evolving mapping techniques have on the engagement of food stakeholders. Lastly, the VGI systems framework, which is embedded in participatory geographic information system and participatory action research methods, is applied to support participatory mapping of regional food assets in Durham Region.

This research gathered contributions on over 200 food assets in Durham Regionan upper-tier municipality just east of Toronto consisting of eight lower-tier municipalities-effectively capturing the distributed intelligence of government, not-forprofit, and community stakeholders. The crowdsourced data include locations, descriptions, and media related to farms, markets, community gardens, foodscapes, and 
other innovative food assets. The community identified urban food assets as a central strength of the regional food system. Overall, this project enabled the creation of an open food assets dataset, further supporting the development of an online Food Assets map and a Crowdsourcing Urban Food Assets report, which are collective used to inform future food policy, regulation, and program development. Overall, this research revealed a uniquely local and community-driven perspective about food system assets within Durham, while serving as a prototype of the VGI systems framework. 


\section{ACKNOWLEDGEMENTS}

The acknowledgements contained herein are a mere fraction of the gratitude I have for the vast support network that lead to my ability to complete this research.

First and foremost, I would like to thank my supervisor, Dr. Claus Rinner. It has been an honour and a privilege to be his first graduating PhD student. With Dr. Rinner came the connection to the GEOIDE (PIV-41) and Geothink research projects, both led by the talented and exuberant Dr. Renee Sieber (McGill University), which introduced me to a network of academics, students, speciality conference and research meetings, and ways of thinking that undoubtedly enriched my personal research process. A 3-year SSHRC JosephArmand Bombardier Doctoral Scholarship, a 1-year Ontario Graduate Scholarship, and contributions from the Environmental Applied Science and Management program funded this work, allowing me to focus on my research and complete on time.

Beyond my supervisor, research network, and funding, there are so many other people I would like to acknowledge for their support, mentorship, and friendship. The following is the installation of a perpetually evolving list of influential people, and I humbly recognize that it is nowhere near complete:

Dr. Chris Gore, Dr. Eric Vaz, and Dr. Jessica Wegener - PhD committee

Dr. Nick Chrisman - GIS guru and external examiner

Ms. Suzanne Elston - inspiring environmental advocate

Dr. Marilyne Jollineau - lifelong advisor

Dr. Michal Bardecki - program advisor

Ms. Elias Chu - program administrator

Ms. Kathryn Enders - trusted advisor

Fast, Tasker, and Powell families - personal support network

Natalya Androsova and Christina Halliday - dissertation coaches

Geography and Environmental Studies at Ryerson University - colleagues and friends

Yates School of Graduate Studies and related support networks - Ryerson University

Finally, this work could not have been completed without the active participation of Durham Region's food community and the partnership with the Durham Food Policy Council. Thank you for letting me be your local food champion! 
This work is dedicated to all the amazing people

in Durham Region and around the globe, working tirelessly to build a better food system...

for all. 


\section{TABle of Contents}

Author's Declaration...................................................................................................... ii

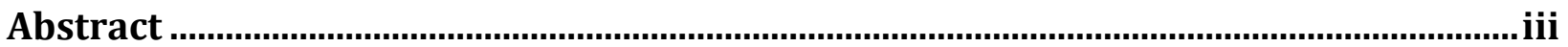



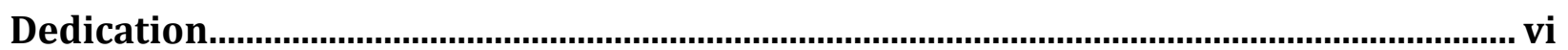



List of Tables .................................................................................................................

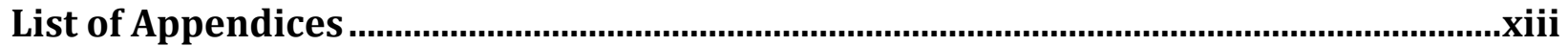

1. Introduction

1.1 Local and Regional Food Systems ......................................................................................... 1

1.2 Turning toward Volunteered Geographic Information ............................................................ 3





1.5 Outline of Chapters and Authorship Statement ………............................................................. 6

2. A Systems Perspective on Volunteered Geographic Information ...............................10

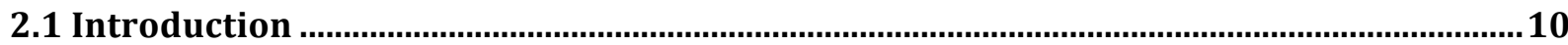

2.2 A Brief History of VGI ...........................................................................................................12















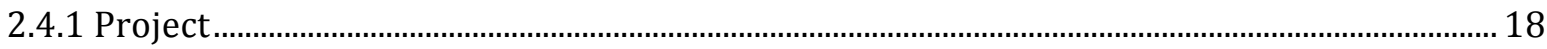



2.4.3 Technical Infrastructure: Hardware, Software, and the Geoweb ............................................ 21

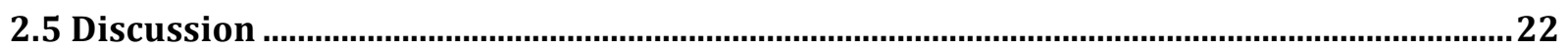

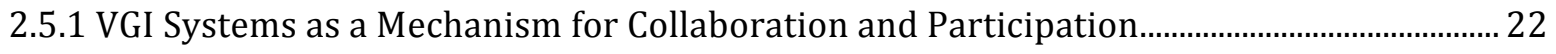

2.5.2 Critical Assessment of Collaboration and Participation within VGI Systems ........................ 24 


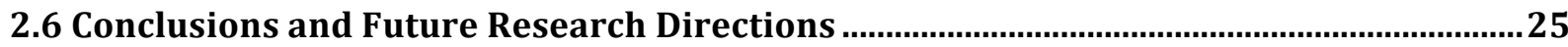

3. Food Mapping 2.0: Climbing the Ladder of Stakeholder Engagement......................27

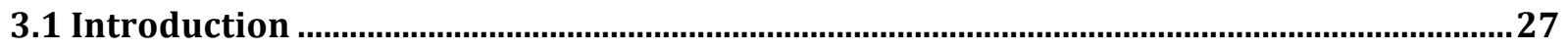

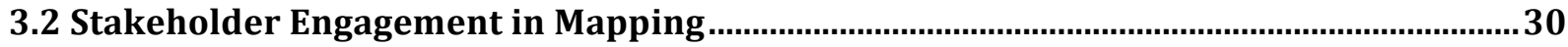

3.2.1 Geographic Information Systems and Participatory GIS .......................................................... 31

3.2.2 Web 2.0

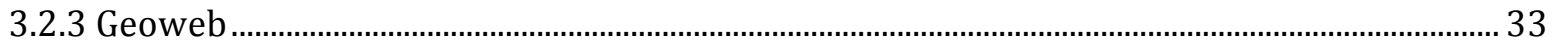

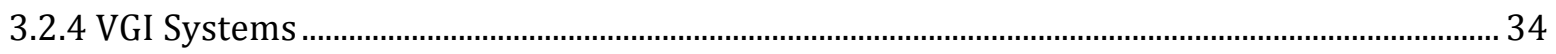

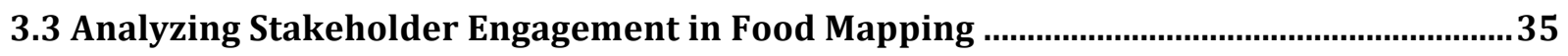





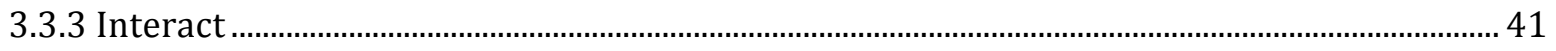

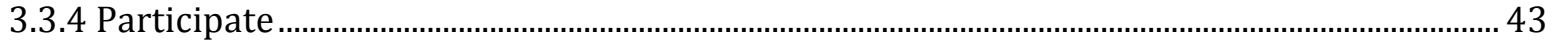

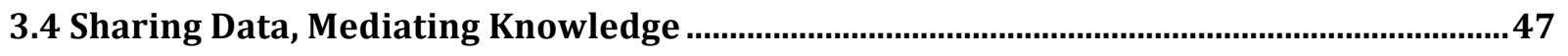

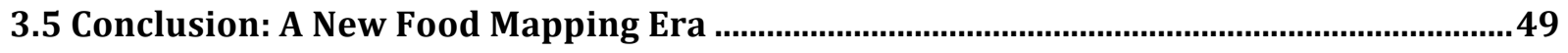

4. Methods: Building the Durham Food Map using Volunteered Geographic

Information Systems.........................................................................................................50

4.1 Building a VGI System using Active and Participatory Methods...........................................50

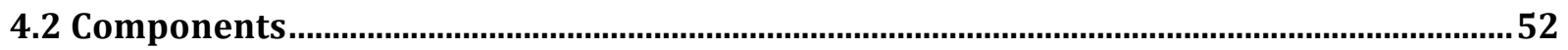

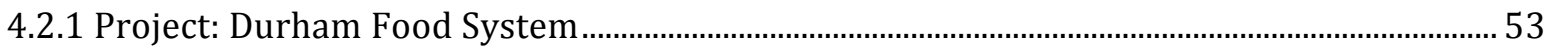

4.2.2 Participants: Durham Local Map Actors ……….............................................................................. 55

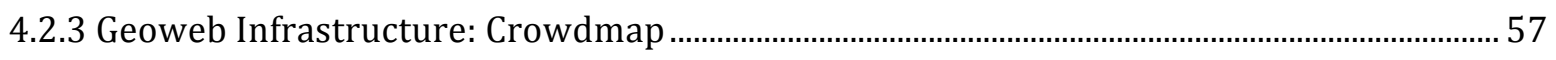

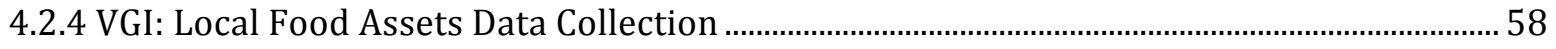

4.3 Functions



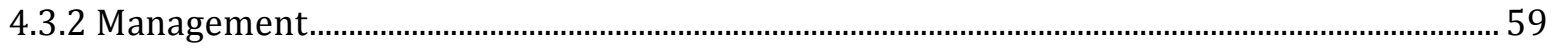



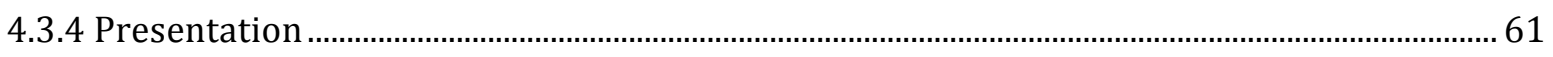

4.4 Conclusion

5. Results and Discussion: Reporting Food Assets in Durham Region .........................66

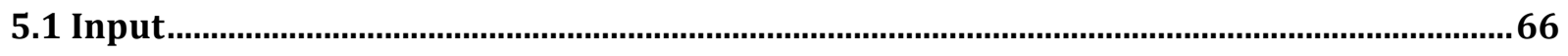




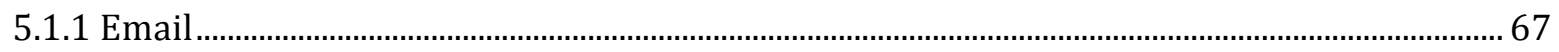

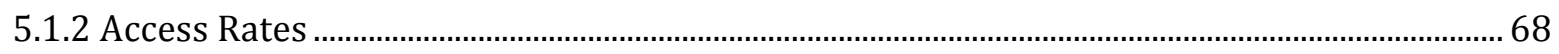

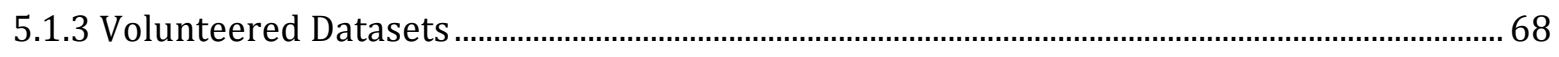

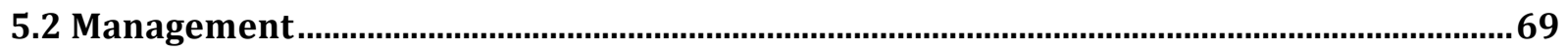

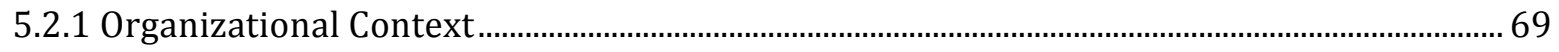

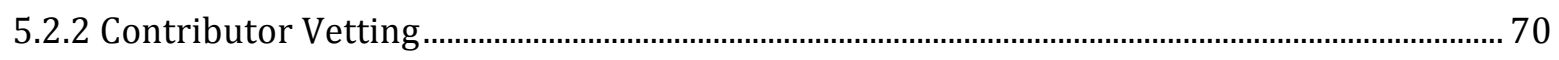

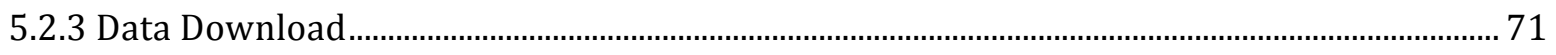

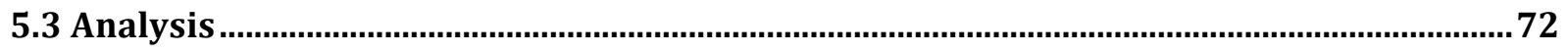

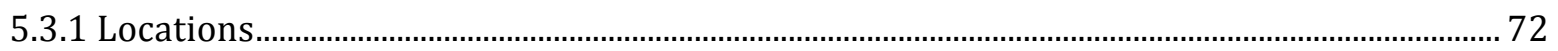

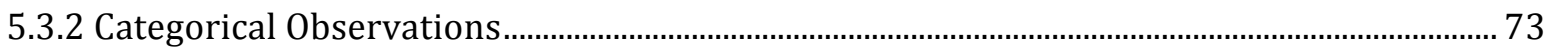

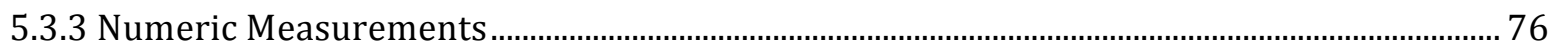

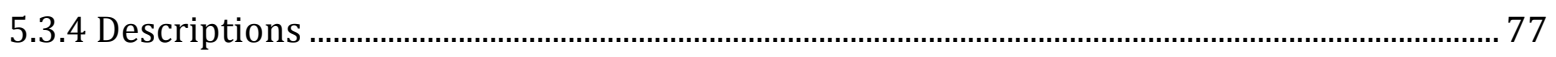

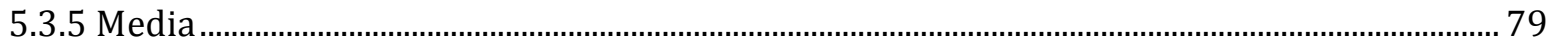



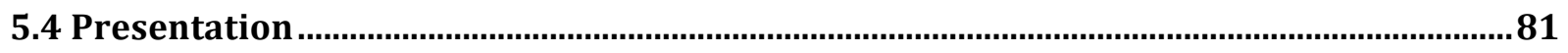

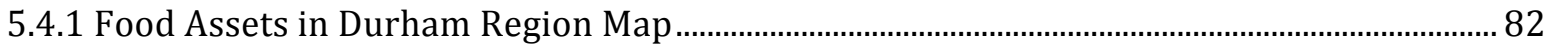

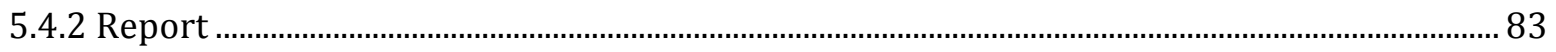

5.5 Process Benefits: Engaging the Regional Food Community …........................................... 84

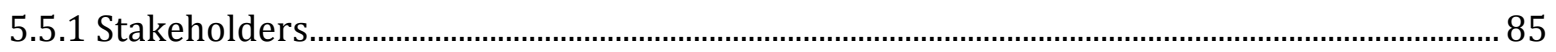

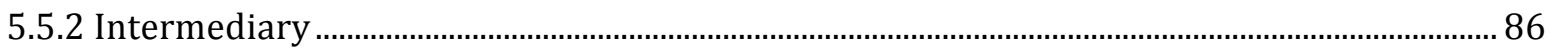

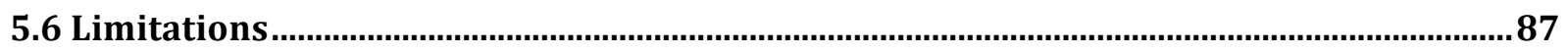

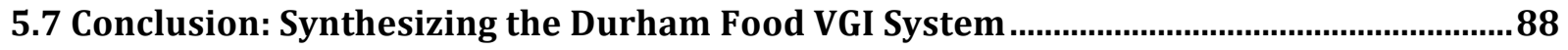

6. Conclusion: Learning from VGI Systems ............................................................ 122

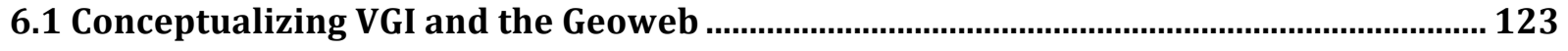

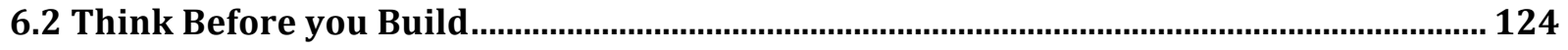

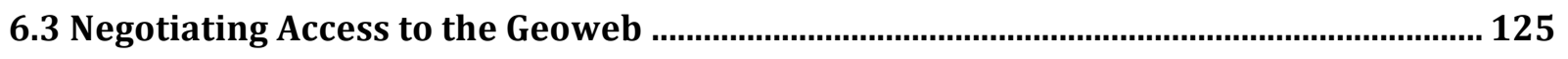

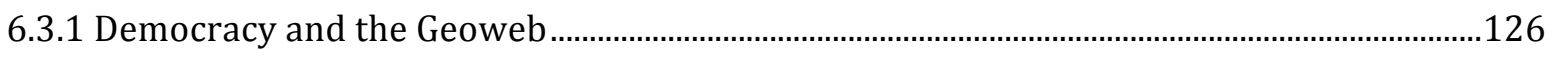

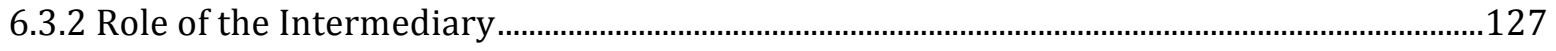

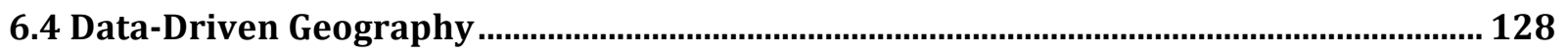

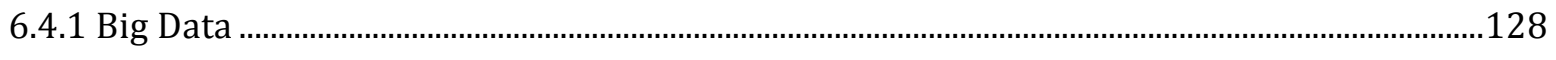

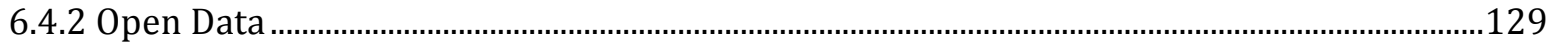


6.4.3 Data, Information, and Knowledge in VGI

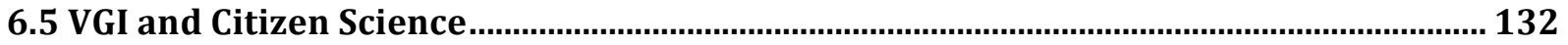

6.6 VGI systems: Beyond Food to Mental Health and Air Quality Monitoring...................... 133

6.6.1 Crowdsourcing Mental Health Resources …….........................................................................133

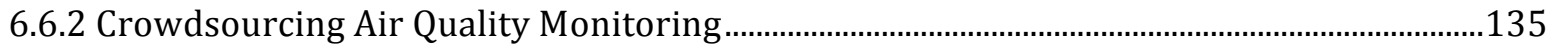

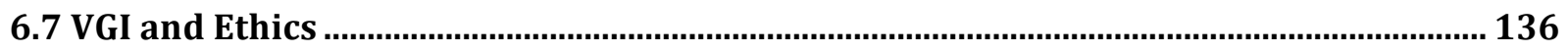

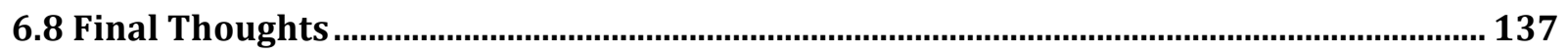

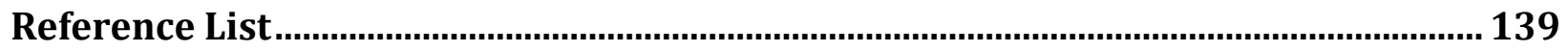

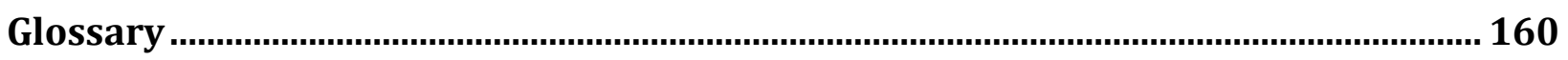

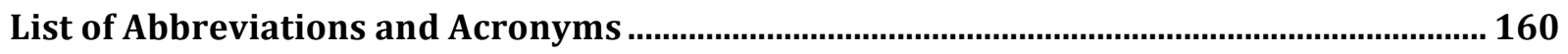

List of Software and Applications.............................................................................. 160

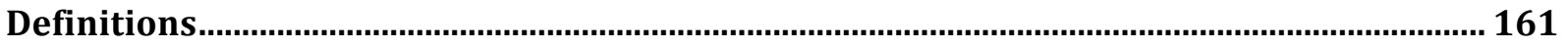




\section{LIST OF FIGURES}

Figure 1.1: Incidences of \#LocalFood tweets in the Greater Toronto and Hamilton Area ... 4

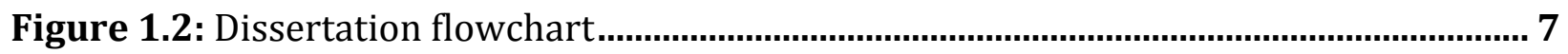

Figure 2.1: The components of volunteered geographic information (VGI) systems............18

Figure 3.1: The ladder of stakeholder engagement in food mapping ……..............................36

Figure 3.2: Levels of participation within the ladder of stakeholder engagement ................44

Figure 5.1: Sessions recorded via Google Analytics from February to May 2015 ..................68

Figure 5.2: Food Assets in Durham Region map created using CartoDB and data

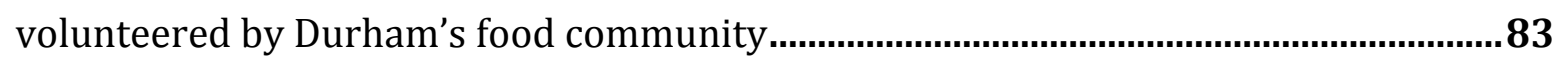

Figure 6.1: The range of VGI contributor characteristics .................................................. 131 


\section{LIST OF TABLES}

Table 4.1: Components and functions of Durham's Local Food VGI system...........................52

Table 5.1: Summary of volunteered contributions, vetting, and input ..................................67

Table 5.2: Typology of volunteered contributions to the Durham Food Map........................72

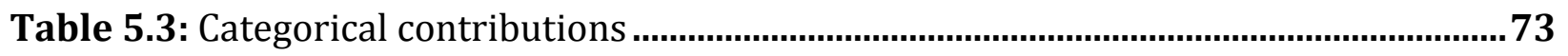

Table 5.4: Types, fields, and subfields in Durham's food asset dataset ..................................81 


\section{LIST OF APPENDicES}

Appendix 4A: Summary of Stakeholder Groups, Contact, and Outreach ..............................63

Appendix 4B: Email to Local Food Stakeholders ……........................................................64

Appendix 4C: Promotional YouTube Video Script .............................................................65

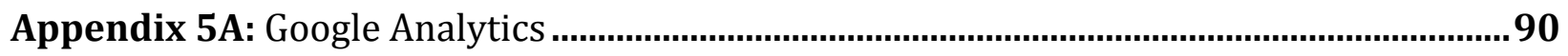

Appendix 5B: Detailed Contribution Types Receiving from Each Contributor Group..........91

Appendix 5C: Crowdsourcing Urban Food Assets ...................................................................92 


\section{INTRODUCTION}

\subsection{Local and Regional Food Systems}

Food systems are essential to everyday life, providing nourishment for a growing population. However, food systems are vulnerable to the threats posed by a changing climate, population pressures, the shift to urban living, and the loss of productive agricultural land (Hoffmann, 2013). Further, there is growing evidence that the current

food system is inequitable, unsustainable, not producing a healthy diet for the population (Scharf, Levkoe, \& Saul, 2010). These threats highlight the need for adaptive strategies to build more resilient food systems. Local food systems are increasingly being studied and implemented as a part of the solution to make food systems more resilient, sustainable, secure, and just.

Local food systems are hard to concretely define, and encompass many variations (Hincrichs, 2003). Local food systems represent the actions of community groups (Levkoe, 2011), municipalities (Deloitte, 2013), provinces (Baker, Campsie, \& Rabinowicz, 2010), and even the actions of nations (Levkoe, Bebee, Wakefield, Castel, \& Dávila, 2012). The term equally encompasses the 100-mile diet and the 100-metre diet (Morrison, Nelson, \& Ostry, 2011; L. Newman \& Dale, 2009); the difference between food grown in the region of consumption versus food grow in backyard gardens. The initiatives within the broad spectrum of local food consist of many diverse and hyper-local places of food production, sharing, and consumption, which are contributing a sizable, but largely unmeasured, amount of food to communities.

When it comes to food system planning, Clancy \& Ruhf (2010) ask: "Is local enough?" They assert that regional food systems are more concretely defined, and have greater economic, policy, and program development capacities than local food systems alone. In Canada, regional municipalities operate below the province and above cities and towns, and have jurisdictional authority over local food systems; decision-makers are 
responsible for undertakings such as land use planning, food policies, and supply chain management (Baker et al., 2010; Feagan, 2007). Food hubs are a prominent example of a regional food system jurisdiction, which aims to foster regional distribution and purchasing for both wholesale and retail purposes (Mount \& Andrée, 2013).

There are many stakeholders operating within the regional food system, including government, not-for-profit organizations, businesses, researchers, community groups, and civil society. There are also many food assets contained within the regional food system, encompassing urban and rural interests. Urban food assets typically manifest themselves at a municipal scale or smaller, and are often labeled urban agriculture (Macias, 2008; Pothukuchi, Joseph, Burton, \& Fisher, 2002; Scharf et al., 2010). Related activities include establishing and maintaining community gardens, hosting food-related events, and promoting food literacy through workshops (Deloitte, 2013). Rural food assets typically focus on the more traditional farms, encompassing production, distribution, and processing resources.

Regional food systems have the potential to enact the greatest change to the food system, as the decision-makers within are able to adapt to the local environment and respond to the unique needs of the urban and rural factions. In order to strengthen the capacity of regional food systems, there is a call for better connections across the spectrum of food system stakeholders and a need to understand the local context (Dubbeling, Hoekstra, Renting, Carey, \& Wiskerke, 2015; Rural Economic Development Program, 2013). To this end, an important step to catalyzing change in the regional food system is to convene the wide range of food stakeholders who are active in regional food systems and create a detailed understanding of food assets. This stakeholder engagement and data on food assets in the region can then be used to support the development of locally appropriate, innovative, and inclusive (multi-sector) food policies. 


\subsection{Turning toward Volunteered Geographic Information}

Digital and Web technologies have been identified as a prospective, yet currently underdeveloped, avenue to support engagement and data creation within regional food systems (Bill 36, 2013; Rural Economic Development Program, 2013). While there are currently few mechanisms to report food assets, volunteered geographic information (VGI) could support greater engagement and knowledge sharing across diverse people and subjects. Part of the broader phenomenon of crowdsourcing (Brabham, 2009), VGI refers to user-generated contributions that contain a location component (Goodchild, 2007; Sui, Elwood, \& Goodchild, 2013). In fact, individuals create, share, and use various forms of VGI near daily.

Currently, there are various types of VGI. Footprint VGI refers to information containing location attributes (e.g., latitude/longitude, address) that the public unknowingly contributes when they are interacting with common processes (e.g., retail point of sale) or applications (e.g., location-enabled smart phones). Rabari \& Storper (2014) refer to this as the digital skin of cities and relate it to big data, suggesting that urban environments are turning into information factories. Examples include tracking the location of credit card purchases, which can be used to help banks identify fraudulent credit card behaviour or track purchasing behaviours for future marketing purposes. Beyond this introduction, this research does not employ footprint VGI.

Passive VGI refers to information, again containing location attributes, that the public are knowingly producing but they are not intending the information to be used for further (spatial) analysis. For example, individuals using Twitter to tweet about \#LocalFood do not intend for their data to be used to map the hashtag \#LocalFood around the Greater Toronto Area (Figure 1.1). Passive VGI is more closely associated with the initial 'citizen as sensors' conceptualization of VGI, introduced by Goodchild (2007). Since the inception of VGI in 2007, there has been a profound transformation in how VGI is created, distributed, and consumed (Sui et al., 2013). 


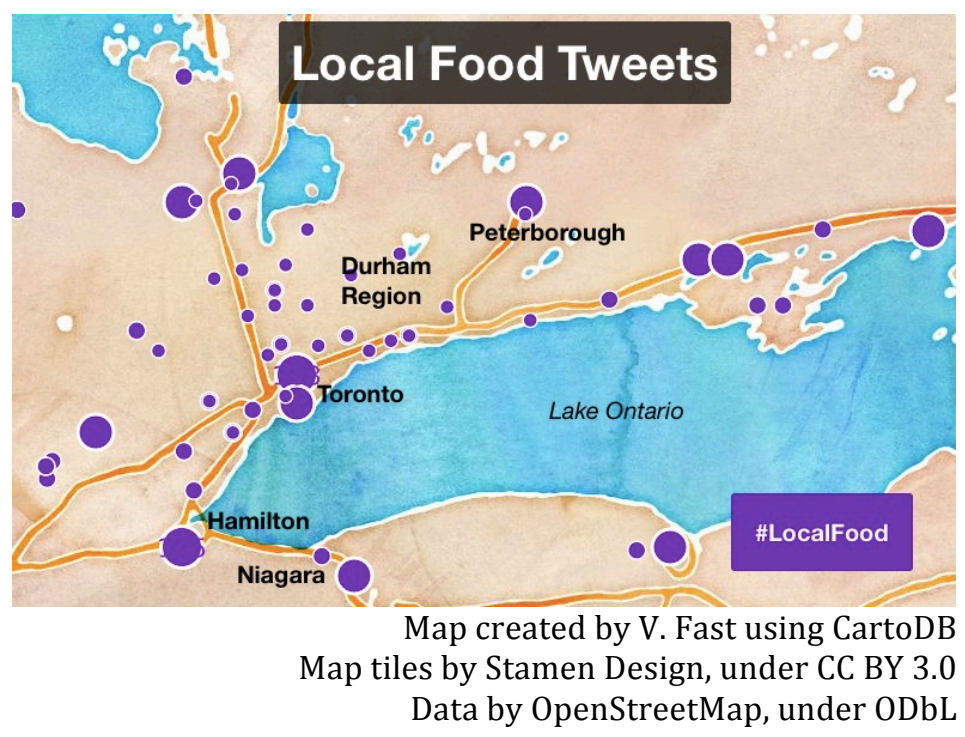

Figure 1.1: Incidences of \#LocalFood tweets in the Greater Toronto and Hamilton Area, November 2014

The last type of VGI is active contributions, where the public knowingly and intentionally contribute information for the purpose of the project (Haklay, 2013a). This type of VGI is often collected in citizen science projects where the public is engaged to actively contribute to various aspects of scientific research, such as employing hikers to monitor alpine plant life cycles in New Hampshire mountains (Wiggins \& Crowston, 2015). Within the geographic realm, there has been substantial progress in participatory mapping methods directed at collecting active VGI from a range of citizens and stakeholders who are, in some cases, also involved in project development (Haklay, 2013a).

This type of participatory mapping is creating space for dialogue among many diverse actors. The public engagement enabled by VGI, and crowdsourcing more broadly, is unprecedented and continues to expand. This engagement has been shown to lead to meaningful public contributions in both science and policy realms. For example, there is evidence that active VGI has engaged the public to create relevant data related to the monitoring forest disease (Connors, Lei, \& Kelly, 2012), report outdoor skating rink conditions as a proxy for winter weather trends (Lawrence, Robertson, \& McLeman, 2013), and discuss sustainable neighbourhood planning with the urban community (Rinner \& Bird, 2009). Further, VGI is increasingly being used by government to support evidencebased decision-making (Johnson \& Sieber, 2012a, 2012b; Vaz \& Arsanjani, 2015). 


\subsection{VGI and Food Asset Mapping}

Currently, there are few known examples of VGI being applied to map food systems. OpenStreetMap (OSM), designed to crowdsource mapping the world, has been incredibly successful at generating active VGI related to features and assets on the earth's surface. It has been most notably used in instances where authoritative base data are non-existent, out of date, financially inaccessible, or lack detail (Neis \& Zielstra, 2014). However, the focus of OSM contributions is on physical features on the earth's surface that can be represented using static geographic data, such as points, lines, and polygons, and simple attributes (e.g., type of object or name). Examples of food-related assets that are included in OSM are restaurants, cafes, and other food vendors.

OpenStreetMap does not include the many diverse and hyper-local food places because they are not permanent fixtures on the earth's surface. These provisional food assets, which are central to the regional food system, include pop-up farmers' markets, community gardens, and seed swaps that typically occur before or during the growing season, rather than year round. While recent OSM efforts have been dedicated to placing some of the temporary places of food on the map, such as institutionalized farmers' markets and well-established community gardens, many food assets remain underrepresented or entirely missing from OSM. I suspect that active VGI has the potential to support greater engagement and knowledge sharing within regional food systems.

\subsection{Research Objective}

The purpose of this research is to investigate how VGI can be used to engage a wide range of food system stakeholders in order to add local information to the broader regional food policy arena. To achieve this objective, the following three interrelated research questions are addressed in this thesis.

Research question 1: What processes support the creation of VGI?

Research question 2: How has mapping been used to support food systems, and what is the impact of mapping on the engagement of food system stakeholders?

Research question 3: Applying a VGI systems approach, what does VGI contribute to Durham's food system and its stakeholders? 
Overall, these interrelated research questions guide the development and deployment of the Durham Food Map, a participatory map of location-based food assets created using a VGI systems approach. This policy-relevant research aims to inform our understanding of the assets by engaging stakeholders within the local food system in order to improve Durham's regional food system. Further, the map is intended to leverage stakeholders' knowledge to increase the transparency and accessibility of information on the regional food system.

\subsection{Outline of Chapters and Authorship Statement}

The research in this dissertation is organized into six chapters (Figure 1.2). Following this introduction, the foundational work is presented in Chapters 2 and 3. Chapter 2 addresses research question one by establishing the VGI systems framework, which is then used as the conceptual framework for the research study. Chapter 3, addressing research question two, assesses how food system mapping has been used to support knowledge sharing and its impact on engagement. Building on the work in Chapters 2 and 3, research question three is presented in Chapters 4 and 5 . In this section of the thesis, the VGI systems framework is applied to supporting regional food mapping and food stakeholder engagement in Durham Region. Lastly, Chapter 6 wraps up the dissertation with a series of lessons relevant to the burgeoning VGI field.

The thesis has been written in a combination of manuscript-style (chapters 2 and 3) and traditional style (chapter 1, 4, 5, and 6), as permitted by the guidelines of the graduate program. The remainder of the thesis consists of the following chapters. 


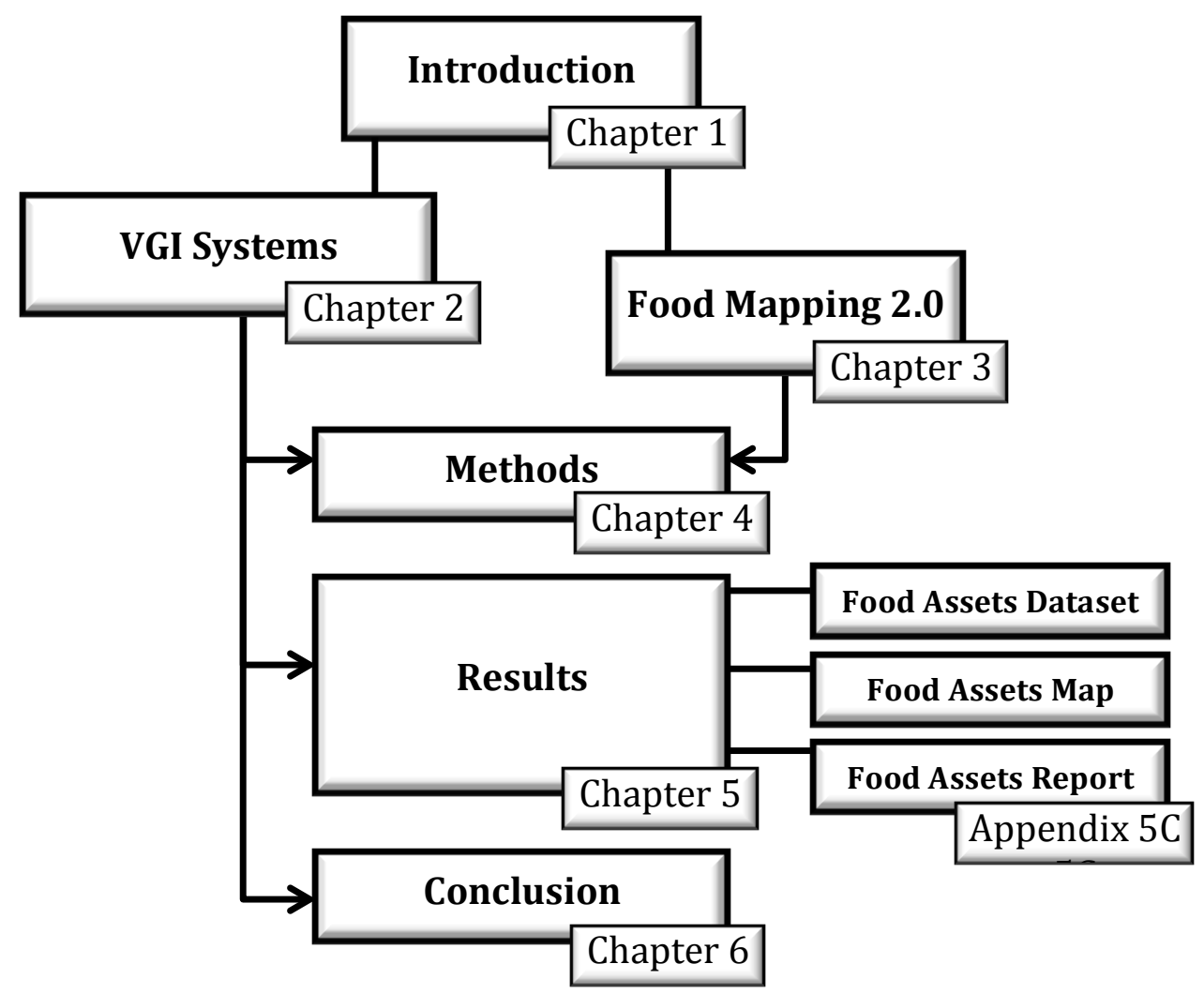

Figure 1.2: Dissertation flowchart

Chapter 2, A Systems Perspective on Volunteered Geographic Information, reviews recent developments in VGI, the Geoweb and GIS, for the purpose of establishing a framework to support the creation of VGI. The VGI systems framework-defined by the project, active involvement of participants, Geoweb, and VGI-institutes the structure for the case study developed later in the thesis. Applying a systems perspective leads to a better understanding of the components and functionality needed to effectively create VGI. Authorship statement: Victoria Fast and Claus Rinner conceived the concept of VGI systems, and Victoria Fast developed the framework and wrote the manuscript with input from Claus Rinner.

This chapter has been published as follows:

Fast, V., and Rinner, C. (2014). A Systems Perspective on Volunteered Geographic Information. ISPRS International Journal of Geo-Information, 3(4), 1278-1292. doi:10.3390/ijgi3041278 
Chapter 3, entitled Food Mapping 2.0: Climbing the Ladder of Stakeholder Engagement, explores rapidly evolving mapping technologies have been applied to communicating the intricacies of complex food systems. Recent advancements in mapping are presented, using a ladder of engagement to highlight the visualization, collaboration, interaction, and participation capacities currently used in food system mapping. While many projects achieve visualization and collaboration using GIS and data sharing, interaction and participation using the Geoweb and VGI can be a potentially underdeveloped resource to support community and knowledge sharing to build a sustainable and resilient food system. Authorship statement: Victoria Fast wrote Chapter 3 as a single-author manuscript for submission as a review paper.

The methods developed in Chapter 4, Building the Durham Food Map using VGI Systems, establish the process of creating a VGI system to support the participatory mapping of Durham's local food assets. They are rooted in participatory methods, blending active participant observation with participatory geographic information systems to maximize the involvement of the researcher and the regional food community, respectively. The methods adhere to the components and functions of VGI systems established in Chapter 2, providing details on the project, participants, Geoweb, and VGI components and the input, management, analysis, and presentation functions supporting the creation of the Durham Food Map. Authorship statement: Victoria Fast wrote Chapter 4 in traditional thesis style for subsequent revision towards publication.

Chapter 5, Reporting Food Assets in Durham Region, presents the findings and outcomes of implementing a VGI system to support the participatory mapping of Durham's regional food assets. First, the process of establishing the input, management, analysis, and presentation functions are reported. Emerging from this project is the food assets dataset generated by the food community in Durham Region. This dataset enabled the development of an online interactive map on Food Assets in Durham Region. Further, this project enabled the development of the Crowdsourcing Urban Food Assets report, prepared as a white paper for the Durham Food Policy Council. These resources are informing current and ongoing discussions and policy development aimed at strengthen the regional food system. The discussion elaborates on the engagement of the various 
stakeholder groups, including the regional food community and the project intermediary. Overall, this research served as a case study to test the VGI system framework, while contributing new information about assets operating in Durham's Regional food system. Authorship statement: Victoria Fast wrote Chapter 5 in traditional thesis style for subsequent revision towards publication.

The final Chapter 6, Conclusion: Learning from VGI Systems, summarizes the research results, discusses progress made toward answering the research questions, and considers the overall research goal. The bulk of this chapter concludes with a series of reflections, lessons learned, and areas for future research, focussing on VGI and Geoweb considerations that warrant further attention. Authorship statement: Victoria Fast wrote Chapter 6 in traditional thesis style, where the ideas within are direction for both future work and publication. 


\title{
2. A Systems Perspective on VolunteERed Geographic Information
}

\begin{abstract}
Volunteered geographic information (VGI) is geographic information collected by way of crowdsourcing. However, the distinction between VGI as an information product and the processes that create VGI is blurred. Clearly, the environment that influences the creation of VGI is different than the information product itself, yet most literature treats these as the same. Thus, this research is motivated by the need to formalize and standardize the systems that support the creation of VGI. To this end, we propose a conceptual framework for VGI systems, the main components of which-project, participants, and technical infrastructure-form an environment conducive to the creation of VGI. Drawing on examples from OpenStreetMap, Ushahidi, and RinkWatch, we illustrate the pragmatic relevance of these components. Applying a systems perspective to VGI allows us to better understand the components and functionality needed to effectively create VGI.
\end{abstract}

Keywords: crowdsourcing; geographic information science; geographic information systems; Geoweb; public participation GIS; systems science; volunteered geographic information

\subsection{Introduction}

The geospatial Web 2.0, or Geoweb for short, is a collection of online locationenabled services and infrastructure that is engaging a wide range of stakeholders in mapping processes. The interactions between individuals and groups with the Geoweb environment is, in some instances, generating volunteered geographic information (VGI). Simply defined, "VGI is crowdsourced geographic information provided by a wide range of participants with varying levels of education, knowledge, and skills" (Haklay, Antoniou, 
Basiouka, Soden, \& Mooney, 2014, p. 8). This type of geographic information, or geoinformation, derived from the public through active or passive engagement is part of the larger phenomenon of user generated or crowdsourced content (Goodchild, 2007), and is producing novel, and often valuable, sources of geo-information (Flanagin \& Metzger, 2008; Goodchild \& $\mathrm{Li}, 2012$ ). In the context of the general trend of declining resources for national mapping agencies and the elimination of the Statistics Canada long-form census (Walton-Roberts et al., 2014), VGI is becoming especially important where authoritative geographic information is lacking (Haklay et al., 2014).

Adding to the value of a novel source of geographic information, there is mounting evidence that institutions-including government and non-government organizations (NGOs) - can use VGI as a mechanism to build local capacity to support collaboration, supplement traditional data sources, and inform decision-making. Johnson \& Sieber (2012a, 2012b), for example, explored both the motivation driving government adoption of the Geoweb, and strategies for increasing access to and use of the data subsequently produced. Haklay et al. (2014) studied VGI use in government, providing the most comprehensive guide for VGI implementation to date. They further noted that the process by which the data are collected-including organizational practices, regulatory issues (i.e., license conditions), and technical specifications-is more likely to impede the acceptance of VGI than the early concerns associated with quality, accuracy, and completeness of VGI. This raises the question: what are the organizational practices, regulatory issues, and technical specifications that support the production of VGI? Essentially, what systems support the creation of VGI?

Recent literature has alluded to the fact that there needs to be a formal, standardized framework for the creation of VGI for various reasons, which include increasing the completeness, accuracy, and reliability of the VGI produced. For example, Goodchild \& Li (2012, p. 118) highlighted that "the rules in use have been assembled pragmatically and without a conceptual or theoretical framework", suggesting that a framework can help formalize the VGI process and make it "amenable to implementation". Peng \& Tsou (2003) also encouraged Internet GIS users to understand the mechanisms of system implementation before applying Web-based GIS to the range of geographic 
problems. Finally, Goodchild stated, in a conversation with Turner, "I think the binary between local and professional knowledges is becoming problematic. We need to study the systems that have been used in some VGI projects to measure trust, rather than relying on simple surrogates like professional qualifications or membership in organizations" (M. W. Wilson \& Graham, 2013, p. 17). Indeed, studying the systems that have been used to generate VGI can tell us more than just about trust. Understanding the systems expands our knowledge of the conditions in which data are acquired; the people, both professionals and citizens, who are involved; and the technical infrastructure that enables the input, management, analysis, and presentation of VGI. As such, this paper proposes a conceptual framework for the systems that support future practical implementations of VGI.

Following this introduction, Section 2 of this paper provides a brief history of VGI, using OpenStreetMap, Ushahidi, and RinkWatch as examples. In Section 3, we look through the lens of systems science and geographic information systems to inform the development of VGI systems. In Section 4, we present both the components (project, participants, and technical infrastructure) and functions (input, management, analysis, and presentation) that are relevant, in varying degrees, to all VGI systems. Section 5 presents a discussion of the potential and limitations of VGI systems as a mechanism for collaboration and participation. We conclude with recommendations for future VGI systems research, development, and application, calling for strategic consideration of the systems that support the production of VGI.

\subsection{A Brief History of VGI}

Recognizing the value of geographic information created by non-experts, Goodchild (2007, p. 212) coined the term volunteered geographic information in 2007 "as a special case of the more general Web phenomenon of user-generated content". Goodchild referred explicitly to the notion of 'citizens as sensors', which was introduced previously by Burke et al. (2006) as 'participatory sensing'. VGI has also been described as 'user-generated geographic content' (Goodchild, 2008). The concept of geographic information that is crowdsourced is not new. Non-experts have been capturing, describing, and recording the spatial nature of their experiences throughout history; a sort of non-digital VGI. One of the 
most well-known examples is the Christmas Bird Count; starting in 1900, tens of thousands of participants voluntarily reported bird sightings at Christmas time, which led to an "unparalleled database of migratory and bird population data" (Flanagin \& Metzger, 2008,

p. 143). However, VGI was not a prominent topic in geographic research previously because it was difficult to capture these spatial experiences with enough detail to make a significant contribution to the development of spatial data and maps. It is within the VGI paradigm-enabled by the Geoweb, location-aware devices, and citizens acting as sensors - that the tools and resources for collecting and processing geographic information from volunteers are readily available. There are various aims for implementing a VGI system, which include base mapping coverage, emergency reporting, and citizen science. We highlight each of these drivers using OpenStreetMap, Ushahidi, and RinkWatch as examples.

\subsubsection{VGI and Base Mapping Coverage}

Arguably, one of the most successful VGI projects is OpenStreetMap (OSM), a global mapping application created by volunteers. Based on Wikipedia's peer production model, OSM provides free, editable, and downloadable coverage for the locations and geometries of topographic features (Haklay \& Weber, 2008). When compared to traditional mapping projects, the data generated through OSM is, in some areas, more detailed and accurate than the authoritative maps produced by national mapping agencies, such as the United Kingdom's Ordnance Survey (Haklay, 2010). Given the efforts of volunteers, these data are more readily updated, especially when there is an immediate need for more detailed data. Prior to the 2010 earthquake in Haiti, OSM data in the area surrounding Port-au-Prince were quite basic: shorelines and rudimentary road coverage. Immediately following the earthquake, the urgent need for detailed topographic data triggered a massive response by the OSM community. Both on the ground (i.e., uploading GPS tracks) and remote (i.e., tracing satellite images) contributions were uploaded, totaling over 10,000 edits in just a few short weeks, which effectively helped thousands of relief workers navigate the disaster area (Zook, Graham, Shelton, \& Gorman, 2010). The utility and open access of OSM is also extending the base mapping coverage to many thematic uses. In fact, in the report on 
'Crowdsourcing Geographic Information Use in Government', 10 of the 29 case studies rely on the OSM data, platform, and/or community (Haklay et al., 2014).

\subsubsection{VGI and Emergency Reporting}

Similar to the disaster relief efforts enabled by OpenStreetMap, VGI is popular in what has been described as humanitarian aid (Haklay et al., 2014), emergency reporting (Coleman, Georgiadou, \& Labonte, 2009), and crisis mapping (Beaudreau, Johnson, \& Sieber, 2012). It is within these humanitarian aid efforts where we start to understand the power of the crowd, or what Dodge \& Kitchin (2013, p. 19) describe as "the power that can emerge from a mass of individuals converging to tackle a set of tasks". The motivations to volunteer are diverse; they seem to be imbedded in the social practices associated with VGI (Elwood, Goodchild, \& Sui, 2012), which facilitate the ability to "connect socially, communicate meaningfully, and contribute collectively" (Dodge \& Kitchin, 2013, p. 20). Motivations aside, there is a growing response by volunteers to contribute geo-information to emergency response. Haklay et al. (2014) categorize the use of crowdsourced geographic information in humanitarian efforts as either proactive (natural disaster preparedness) or reactive (crisis management).

As an example, map based emergency reporting was used during the political turmoil that ensued from the 2007 Kenyan presidential election. Striving for a more accurate understanding of what was happening on the ground during the crisis, local activists developed the Ushahidi (meaning 'testimony' in Swahili) platform, which enabled citizens to report incidents of violence to the online map using both simple text messages (SMS) and the Web (Okolloh, 2009). Since the initial development of Ushahidi, the platform has been packaged and made available to the public, meeting a wide range of crisis mapping (and crowdmapping) needs and supporting thousands of new deployments, including relief efforts following the Haitian earthquake (Zook et al., 2010). Interestingly, what initially began as overcoming the weaknesses of traditional media (Okolloh, 2009) has turned into a supplemental, and sometimes superior, alternative to traditional information channels in times of crisis. 


\subsubsection{VGI and Citizen Science}

VGI is increasingly being used in the domain of science and research. Broadly categorized as citizen science, these "projects engage members of the public in working with professional scientists in a diverse range of practices" (Edwards, 2014, p. 1). Although citizen science predates VGI, Goodchild (2007) first introduced the term VGI by relating it to the concept of citizen science because scientific observations are often associated with well-defined geographic features. Haklay (2013) describes the integration between citizen science and VGI as 'geographical citizen science'. Within the citizen science scope, VGI is being used most frequently in environmental monitoring (Gouveia \& Fonseca, 2008; Rinner, Kumari, \& Mavedati, 2011; Seeger, 2008). A notable example of VGI in the realm of citizen science is RinkWatch: a project that gathers VGI from people who have backyard ice rinks in the winter months. Aided by the Geoweb, rink enthusiasts make routine observations regarding the 'skatability' of their rinks, which in turn, builds a detailed database about environmental conditions and their change over time. The project is helping researchers study the micro-level impacts of climate change (Damyanov, Damon Matthews, \& Mysak, 2012). The growing number of citizen science projects is filling in information gaps between the public, scientists, and decision-makers, by drawing on a range of trained and ad-hoc observers (Connors et al., 2012). Moving forward, we draw on OSM, Ushahidi, and RinkWatch examples throughout the paper to demonstrate how the creation of VGI can be conceptualized.

\subsection{Toward Defining VGI Systems}

Various authors have already identified a range of components, functions, and subsystems that govern VGI systems. For example, Hardy, Frew, \& Goodchild (2012) referred to the collection, storage, visualization, analysis, and application of VGI. Turner (by way of Wilson and Graham, 2013) discussed the production, consumption, analysis, visualization, and sharing of VGI. Goodchild (2008) addressed the collection, compilation, indexing, and distribution of VGI. Brown (2012, p. 7) stated "VGI is the harnessing of tools to create, assemble, and disseminate geographic data provided voluntarily by individuals". Characteristic of more traditional geographic information systems in the realm of Web 2.0 
(the interactive Web), Elwood (2009, p. 257) identified new geovisualization technologies "as 'not-quite-GIS' assemblages of hardware, software, and functionalities". Common to these different views of VGI is the consideration of multiple system components and their interactions, although this is not explicated by any of the authors. In the following sections, we therefore briefly outline the definition of a system in systems science and explore the parallels between geographic information systems and VGI systems.

\subsubsection{System Definition in Systems Science}

According to Kulla (1979), systems science emerged from a combination of concepts developed in general systems theory (Bertalanffy, 1968) and cybernetics (Wiener, 1961). In an approach to better understand natural phenomena and tackle increasingly complex socio-economic processes, researchers proposed to view the world through a systems perspective. A system is defined as "a set of objects together with relationships between the objects and between their attributes" (Hall \& Fagen, 1956). The systems perspective provides a holistic view on real-world objects and their relationships, and acknowledges important properties of systems that may otherwise go unnoticed, including: complexity, openness, dynamics, and directedness (finality) (Kulla, 1979). To encompass the many different facets of the systems perspective that have since developed in science, researchers like Klir (2001) now define it broadly as "the field of scientific inquiry whose object of study are systems". Therefore, computer systems, such as GIS, can serve as both the object of study for systems scientists as well as the tool by which to represent, analyze, and visualize complex real-world systems.

\subsubsection{Geographic Information Systems (GIS)}

In addition to the foundations of systems science, the common link of 'geographic information' between VGI and GIS warrants the consideration of traditional GIS components before delineating the parts of VGI systems. Relating specifically to spatial analysis tools implemented in GIS, but mimicking a current need in VGI research, Goodchild (2008, p. 14) stated the necessity to "systematize what is otherwise a confusing mass of methods". Tomlinson's (2007) GIS implementation framework considered the information products resulting from the components and functions within the system. GIS could be 
defined based on its primary subsystems, in which geographic information emerges as an information product resulting from the interplay of the hardware, software, data, and people components, and is shaped by a series of functions for geographic data input, management, analysis, and presentation within GIS (Bill \& Fritsch, 1999; Heywood, Cornelius, \& Carver, 2006; Longley, Goodchild, Maguire, \& Rhind, 2011; Tomlinson, 2007). This definition identifies stages in the GIS process; however, it does not consider the interaction between those stages or reflect the experience of implementation. Heywood et al. (2006) extended the traditional systems perspective when defining the components of GIS by taking the position that "GIS cannot operate in isolation from an application area".

To overcome the limitations of a linear systems approach, Chrisman (1999) proposed a view of GIS as a set of nested components with interactions that encompass the

technical components as well as the larger context and institutional arrangements. The nested rings in Chrisman's conceptual framework are, from the simplest to the most complex level: measurements, representations, operations, transformations, institutional context, and social and cultural context. Each ring depends on components addressed on a simpler level, while embedding the considerations that are involved in operating the entire GIS. It is Chrisman's (1999) definition of the subsystems that shape GIS, which most influences how we understand VGI systems.

\subsection{VGI System Components}

VGI systems can be regarded as an environment for the production of VGI as an information product. The components, which serve as the building blocks for the system, are a complex arrangement between the project and its initiators, the participants who volunteer their geographic information, and the technical infrastructure (hardware, software, and the Geoweb); together, these components lead to the creation of a crowdsourced information product, or VGI (Figure 2.1). Within the technical infrastructure, the functions allow for the input, management, analysis, and presentation of VGI. Mimicking Chrisman's (1999) nested rings used to understand how GIS operates, VGI systems consist of interdependent components with interactions that address technical, contextual, and organizational considerations. Further, the considerations within each 
component have a substantial impact on the entire VGI system, and subsequently, on the VGI produced. Although the framework needs to be tailored to fit specific projects, we illustrate each component using OpenStreetMap, Ushahidi, and RinkWatch as examples.

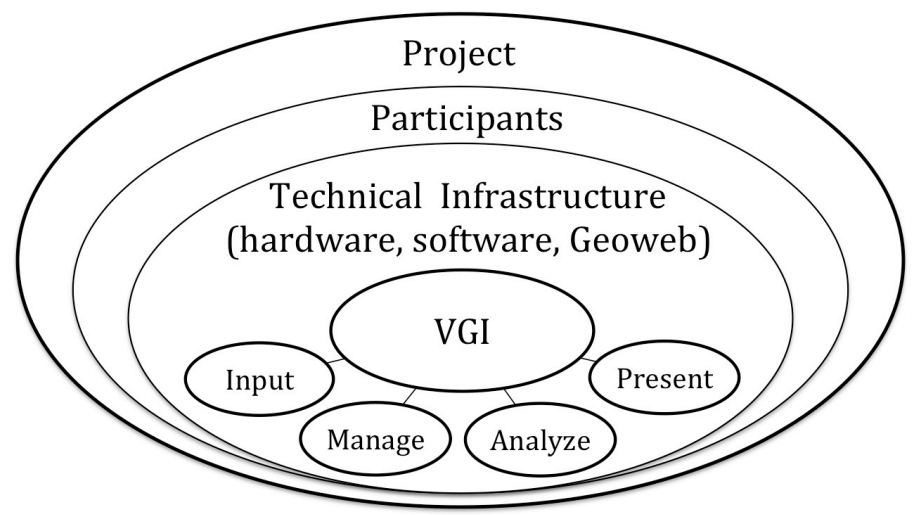

Figure 2.1: The components of volunteered geographic information (VGI) systems

\subsubsection{Project}

VGI systems are often initiated around a problem or a purpose, and are executed through a project. Projects can be triggered by an event, such as a political crisis or natural disaster. Ushahidi, for example, was first initiated in response to the political upheaval following Kenya's 2007 presidential election (Okolloh, 2009). Alternatively, there is the less urgent (but arguably equally important) need to gather and share topographic or thematic geo-information, such as in the cases of OpenStreetMap and RinkWatch. Regardless of the initiating motivations, the goal and strategy of all VGI systems needs to be clearly defined at the onset of a project. Otherwise, a project might suffer a similar fate as the thousands of Ushahidi maps that have ended up in the 'Ushahidi graveyard'; a collection of purposeless crowd maps (Vota, 2012). Although some now defunct maps did serve as learning and training tools for those experimenting with crowdmapping, the graveyard is an important reminder to consider the purpose and plan for sustainability within a project.

The project is often closely related to the domain of the initiator, and in the early stages of VGI system development, the initiators have the greatest control over the design. As individuals or groups, they make important methodological decisions that influence the VGI system produced. Key considerations include the study location (e.g., global, Kenya, or Canada), and the timeframe of the project (e.g., ongoing, immediate emergency response, 
or duration of a funded research project). In traditional GIS, the people component typically refers to professionals (i.e., researchers, consultants, or technicians) and applications are tied to institutions (i.e., academic, business, or government) (Longley et al., 2011). In VGI systems, on the other hand, the people initiating the application still plan, implement, and operate the system but may not have formal training in GIS or institutional ties, and often present a unique arrangement between subject, producer, communicator, and consumer (Goodchild, 2009).

Despite the changing roles between producers and users, or 'produsers' (Coleman et al., 2009), the initiators leading the development of VGI systems have typically been associated with grassroots movements, and encompass individuals, community groups, and organizations. Such is the case with Ushahidi, which was initiated by a group of Kenyan activists led by Okolloh, a prominent Kenyan blogger (Okolloh, 2009). However, the increasing institutional interest in VGI and crowdmapping, especially by government, represents a more traditional top down approach and introduces a new set of incentives for initiating VGI systems. In the report on crowdsourcing geographic information by Haklay et al. (2014), each of the 29 case studies presented include various levels of government involvement. The interactions, or information flows, were broadly categorized as: publicgovernment, government-public-government, or, public-government-public. Regardless of the domain of the initiators, they ultimately make critical decisions about the participation strategy and technical infrastructure used, as discussed next.

\subsubsection{Participants}

Within the application area, project initiators need to identify from whom they wish to collect the VGI. This participation strategy varies substantially between projects. Related to geographical citizen science specifically, Haklay (2013) identifies that the role of the volunteer can be 'active' or 'passive'. We believe this concept extends to VGI, where participants can contribute to VGI both actively and passively. With projects aimed at collecting active contributions, the participants are often drawn from an engaged group of stakeholders such as a purposely selected community group, a pre-selected segment of the population, a set of authorized and trusted contributors, or unknown contributors 
motivated via a media or outreach campaign. In the case of RinkWatch, initiators identify those who maintain backyard ice rinks as their primary participants, while OpenStreetMap relies on a broad range of participants to contribute information on their local community (Damyanov et al., 2012; Haklay \& Weber, 2008). In all cases of VGI systems aimed at collecting active content, the participant "is expected to consciously contribute to the observation or the analysis" (Haklay, 2013a, p. 112).

Conversely, in projects that aim to gather passive contributions, "the contributor is acting more as an observation platform and the data are gathered without active engagement" (Haklay, 2013a, p. 112). In these types of projects, the participants use technology, such as GPS transmitting a signal from a smart phone or other hand-held device. Although the participant may not be actively volunteering content, such as logging into a Geoweb environment and adding a contribution to a map, they are volunteering to contribute their geo-information. A well-known case of passive contribution is the Google Maps application that employs user-authorized GPS information to crowdsource traffic information (Barth, 2009). It is important to note that active and passive content is not mutually exclusive. OpenStreetMap, for example, relies on passive contributions when a participant uses GPS tracking to map a road, and relies on active contributions to clean the GPS recordings and add relevant attribute data (Haklay \& Weber, 2008).

In many projects, a well-defined methodology for generating participation increases the likelihood of volunteer contributions. Thus, a major consideration related to participants is the media or promotional strategy employed. In addition to social media as an obvious avenue for promotion, combining Web outreach with more traditional media, including radio and newspapers, has proven to increase the reach of a project. For example, RinkWatch organizers observed spikes in participation on their website during promotional campaigns and most notably, when the project was picked up by the local newspaper and national radio (Lawrence et al., 2013). Because of the variability within VGI systems, suitable media strategies are contingent upon the project at hand. Although there is not yet an established methodology for generating participation in VGI systems, purposefully devising a participation strategy could lead to a greater understanding of the type of VGI created. 


\subsubsection{Technical Infrastructure: Hardware, Software, and the Geoweb}

A technical infrastructure supports the creation of VGI, and each system depends on a unique array of hardware and software components. The combination of technical infrastructure deployed ultimately depends on the type of VGI desired, and varies greatly across projects. VGI systems hardware can include server and client computers, and location-enabled devices, such as GPS units and smart phones. The software component can include proprietary and open-source platforms, such as ArcGIS Online (e.g., RinkWatch) or Ushahidi, respectively. There are also two sides to the technical infrastructure: the user interfaces or client-side architecture, and the developer or serverside architecture. OpenStreetMap, for example, relies on navigation (e.g., GPS), a desktop computer, server hardware, and dozens (if not hundreds) of software options (for more, see the OSM Software/Desktop Wiki, 2014).

The compilation of hardware and software that enables Web mapping is more commonly understood as the Geoweb, a collection of online location-enabled services and infrastructure. Initially limited to a one-way flow of information from producers to users, the Geoweb evolved to be participatory, enabling a two-way flow of information and thus facilitating the production of VGI (Johnson \& Sieber, 2012b). The Geoweb can provide the user interface for the collection of VGI. However, not all Geoweb infrastructures are capable of collecting VGI; similarly, not all VGI is collected by way of the Geoweb. One notable advantage of the Geoweb is the layers of geo-information that support the mapping interface, which provide geographic context and allow contributors to identify the relevant geographic area (i.e., seed content).

The technical infrastructure employed also dictates the functions available to create and manage VGI. Although there are a host of functionalities within the spectrum of VGI systems, we define the main functional groups (in analogy to GIS) as input, management, analysis, and presentation. An example of the technical infrastructure supporting the collection of VGI is the Ushahidi platform; an open-source self-contained Geoweb tool with customizable crowdmapping options. Initially designed to facilitate the sharing of information during the Kenyan election crisis, it has been repurposed thousands of times to gather a diversity of spatial information from the crowd (Okolloh, 2009). 
Zook et al. (2010) profiled Ushahidi and three other Web-based mapping services (CrisisCamp Haiti, OpenStreetMap, and GeoCommons) that were deployed to crowdsource disaster relief during the 2010 Haitian earthquake. The Ushahidi platform demonstrates the unique data input options, including short message service (SMS) and Twitter, which allow project initiators to gather local, on-the-ground knowledge (Zook et al., 2010). Beyond the input functions, the Ushahidi platform also offers functionality for management (e.g., administrator approval of participant contributions), analysis (e.g., contributor statistics), and presentation (e.g., interactive Web map) of the VGI within the technical environment. With an abundance of hardware, software, and Geoweb considerations and combinations available for VGI systems, coupled with an array of functional options, the technical infrastructure needs to be evaluated on a system-by-system basis.

\subsection{Discussion}

Through this research, we have come to understand VGI systems as a set of components that help tackle the increasingly complex task of creating VGI. In addition to providing a novel source of geographic information, the system that drives the creation of VGI is, in itself, collaborative. Crowdsourcing "is about creating fluidity in data sharing and collaboration by breaking down barriers in access to technology and participation through the Web, open standards, and simplified interfaces" (Zook et al., 2010, p. 23). Thus, beyond another mechanism for generating (geo-) information, akin to a survey, there is the added benefit of fostering collaboration and participation. The following sections explore the collaboration and participation enabled by VGI systems, as well as provide a critical assessment of issues associated with the implementation of VGI systems.

\subsubsection{VGI Systems as a Mechanism for Collaboration and Participation}

There is a long history of government and decision-makers relying on a broader public to participate in, and provide valuable information to aid, decision-making. Arnstein (1969) identified a ladder of citizen participation to typify the extent of citizen power within the participation process associated with federal social programs back in 1969. Later, in geographic information studies, Participatory GIS (PGIS) responded to the need to develop a collaborative and partnered approach to GIS (Sieber, 2006). Furthering the goals 
of PGIS, participation on the Geoweb is bringing together diverse stakeholders, both professionals and the public alike, representing the convergence of spatial information and technologies with digital media (Leszczynski \& Wilson, 2013). The participatory Geoweb, in some instances, seems to be achieving a higher rung on Arnstein's (1969) ladder of citizen participation than PGIS because the public can achieve greater control over the system.

Expanding on the participation enabled by the Geoweb, VGI represents a social transformation in the way data can be collected and shared. Web-based participation and the production of VGI are supporting novel types of collaboration (Butt \& Li, 2012). The participatory nature of VGI is demonstrated through the plethora of VGI projects that employ Geoweb tools to collect data from actively engaged citizens and groups (Tudge et al., 2012). For example, the MapChat tool (Hall, Chipeniuk, Feick, Leahy, \& Deparday, 2010, p. 766) was "developed to facilitate Web-based interaction between individual citizens and groups interested in discussing issues of local spatial relevance". Similarly, Rinner \& Bird (2009) and Cinnamon \& Schuurman (2012) used a participatory approach to collect and map observations and opinions related to sustainable neighbourhood planning and public health, respectively.

However, it is important to note that not all VGI systems are participatory. While active contributions can be considered participatory, passive contributions do not require the same level of engagement from volunteers. Rather, content is volunteered by consent, rather than active participation. Given this distinction between active and passive contributions, we are more confident stating that VGI systems are collaborative but not necessarily participatory. VGI systems support a distributed process, where tasks are outsourced to a diverse network of individuals and institutions, enabling a wider group to collaborate in information creation and knowledge sharing (Roberts, Grosser, \& Swartley, 2012).

Owing to the distinction between active and passive contributions, how VGI systems fit into the PGIS paradigm is still to be fully understood. PGIS emerged from critiques of GIS in the 1990s, calling for more inclusive use of GIS that engages and empowers the public while developing more sustainable community-driven GIS practices (Brown, 2012; Sieber, 
2006). Tulloch (2008) explored the extent to which VGI and PGIS demonstrate overlapping boundaries, and Hall et al. (2010) later concluded that it is more constructive to view those boundaries as an intersection, rather than a division. Although it seems to follow that VGI and PGIS are not synonymous, Elwood (2008) emphasized that PGIS can offer a productive framework to motivate VGI research.

\subsubsection{Critical Assessment of Collaboration and Participation within VGI Systems}

Since VGI systems can engage the public in collaborative and sometimes participatory ways, it is important to step back to look at the fundamental issues raised by their implementation. The creation of VGI lies at the intersection of technology and society (Elwood et al., 2012; Sui \& Goodchild, 2011). Thus, VGI systems have not only technical, but also social and political, ramifications. Discussions surrounding the implications of VGI are already in progress, with a growing body of literature related to credibility (Flanagin \& Metzger, 2008), uncertainty (Grira, Bédard, \& Roche, 2009), privacy (Scassa, 2013, 2014), the data-divide (Cinnamon \& Schuurman, 2012), and contributor motivations (Dodge \& Kitchin, 2013). In response to the critical appraisal of the inherent issues that come with an evolving system, Mooney \& Cocoran (2011) counter that the risk of obtaining a fragmented dataset is trumped by the collaboration it can generate.

The capacity of VGI to democratize the creation, use, or dissemination of geographic information is also an important consideration. Haklay (2013b, p. 67) affirmed that "a concerted effort is required to integrate new groups in society in the design and development of technological objects and systems and an ongoing effort to reach out to those who are under-represented". Although there are inherent issues in the democratization of VGI, or what Haklay (2013) referred to as the delusion of democracy, Hardy et al. (2012) stressed the importance of working collaboratively, which can act as a process of empowerment. Poore \& Chrisman (2006) explored a social theory for the production and use of GIS; similarly, we need to continue to critically consider the production of VGI systems, while addressing the fundamental issues instigated by their use. 


\subsection{Conclusions and Future Research Directions}

This paper presents an investigation into the creation of VGI from a systems perspective. VGI itself is understood as a crowdsourced geographic information product, while VGI systems enable the creation of VGI. The VGI system framework breaks down the process of creating VGI into three connected components: the underlying project, the participants, and the technical infrastructure. By identifying these primary components, and the considerations within each one, those initiating VGI systems are better able to make informed decisions on the system design, which will ultimately influence the outcomes, whether the desired outcome is to generate new geographic information or promote greater collaboration. Overall, VGI has the potential to add to our collection of maps and spatial data and serve as an information source that can enrich our research programs. VGI systems, then, should be viewed as a method to harness the crowd and connect us to the phenomena we are most interested in studying.

There is more to add to this conversation. As concluded by Hardy et al. (2012, p. 16), "research on VGI production is a nascent area with many unexplored avenues". To date, VGI remains largely untapped as a resource for exploratory and analytical research (Haklay, 2010). Now that we have established a conceptual framework for the many moving parts that make up VGI systems, we need to evaluate how existing projects apply the components and functions within the framework. Adding to Beaudreau, Johnson, and Sieber's (2012) research on strategic choices made when developing Geoweb applications, we need to evaluate the strategic choices made during VGI system development, and the impact those choices have on the resulting VGI.

Next, within the VGI systems framework, we did not address temporal considerations. Recent research by Resch (2013) emphasized the importance of incorporating (near) real-time collection of observations and measurements from both people as sensors (or what we describe as active) and collective sensing (passive) networks. Future work could explore incorporating sensor networks into VGI systems to enable real-time monitoring. Finally, it is necessary to explore Geoweb environments that are capable of supporting the collection of VGI. While Ushahidi and OpenStreetMap are good examples of Geoweb platforms that support VGI systems, the increasing interest in 
crowdmapping from public, private, and not-for-profit sectors necessitate a more strategic review of the tools readily available to support VGI systems. It is only once the system is understood that we can better implement VGI as a viable approach to address the host of geographic problems that may arise in the future. 


\title{
3. Food Mapping 2.0: Climbing The LAdDER of STAKeholder Engagement
}

\begin{abstract}
Due to the spatial nature of food systems, many food initiatives employ some form of mapping to communicate the intricacies of a food system. Rapidly evolving mapping technologies-including GIS, Web 2.0, the Geoweb, and volunteered geographic information-have expanded into food mapping. As such, this paper explores recent advancements in mapping, and uses a ladder of engagement to introduce and provide examples of visualization, collaboration, interaction, and participation in food mapping. While many projects achieve visualization and collaboration using GIS and data sharing, interaction and participation using the Geoweb and VGI are rarer, but a necessary step toward building sustainable and regenerative food systems.
\end{abstract}

Keywords: collaborative asset mapping; food mapping; geographic information systems; Geoweb; Web 2.0; volunteered geographic information systems

\subsection{Introduction}

Challenges faced by the global food system are interrelated with problems associated with climate change, poverty, nutrition, social justice, economic security, and environmental sustainability (Francis, 2003). Given these interconnections, the United Nations' Trade and Environmental Review emphasize that a fundamental transformation of agriculture that shifts from a conventional monoculture-based agri-industry to a mosaic approach for sustainable, regenerative local food systems is necessary (Hoffmann, 2013). Feagan (2007) explored the many permutations of beneficial actions within the local food systems approach, which include alternative food initiatives, shortened food chains, and the community food security movement. 
This paper focuses on local food systems broadly, which emphasize locally grown and processed food; driven by a concern for a healthy, just, and resilient food system; and a shifting dependence away from global agri-industrial food production. It should be noted that not all agree with the local food system approach; globally, there is an alternative view that includes greater use of biotechnology to grow and modernize the global agri-industry food system.

Continuing with local food systems, food leaders all over the world emphasize that a shared vision and collaborative approach is needed to build and maintain an adaptive and resilient food system (Deloitte, 2013; Knapp \& Trainor, 2013). This is no small task. A mosaicked approach to local food systems is multi-faceted, creating space for a full range of actors to discuss problems, leverage resources, and contribute to solutions (Baker et al., 2010).

These actors range from government and non-government agencies, academic and public service institutions, to community groups, and individuals, and can be socially, culturally, ecologically, or politically oriented (Feagan, 2007). In fact, some stakeholders do not even consider themselves food system stakeholders; they are the farmers, vegetable gardeners, or business people who are going about their work or hobbies while unknowingly contributing to their local food system. According to Pothukuchi, Joseph, Burton, \& Fisher (2002, p. 5), "while most of these efforts are small-scale, they represent the seeds of creative and lasting solutions to food system problems."

These actions and initiatives led by food stakeholders can be described as the diverse hyper-local places of food systems. They are diverse because a range of actors is involved, working on initiatives that are unique in scale, location, and goals. Levkoe (2011) describes the Canadian Food Movement as "a decentralized network of diverse, selforganizing, interconnected initiatives with no identifiable beginning or end."

They are hyper-local because the focus is on individuals or small groups of actors within a community that emphasize food production at community or neighbourhood scales; in contrast to "local" food, which can cover entire regions, such as Ontario's Local Food Act. In fact, hyper-local initiatives are not even captured by sustainability plans or 
official policy, such as local food advocates at city hall deciding to plant food in garden beds typically reserved for flowers (Fraser, 2014).

Finally, they are places of local food systems because these initiatives are happening within geographic spaces (a geographically defined location) that are context-sensitive and convey some aspect of meaning (Feagan, 2007; Feick \& Robertson, 2014). The place versus space debate has been an ongoing topic in geographic literature; space is considered a geographically defined location, while place links people, culture, and resources within a space (Feagan, 2007; Pothukuchi et al., 2002). Unfortunately, while place is inextricably intertwined with food, our food has been divorced from the places it comes from in the context of global agri-industry.

Collectively, these diverse and hyper-local places within the larger food system are contributing to lasting and real change in what some consider a broken food system (Baker et al., 2010; Scharf et al., 2010). However, with so many stakeholders and diverse initiatives operating at different scales, a mosaicked approach to supporting sustainable and regenerative food systems is a major challenge. As such, mapping various aspects of food systems could be one part of the solution to aid in coordinating cross-sector engagement of all food system stakeholders.

Much of the information relevant to food systems-the locations of farms and farm gate operations, farmers' markets, and community gardens; demographics, land use, and zoning; transportation and distribution infrastructure-has a spatial component, which lends itself to mapping as a way to inform local food decision-making. Maps can be used to restore the inherent spatial attributes of food systems. Further, while mapping is playing an increasingly supportive role in putting place back into food, evolving mapping technologies-including geographic information systems (GIS), Web 2.0, the geospatial Web, and volunteered geographic information (VGI) systems-are demonstrating the potential to encourage greater engagement among and between relevant local food stakeholders and the broader public.

This research emerges from the increasingly urgent need to assess how mapping has been used to coordinate existing capacities within local food systems. By examining the 
rapidly evolving mapping technologies used in food systems, this paper explores to what degree these tools support stakeholder engagement in the mapping process. While the focus of this paper is Ontario, Canada, the examples illustrate both domestic and international mapping initiatives that are ultimately supporting a mosaicked, coordinated, and local food system approach.

Following this introduction, Section 2 of this paper presents a brief history of stakeholder engagement in mapping and the associated advancements in mapping technologies. Section 3 organizes food-specific mapping initiatives by a ladder of engagement ranging from visualization, to collaboration, interaction, and participation. Finally, Section 5 concludes the paper with recommendations for future research, calling on all food system stakeholders to strive for greater engagement. This paper is intended to serve as a resource for those wanting to learn more about recent mapping developments, current status of food mapping, and types of stakeholder engagement mapping can facilitate, both within and beyond food environments.

\subsection{Stakeholder Engagement in Mapping}

Mapping has been used all throughout history to communicate spatial information, revealing patterns not obvious by looking at the data alone. One of the most famous examples is John Snow's 1854 cholera map (Johnson, 2006). While the popular notion of the cholera epidemic that killed many London residents was attributed to 'bad air', Snow was suspicious of a tainted water supply. Without a sound understanding of disease transmission at the time, Snow was the first to study the pattern of disease by talking to residents and mapping the residences of the deceased. The map clearly illustrated the outbreak occurred around a public water pump and by removing the handle, the outbreak diminished rapidly. Thanks to the insight gained from his mapping approach, Dr. Snow was widely credited with stopping the cholera epidemic (Johnson, 2006).

More recently, maps have been helpful in tracking the spread of the Ebola virus. One of the many examples of Ebola mapping efforts, the Red Cross is enlisting the help of volunteers to create detailed maps of rural areas in Africa so epidemiologists have more detailed geographic information to track the virus as it spreads (Mohney, 2014). Both of 
these mapping efforts, Cholera in 1854 and Ebola in 2014, use citizens to gather their data and strengthen the impact the map can have on decision-making. The involvement of the communities is critically important to mapping. As technologies progressed, so has the ability of those initiating mapping projects to engage the communities they seek to map.

Before we delve into the progress of food mapping in particular, we first need to lay the groundwork for important cartographic and technological considerations that have enabled greater citizen engagement in mapping. Early map-making, known as cartography, was quite simple: use data to (hand) draw a map. While early maps were often quite artistic, cartographers were limited in the number of people they could engage in the mapping process. However, technological advancements have increased the capacity of maps and their makers to engage a wider public. These technologies include geographic information systems (GIS), the Web, and most recently, the Geoweb and volunteered geographic information (VGI) systems.

\subsubsection{Geographic Information Systems and Participatory GIS}

In the early 1960s, Roger Tomlinson discovered the value of digitizing and overlaying various layers of information (e.g., forest areas, soil types, farmland, etc.) to assist the Canadian government in land use planning. This early 'computer-aided cartography' quickly evolved into an entire system of managing geographic information (Tomlinson, 1968) and later evolved into a domain of science known as GIScience (Goodchild, 1992; Rhind, 1977). Goodchild (2008) highlighted that the analytical functions of GIS (such as spatial analysis, modeling, and geostatistical techniques) is what made it such a powerful tool, revealing insights not otherwise evident.

Central to GIS are data. Data with geographically determined interest have "patterns that are well behaved and therefore amenable to modeling; and of sufficient variability to impact locational decisions" (Goodchild, 1997, p. 387). The data plugged into GIS are particularly useful for presenting complex spatial information in a visual and engaging way, and analyzing spatial trends. Maps produced using GIS software (such as ArcMap, MapInfo, and increasingly open source options such as Quantum GIS) are used prolifically in urban planning, environmental management, demographics, and community planning. Most 
often, the outcome of this process is a static map, which can be printed and used in reports, planning documents, or internal use. Alternatively, it can be uploaded online so a wider audience can access the map. It is often professionals with high-level skills and training creating traditional GIS maps, and its use is limited to the domain of larger institutional settings (e.g., government and academic).

Owing to this strongly professional and authoritative control of GIS mapping, participatory GIS (PGIS) emerged from critiques of GIS in the 1990s, calling for more inclusive use of GIS that engages and empowers the public while developing more sustainable community driven GIS practices (Brown, 2012; Pickles, 1995; Sieber, 2006). The value of participatory mapping is rooted in the profound knowledge local citizens have about their community; knowledge that is typically underrepresented, if represented at all, in official plans, policies, and maps. The knowledge acquired through the process of participatory mapping helps local committees, councils, NGOs, and policy- and decisionmakers know what community initiatives need to be supported, fostered, and enhanced, while identifying strengths within the community. The early work in PGIS was further advanced with Web-based technological development that ultimately enabled greater engagement within the mapping process.

\subsubsection{Web 2.0}

The first inception of the World Wide Web, or what some refer to as Web 1.0, enabled a one-way flow of information from producer to consumer. The content on the Web was created by few and consumed by many, and used primarily as a tool for extracting information (Batty, Hudson-Smith, Milton, \& Crooks, 2010). This early version of the Web relied on formal organizations, such as government and academic institutions, to produce Web content.

With the new millennium came the development of the second generation of the World Wide Web, dubbed Web 2.0. Web 2.0 technologies enabled a two-way flow of information between producers and users, allowing users to create content, as well as extract information (Batty et al., 2010). Dodge \& Kitchin (2013) referred to this as the read+write media. The broad public, who was once the target of Web content, began 
producing user-generated content (UGC) in the form of comments, photos, reviews, social media, blogs, and personal websites (Johnson, Sieber, Magnien, and Ariwi, 2012). Web 2.0 can been seen as the interactive Web that is created by many for many, facilitating significant advancements in Web-based engagement and decision support (Rinner et al., 2008).

An interesting side note: Web 3.0 refers to the 'Internet of Things'. With the sharply declining size and cost of microprocessors, many devices are starting to be connected to the Web, which enable remote (at a distance) control over our home thermostats, car starters, and smart cities (for more on smart cities and the Internet of Things, see Liang et al., 2013; Townsend, 2013).

\subsubsection{Geoweb}

Web 2.0 developments converging with rapid advancements in location-enabled and information communication technologies-such as smart phones, laptops, tablets, and portable GPS devices-led to the development of the geospatial Web 2.0, or Geoweb for short. The concept of the Geoweb was initially conceived because of the high-volume of information on the Web that contained spatial attributes (Haklay, Singleton, \& Parker, 2008). Geoweb is an "online collection of frameworks and services that can be used to gather, display, analyze, and share geospatial data" (Johnson and Sieber, 2012, p. 58). While the scope of the Geoweb extends beyond online Web mapping environments and encompasses the many permutations of the geographically enabled Web, we herein refer to interactive Web mapping platforms as the Geoweb. It allows a broader public to interact with mapped data online, enabling users to adjust the zoom, layers of data visible, and other basic map functions. One early and popular example of the Geoweb is Google Maps, allowing remote (web-based) access to mapping functions as if it was installed on the local computer (Elwood, 2010). 
In addition to making mapping applications a ubiquitous part of life, it has been asserted that the pervasive nature of the Geoweb is "rapidly altering the ways in which we interact with not only one another but indeed interact with, experience, and build attachments to space/place" (Leszczynski \& Wilson, 2013, p. 916). As an example, we are no longer using a map to just locate a local café; instead, we are reading reviews about that café, checking in and sharing our location and experience using Facebook or Foursquare, tweeting, and blogging about our experience at that location. This is creating a new spatial media, one in which the mediating technologies are enabling, extending, and enhancing the ability for citizens to engage with geographic information online (Crampton, 2009; Elwood \& Leszczynski, 2013; Leszczynski \& Wilson, 2013). As such, the Geoweb has the potential to significantly increase citizen interaction with both spaces and places through mapping and geographic information.

\subsubsection{VGI Systems}

Building on the increasingly interactive nature of the Geoweb and rapidly expanding location-enabled technologies, engaged citizens and stakeholders are increasingly creating a type of spatially explicit user-generated content, known as volunteered geographic information (VGI). Initially coined by Goodchild (2007), VGI has also been described as user-generated geographic content (Goodchild, 2008) and crowdsourced geospatial data (Crampton, 2009). The spatial attribute of VGI can be geographically explicit, such as geographic coordinates of a building, or geographically implicit, such as the name and intersection of that building (Haklay, 2013a). Contributions also vary by type, ranging from geographic coordinates, geotagged photos, location-enabled tweets and Facebook posts, and comments on mapped content (Rinner and Fast, 2014; Rinner and Bird, 2009).

While the development of VGI systems are still in their infancy (Fast \& Rinner, 2014), much research is dedicated to quality, completeness, accuracy, social impact, and contributor motivations (Coleman et al., 2009; Flanagin \& Metzger, 2008; Goodchild \& Li, 2012). Further, the process of creating VGI can, in some instances, act as a mechanism to engage stakeholders. VGI systems represent a new form of knowledge production that taps into the networked publics to build new spatial narratives (Lin, 2013). Dodge \& Kitchin 
(2013) explored how the notion of crowdsourced cartography is radically transforming the process of making and using maps; crowdsourcing is quickly becoming a dominant form of geographic knowledge production and its implications are just starting to be realized.

The cumulative impact of GIS, Web 2.0, the Geoweb, and VGI systems enables various levels of engagement in the mapping process across a wide range of application areas. The remainder of this paper examines these mapping developments as they have been applied to food system mapping, in an effort to understand if and how mapping facilitates engagement across the range of food stakeholders.

\subsection{Analyzing Stakeholder Engagement in Food Mapping}

These mapping advancements have translated into impactful food mapping projects, which have been applied in innovative ways to communicate the intricacies of decentralized and location-dependent food places. To facilitate a greater understanding of the range of food mapping projects, this paper categorizes them according to the role that food stakeholders play in creating the map. In particular, it is valuable to borrow from Arnstein's (1969) "Ladder of Citizen Participation," which serves as a powerful framework symbolizing the level of influence citizens have on government decision-making. On Arnstein's ladder, each rung corresponds to a higher level of meaningful citizen participation in government programs. While the ladder has been repurposed in other disciplines, the concept (rather than the rungs specified by Arnstein) is particularly useful to understand the rungs of stakeholder engagement in mapping. Fast and Rinner (2014) suggest that new mapping technologies-introduced above as the GIS, Web 2.0, Geoweb and VGI systems-enable stakeholders to achieve greater engagement, or a higher rung on the ladder of citizen participation. While inspired by Arnstein's ladder, we adapted the rungs to relate to mapping food places, and categorized them as visualization, collaboration, interaction, and participation (Figure 3.1). 


\begin{tabular}{|c|c|c|c|}
\hline $\begin{array}{l}\text { STAKEHOLDER } \\
\text { ENGAGEMENT }\end{array}$ & TYPE OF MAP & $\begin{array}{c}\text { ENABLING } \\
\text { TECHNOLOGY }\end{array}$ & MAPPING EXAMPLES \\
\hline $\begin{array}{l}\text { Participate } \\
\text { (3.4) }\end{array}$ & Participatory map & $\begin{array}{l}\text { VGI } \\
\text { Systems }\end{array}$ & $\begin{array}{l}\text { (4) Extreme VGI; } \\
\text { (3) Participatory VGI; } \\
\text { (2) Citizens as reporters; } \\
\text { (1) Crowdsourcing }\end{array}$ \\
\hline $\begin{array}{l}\text { Interact } \\
(3.3)\end{array}$ & Interactive map & Geoweb & $\begin{array}{l}\text { Durham Farm Fresh Google API; } \\
\text { Maryland Food Map }\end{array}$ \\
\hline $\begin{array}{l}\text { Collaborate } \\
(3.2)\end{array}$ & $\begin{array}{l}\text { Static map, } \\
\text { collaborative dataset }\end{array}$ & $\begin{array}{l}\text { Web } 2.0 / \\
\text { GIS }\end{array}$ & $\begin{array}{l}\text { Good Food for London; GHFFA } \\
\text { asset mapping; Gorilla Food Atlas }\end{array}$ \\
\hline $\begin{array}{l}\text { Visualize/ } \\
\text { Analyze (3.1) }\end{array}$ & $\begin{array}{l}\text { Static map, printed } \\
\text { or online }\end{array}$ & GIS & $\begin{array}{l}\text { Global analysis of food production; } \\
\text { Local analysis of food deserts }\end{array}$ \\
\hline
\end{tabular}

Figure 3.1: The ladder of stakeholder engagement in food mapping

\subsubsection{Visualize and Analyze}

Traditional GIS mapping and analysis have been used to understand the 'spaces' of local food; that is, the analysis of a particular location. These maps can be incredibly informative for visualizing and analyzing spatial patterns of food environments. These food environments range from the global through to the local. The examples of traditional GIS mapping are typically presented as static maps, which can either be hardcopy (e.g., printed in a report or journal) or digital (e.g., uploaded to the Web). They are considered 'readonly' material. Creating a traditional map requires GIS software and knowledge of cartography and spatial analysis, which typically limit them to institutional settings (e.g., government, academic). Most often, actors within these institutions use the maps internally to support knowledge sharing and evidence-based decision-making.

Given the high level of skills and software required to make these maps, the visualization and analysis enabled by these maps is at the bottom of the ladder for engagement. However, the importance of traditional maps in visualizing and analyzing complex interactions within local food systems cannot be understated. They provide valuable support for policy and decision-making, playing a central role in planning, zoning, 
and policy documents. Given the institutional support infrastructure (i.e., GIS departments within government) and familiarity working with traditional static maps, they represent the most prevalent rung on the ladder of stakeholder engagement in local food systems.

\subsubsection{Global Analysis of Food Production}

Martellozzo et al. (2014) conducted a global analysis of geographic space constraints by calculating how much food urban areas can produce. These advanced spatial analysis techniques revealed that, for example, Canada is more than capable of producing urban food due to the comparatively high proportion of urban land that is suitable for vegetable production. However, because of the global scale, this analysis is unable to identify individual parcels or even regions that are suitable for urban food production. GIS and spatial analysis have also been applied to foodshed mapping, which reconstructs the geography of where food comes from in relation to where it is consumed (Feagan, 2007). Foodshed analysis, in particular, helps examine the impact long distance global foodsheds have on food security and environmental sustainability in the context of global climate change. Interestingly, multiple studies have indicated that shifting food choices away from meat and dairy toward a plant-based diet, rather than reducing food-miles, provides the best opportunities for reducing greenhouse gas emissions and making agricultural production more sustainable (Edwards-Jones et al., 2008; Garnett, 2012; Peters, Bills, Wilkins, \& Fick, 2008; Weber \& Matthews, 2008).

\subsubsection{Local Analysis of Food Deserts}

Spatial analysis is particularly helpful in analyzing the presence and prevalence of food deserts, understood as a geographic area with limited access to (healthy) food, such as supermarkets, farmers' markets, and other food providers (Baker et al., 2010). For example, Wilson and Mckenzie (2014) combined neighbourhood risk factors (e.g., low income, unemployment, and low education) with a spatially-derived analysis of poor access to food provisions in the isolated northern city of Thunder Bay, Ontario. The study identified two food deserts that persisted across the Statistics Canada 1996, 2001, and 2006 Census of Canada. Morrison, Nelson, and Ostry (2011) also used the Canadian census to map local food production capacity. Using the Moran's I spatial autocorrelation 
technique, the authors found that farmland is significantly clustered throughout British Columbia, Canada, and given these findings, estimates of provincial food self-sufficiency can be devised. In the context of linking food environments to health, Ball and Thornton (2013, p. 1147) reviewed mapping initiatives that describe "food environments in varied settings - within neighbourhoods, supermarkets, and dining venues near educational institutions." Analyzing food environments is a necessary step in building evidence to inform decisionmaking that supports more resilient global and local food systems.

\subsubsection{Collaborate}

While there is no doubt that the diverse and hyper-local actions of food system stakeholders can have a profound impact on food systems (Macias, 2008; Scharf et al., 2010), collaboration is the next rung to realizing the collective strength of local food systems. As such, many of the individuals and groups working toward resilient local food systems in isolation are now acting together to achieve a collective impact. Guelph Wellbeing's (2014, p. 6) report on food security defines collective impact as "the commitment of a group of people from different sectors that form a common agenda for solving a complex social problem. To achieve large scale, lasting solutions for social problems sectors such as government, civil society, and business need to coordinate their efforts and work together toward a clearly defined goal." As such, food system actors are responding to the urgent need to collaborate to strengthen local food systems.

Collaboration within the food system has taken many forms over the years. A prominent non-spatial example-that is, collaboration not requiring mapping-is community food assessments. Recognizing the need to foster stronger local food systems,

the Community Food Security Coalition developed a (non-spatial) systemic community food assessment guide to support a wide range of integrated food system approaches (Pothukuchi et al., 2002). The guide emphasized that the direct participation by citizens and food stakeholders-including private, not-for-profit, academic, and public sectors-is vital for communities to accurately examine the broad range of food initiatives and assets. Adding to this, Mcgarry, Cowan, \& Alencar (2008) see the Web, and Web 2.0 more 
specifically, as a technological development that enables an innovative approach for greater collective impact, or what they define as 'collaborative innovation'.

Collaborative food mapping, and the collaborative rung defined in this paper, are characterized by the sharing of spatial data and maps amongst food system stakeholders. Projects are often initiated to address inter- and intra-organizational interactions, and bring together data contributed by public and private communities. While these mapping projects focus on compiling diverse data sources on local food value chains to make static maps using traditional GIS, effectively encouraging greater collaboration among food system stakeholders, they do not provide a mechanism for interactive engagement with the mapped data. While collaborative mapping projects demonstrate innovative approaches to data sharing across a broad range of food system stakeholders, the map making is controlled by a select few, likely with GIS or information management training. The project is limited to static maps, and the collaborative database is difficult to keep up to date. Thus, this rung represents a collaborative database but is limited to static maps. The following three examples highlight notable collaborative food mapping projects.

\subsubsection{Good Food for London Map}

The Good Food for London (England) map series is led by the Sustain Alliance for better food and farming, in collaboration with a wide range of food stakeholders: Marine Conservation Society, Certified Sustainable Seafood, Organic Soil Association, Chartered Institute for Environmental Health, Fairtrade, London Food Link, Compassion in World Farming, and the Mayor's Food Strategy (Sustain, 2013). The purpose of the map series is to rate how well individual Boroughs in London are supporting a healthy and sustainable food future (Sonnino \& Spade, 2014). Each Borough is rated across six food issues:

- Community Food Growing

- Food in Life in Schools

- Fairtrade Food
- Sustainable Fish

- Animal Welfare

- Healthier Catering

The collective score indicates each Borough's overall ability to lead in sustainable food initiatives. This 'fame and shame' map has motivated many food system stakeholders in each Borough, from politicians to civilians, to put healthy, sustainable, and resilient food 
systems on their agendas. In fact, between the 2011 to 2013 editions of the map, most Boroughs have significantly increased their overall score (Sustain, 2013). Further to the collaboration generated by these maps, it is the onus of the decision-makers responsible for food planning to submit, update, and correct the information presented for their Borough. The process of contributing to this mapping initiative is putting food on the radar for many local politicians who prefer to avoid a public shaming.

\subsubsection{Collaborative Asset Mapping}

Part of broader regional food system planning, the Golden Horseshoe Food And Farming Alliance (GHFFA) is a partnership of local food stakeholders in the Toronto and Hamilton, Ontario, area, including provincial, regional, and municipal governments, the Toronto Region Conservation Authority, and Friends of the Greenbelt (Walton, 2012). As part of the GHFFA Grow the Cluster pillar of the Alliance's Action Plan, an "asset mapping project was initiated to establish an understanding of agri-food assets across the Golden Horseshoe area" (Horner, 2013).

Collaborative asset mapping (CAM) is becoming popular among food system stakeholders. CAM "not only builds a database of available assets among individuals and organizations in the community, but the process facilitates relationship-building, increased common ground, and awareness about assets (resources) which could potentially contribute to prevention/mitigation, preparedness, response or recovery activities" (Sullivan, Corneil, Kuziemsky, Louise, \& McCrann, 2013, p. 4).

The GHFFA made a significant investment in a regional collaborative food asset mapping project in order to identify, inventory, and profile the food and farming assets, which includes the products grown, harvested, and processed locally; and the business, education, research, development, and institution services that develop and support food and farming infrastructure. Through this initiative, the GHFFA is able to analyze the strengths, weaknesses, gaps, and opportunities to foster a more resilient and robust food system regionally. 


\subsubsection{Food: An Atlas}

An atlas aggregates individual maps into a collection of maps with a common purpose, allowing the examination of phenomena across a range of locations, scales, and themes. The Gorilla Food Atlas assembled traditional maps, infographics, and map art from a wide spectrum of food mapping initiatives, transforming the individual stories about the

food system into a collective narrative. The atlas was compiled by Guerrilla Cartography, with the support of an impressive list of collaborators; interestingly, this project gathered contributions from over 120 collaborators, employing both crowdsourcing and crowdfunding techniques to complete the atlas (D. Jensen \& Roy, 2013).

The maps in the atlas visualize, for example, the imbalance of the availability of nutritious food, commercial pressures on land for sale in Africa, Canadian food networks, San Francisco's food system climate adaptations and, food swamps in various regional food systems. Broadly, the maps cover global to local scales and are organized into food production, distribution, security, exploration, and food identity categories. Collectively, the maps tell an unparalleled story of the natural resources, political processes, institutions, and individuals contributing to a resilient food system (D. Jensen \& Roy, 2013).

\subsubsection{Interact}

The data collected from collaborative projects is taken a rung higher when it is put into an interactive online Web mapping environment. Food related interactive maps compile diverse datasets-such as those gathered through internal data collection, collaborative mapping initiatives, and open data portals-and present them using the Geoweb. Within the last decade, the increasing number of free, open-source Geoweb options had led to a significant expansion of food-related online interactive mapping applications. These applications range from simple map mashups (combining a geographic dataset with an existing mapping interface) to custom-built mapping environments. Interactive mapping environments enable more people, ranging from those involved in collaborative mapping projects and the general public alike, to interact with the mapped data. In essence, making collaborative mapping available to the public through an interactive web-based map environment qualifies this rung on the ladder. 


\subsubsection{Google Maps Mashup: Durham Farm Fresh Map}

Since Google released its Application Programming Interface (API) in 2005, users have been able to overlay customized (spatial) data with Google's mapping software (Batty et al., 2010). The resulting map mashup can be embedded on a website and shared publicly. The advantage of Google Maps API is that most users are comfortable using the Google Maps base map, it is mobile friendly, and relatively easy to build a custom application, despite limits on daily page views (Yu, Benatallah, Casati, \& Daniel, 2008). Map mashups are readily used on websites maintained by governments, NGOs, and other food system stakeholders in order to share spatial information-such as the location of farms, farmers' markets, or community gardens - with a broader public.

Durham Farm Fresh, for example, maintains a map-based directory of food and farm resources in Durham Region, Ontario ("Durham Farm Fresh Map,” 2015). This online map serves as a spatial directory of food resources within the region, as part of a broader regional food marketing strategy. This mapping example, classified on the 'interact' rung of the ladder, does not require a collaborative dataset but is placed above the 'collaborate' rung because the public has access to the data and the maps, leading to the potential for broader public engagement.

\subsubsection{Custom-Built Geoweb Environments: Maryland Food Map}

Google Maps has dominated as the most widely used and accessible option for creating a simple Web map since its launch in 2005. However, there has been a surge of free and open source software for geo-applications such as OpenLayers, Leaflet, and CartoDB (Crampton, 2009; Haklay et al., 2008). These constantly developing mapping software options enable custom-built Geoweb environments. While the customization options are expanding daily, developing a sophisticated Geoweb application requires a high level of programming and technical skills. Thus, developing a Geoweb application is often limited to public or private agencies that have both budgetary and technical support. While steep barriers exist to the development of the Geoweb, the resulting applications are available through a simple Web browser and thus, more easily accessible for public use. 
The increased popularity and prevalence of the Geoweb means more people are developing, deploying, and using the applications to support food mapping.

A custom-built Geoweb designed specifically for food is the Maryland Food Map. Developed by the John Hopkins Centre for a Livable Future, which is part of the Bloomberg School of Public Health in Baltimore, Maryland, in collaboration with Towson University's Centre for GIS, the interactive mapping tool designed to explore the many facets of Maryland's food system. Gathering information from a wide range of contributorsincluding government data, project partner data, and primary data collection-the tool is a collective resource used to examine all aspects of the food system. The map includes data on how food is grown, distributed, processed, retailed, and consumed. Users can add or remove data from the hundreds of data layers, adjust the geographic area and the zoom level, and query the mapped data. Further, both pre-made maps and select data layers can be downloaded and used to support work beyond the interactive map. For example, this initiative has been used to successfully support city planning, grant proposals, and academic research (Maryland Food System Map, 2015). In addition to the benefits derived by the map, the momentum around the project, including social media outreach and community events, is becoming a resource for both the local and international food community.

\subsubsection{Participate}

On the highest rung of the ladder for engagement in food mapping is participation. Many local food system initiatives already recognize the value of citizen participation. In fact, the field of 'agroecology' is fuelled by a participatory action approach to resilient food systems (Méndez, Bacon, \& Cohen, 2013). Levkoe (2006) explored how participants in local food justice movements-mainly the Stop Community Food Centre's Urban Agriculture program based in Toronto, Ontario-can democratize the forces that control the food system. While simultaneously strengthening their individual knowledge and community engagement, participants also learn about the social, political, and legal systems in which they operate (Levkoe, 2006). 
Similarly, participation in the mapping process is also well established in the participatory GIS (PGIS) literature. However, PGIS initially revolved around traditional (GIS) mapping practices, and was coined long before user-generated content, the Geoweb, or volunteered geographic information (VGI) systems were a common part of the process. These recent mapping developments can enable greater participation among the community of food system stakeholders.

In order to understand the levels of participation enabled by more recent mapping methods, it is useful to learn from Haklay's (2013) levels of participation in geographical citizen science projects. Geographical citizen science, which is closely related to VGI, involves citizen participation to collect, process, and/or analyze spatial data as part of a broader scientific inquiry. Adopting Haklay's ladder to food mapping, the levelscrowdsourcing, distributed intelligence, participatory science, and extreme citizen science-are incorporated in the highest rung of the stakeholder engagement in food mapping ladder to help delineate the array of participation types in food mapping (Figure 3.2). Progressing up this ladder necessitates more meaningful engagement among food stakeholders; however, it is also typified by a smaller number of people engaged, especially compared to the interactive rung on the ladder. The following section introduces and presents mapping examples within each level.

\begin{tabular}{|c|c|c|}
\hline \multirow{5}{*}{ Participate } & \multicolumn{2}{|r|}{$\begin{array}{c}\text { HAKLAY'S (2013) } \\
\text { LEVELS OF PARTICIPATION }\end{array}$} \\
\hline & Level 4: & Extreme Citizen Science \\
\hline & Level 3: & Participatory Science \\
\hline & Level 2: & Distributed Intelligence \\
\hline & Level 1: & Crowdsourcing \\
\hline \multicolumn{3}{|l|}{ Interact } \\
\hline \multicolumn{3}{|l|}{ Collaborate } \\
\hline \multicolumn{3}{|c|}{ Visualize/Analyze } \\
\hline
\end{tabular}

Figure 3.2: Levels of participation within the ladder of stakeholder engagement 


\subsubsection{Crowdsourcing}

At the bottom of the ladder of participation (level one), the professional scientists define the scope of a project while location data (e.g., GPS) are passively crowdsourced from the public. The sensor network, which can be carried by humans, animals, or vehicles, capture measurements from the local environment and are reported back for further interpretation or analysis (Goodchild, 2007). This type of sensing leverages information communication technology, including mobile phone and social media networks. An example of this would be streaming geo-located Twitter data to detect where people are tweeting about \#LocalFood (Fast, 2015). While crowdsourced passive participation has been used to map land use (Vaz \& Arsanjani, 2015), which has implications on how land is assessed and managed for future food planning, it is not currently well established in food mapping.

\subsubsection{Distributed Intelligence}

Level two requires the location data and the knowledge from the participant. According to Resch (2013), this can also be defined as citizens as sensors or participatory sensing, as opposed to a sensor network, since the contextual intelligence and personal knowledge is central to the volunteered contribution. Alternatively, Rinner and Fast (2014) define this level as 'citizens as reporters'. As such, projects of this nature rely on volunteers to interpret what they sense and report it as an observation (Goodchild, 2007). For example, the PlantWatch program engages all Canadians to collect scientific information about plant bloom times to help scientists understand the changing environment (Beaubien \& Hamann, 2011). PlantWatch goes beyond crowdsourcing by using the local knowledge of plant enthusiasts to correctly identify a plant, in addition to reporting its location and bloom time. Additionally, Werts, Mikhailova, Post, and Sharp (2012) also relied on the distributed intelligence of participants to engage in soil and water conservation efforts mediated through an online mapping environment. These projects, and the participation enabled within, provide timely data that would otherwise be unavailable to scientists and decision-makers. 


\subsubsection{Participatory Science}

Level three requires a greater level of participation from the citizen group, where they are included in decisions about project scope and data input, management, analysis, or presentation (Haklay, 2013a; Resch, 2013). For example, the Rainforest Foundation UK is a not-for-profit agency working to protect rainforest ecosystems (including their food generating capacity) by supporting the participation of indigenous and forest communities in governance and management. In partnership with the Mapping For Rights organization, they led the development of an interactive Geoweb environment that directly gathers contributions from over 300 forest communities. While the community members are using GPS and other innovative mapping methodologies to actively participate in the mapping component of the project, the Foundation is central in leading and managing the project; further, the agencies, not the citizens, typically use the maps as evidence to inform rainforest management (The Rainforest Foundation, 2014).

\subsubsection{Extreme Citizen Science}

Level four goes beyond mandating citizen participation by giving actors the agency to define the problem, question, and scope of the project (Haklay, 2013a). In this instance, citizen stakeholders work together toward a common goal to reflect the collective experience, knowledge, and values of the community. The community initiates and manages the project, and uses the outcome to inform decision-making. Given the community nature of these projects and minimal (or non-existent) institutional support (e.g., government or university), these extreme citizen science projects are typically smaller in scale and employ simple, yet effective, tools for the collection and management of geographic information, such as balloon mapping. Again, there is a high level of engagement among participants, but a low number of participants.

For example, recognizing that the proximity to (fecal) contamination is a serious aspect of food insecurity in Mathare, Nairobi, the Kenyan Federation of the Urban Poor initiated the mapping of food environments and environmental hazards (Ahmed et al., 2014). The community-led mapping team, with support from the International Institute for Environment and Development and University College London, used inexpensive balloon 
mapping to get detailed aerial imagery that parallels more expensive and inaccessible satellite imagery. The community then created a consolidated database of the food environment, and maps of food vendors, food types, and physical structures within the slums. The mapping process encouraged discussion between food vendors, livestock owners, consumers, and residents, and created an up-to-date resource to support the community's negotiation with officials over infrastructure and policy development (Ahmed et al., 2014; Tacoli, 2014).

In this and other cases of community-led participatory mapping, the project was initiated out of necessity (i.e., to acquire information to reduce contamination) with bottom-up organization.. Unfortunately, without the direct involvement of decision-makers or other officials, the outcomes of the mapping project can be limited by the choice of officials to uptake, or reject, the data. Beyond formal decision-making channels, however, the community can use the data to influence their own decision-making.

\subsection{Sharing Data, Mediating Knowledge}

This paper served to highlight unique mapping initiatives broadly related to food systems. They present interesting cases where various levels of engagement were sought, and in these notable cases, achieved. Based on what has gone on to date, and the cases chosen here, it is clear that more people are engaged in the mapping process than ever before. Interestingly, paralleling the trend of greater engagement as food mapping projects progress up the rungs of stakeholder engagement, there is greater evidence of the sharing of data.

On the first rung of the ladder, simple visualization and analysis projects rely on authoritative datasets; those collected by national mapping agencies, research projects, or increasingly from open data portals. Analysis of food production and food deserts examples explored in this paper relies on government census data as their primary data source. This is a typical one-way data flow; agencies collect, manage, and selectively distribute data to the public. The push for open data means these data are expanding, but typically focus on government sources rather than data available among stakeholder groups. As previously discussed, traditional GIS maps remain a suitable and often preferable in decision-making 
because of their authoritative nature and concise presentation of information to support decision-making.

The collaborative mapping projects, on the second rung, require the sharing of datasets between and among food system stakeholders, which is something the recent trend toward open data does not capture. The Good Food for London map, the Golden Horseshoe Food and Farming Alliance collaborative asset mapping project, and Gorilla Food Atlas collected data from engaged stakeholders from municipal government, foodrelated NGOs, and academic projects, respectively. Based on this work, great projects are achieved when there is sharing amongst engaged stakeholders. However, the data used in these projects are not considered open and, thus, not accessible to the public in their raw form or in some cases the reports and maps are not available publically. While more governments are sharing their data than ever before, there is still much work to be done related to open data policies (Scassa, 2014; van Loenen \& Onsrud, 2004). Few stakeholder groups have open data policies; most maintain control and limit access to their databases. The sooner food stakeholders start equally and openly sharing their data, the greater the chances of fostering collaboration.

Interactive mapping projects are a step higher because they make collaborative datasets available online, engaging more people with Web-wide dissemination. Relatively few of these interactive maps even make the data downloadable to the public. The increasing ease of use of the Geoweb (not to be mistaken for ease of application development) means more people are creating maps with their own in-house datasets, expanding the mapping capabilities of small NGOs and community groups who had limited mapping capacity previously.

At the highest rung, data sharing is completely flipped. The public is creating the data, to varying degrees of passive to active participation. Since crowdsourcing enabled the (engaged) public to contribute geographic information, citizens are playing a greater role in the knowledge creation process. This engagement not only transforms the role of the citizen, but also the role and responsibilities of scientists (Haklay, 2013). Lauriault \& Mooney (2014) emphasized that scientists need to learn how to be the mediator of knowledge, rather than the sole authority. Those initiating food mapping projects, then, 
should start to think of themselves as mediators of food knowledge; how they use that knowledge, and whom they engage, is entirely dependent on the project and goals at hand.

\subsection{Conclusion: A New Food Mapping Era}

We are entering a new era in mapping; one in which engagement is the norm rather than the exception. Learning through engagement has an 'expansive effect' on the broader food movement (Levkoe, 2006). It can have a substantial impact on how we share and shape ideas through already engaged, albeit diverse and hyper-local, food system stakeholders. The foundation for a viable and desirable food future requires an understanding of food places, encouraging collective impact among all food system stakeholders, and preserving the unique situation of each locale. Based on the examples presented in this paper, food mapping projects builds engagement at all levels, from visualization and analysis to collaboration, interaction, and participation. These maps provide linkages across scales, sectors, and jurisdictions, which further highlights the transformative potential of realigning the inherently spatial attributes of human-food interaction. Collectively, food maps provide unparalleled detail about the built environment, food resources, and the communities that are operating within.

Learning from the legacy of decades of food mapping while capitalizing on evolving mapping technologies, the potential exists to develop more collaborative, interactive, and participatory mapping techniques. These techniques can, as demonstrated by the examples highlighted here, foster flows and linkages between and within all levels of local food stakeholders. In fact, many diverse and hyper-local food places are still not recognized in federal, provincial, or regional food assessments. Food mapping can facilitate greater awareness of the places that comprise a robust and resilient food system; all while engaging the communities who are vested in a food secure future. Through stakeholder engagement in food mapping, we are building a new narrative for local food systems that is community-driven, socially motivated, and cumulating a shared future. 


\title{
4. Methods: Building The Durham Food MaP USing \\ VOLUNTEERED GEOGRAPHIC INFORMATION SYSTEMS
}

\begin{abstract}
The methods developed in this chapter establish the process of creating a VGI system to support the participatory mapping of Durham's local food assets.
\end{abstract}

\subsection{Building a VGI System using Active and Participatory Methods}

In the research context of applying volunteered geographic information (VGI) systems to explore what participatory food mapping can add to the regional food system, the methods outlined here establish the project, participants, Geoweb, and VGI components required to create an environment that supports the creation of VGI. The functions further structure the mechanisms necessary to input, manage, analyze, and present the VGI. In addition to the primary VGI data collection, field notes were collected before, during, and after VGI system development. The contextual observations gathered via field notes are meant to be complementary evidence (Kearns, 2005; Resch, 2013) to the more controlled and formalized VGI system data collection.

The methods established by the VGI systems framework were shaped by both active participant observation (APO) and participatory geographic information systems (PGIS) approaches. APO is a subset of participatory action research. While participant observation was one of the earliest qualitative research methods used to studying human actors (Johnson, Avenarius, \& Weatherford, 2006; Schwartz \& Schwartz, 1955; Seymour, 2001), it has been more recently adapted to studying participants in graphical online environments (Williams, 2007). This type of action research shifts away from hypothesis testing toward experiential and exploratory learning, requiring the researcher to achieve an insider perspective to enact the greatest change (Kearns, 2005; Neumann, Dixon, \& Ekman, 2012). 
This type of active observation is further complemented by a participatory GIS approach. Facilitating advancement in the applications, use, and distribution of community driven GIS, PGIS helped set the foundation for both participatory Geoweb and VGI research (Elwood, 2008, 2009a). Participatory GIS are "context- and issue-driven rather than technology-led and seek to emphasize community involvement in the production and/or use of geographical information" (Dunn, 2007, p. 616). While there are still ongoing issues to realizing the participatory transformation of GIS, participatory GIS did help the technology break away from the almost exclusive government and institutional use, and facilitated a significant increase in community involvement (Sieber, 2006).

By combining APO and PGIS principles, the design of the VGI system prioritized active participation of both the researcher (APO) and the local food community (PGIS). The implementation of this research project is further structured upon procedural evidence from both completed and ongoing VGI projects, established in the VGI systems framework (Fast \& Rinner, 2014). The system (summarized in Table 4.1) was designed to collect active VGI, where the participants knowingly contribute. This is different than passive VGI, where the contributors, for example, stream data from a location-enabled device and are often unaware of project goals (Haklay, 2013a). While the system is presented in sequential order, it did not progress linearly, with many components and functions coevolving. 
Table 4.1: Components and functions of Durham's Local Food VGI system with corresponding section numbers

\begin{tabular}{|c|c|}
\hline \multicolumn{2}{|l|}{ COMPONENTS } \\
\hline $\begin{array}{l}\text { Project } \\
(4.2 .1)\end{array}$ & $\begin{array}{l}\text { Name/scope: Durham Food Map } \\
\text { Location: Regional Municipality of Durham, including eight lower- } \\
\text { tier municipalities } \\
\text { Purpose: gather information about Durham's local food assets }\end{array}$ \\
\hline $\begin{array}{l}\text { Participants } \\
(4.2 .2)\end{array}$ & $\begin{array}{l}\text { Initiator: academic/Durham Food Policy Council (DFPC) } \\
\text { Intermediary: academic } \\
\text { Stakeholders: government, NGO, and community groups in Durham } \\
\text { Region } \\
\text { Promotional strategy: preliminary meetings; requests for } \\
\text { participation via email, YouTube video, and presentations }\end{array}$ \\
\hline $\begin{array}{l}\text { Geoweb } \\
(4.2 .3)\end{array}$ & Mapping infrastructure: Ushahidi’s Crowdmap \\
\hline VGI (4.2.4) & $\begin{array}{l}\text { Seed content: data supplied by the DFPC } \\
\text { Volunteered contributions: information on local food assets in } \\
\text { Durham Region } \\
\text { Other data: field notes }\end{array}$ \\
\hline \multicolumn{2}{|l|}{ FUNCTIONS } \\
\hline Input (4.3.1) & $\begin{array}{l}\text { Seed content: Student datathon } \\
\text { Quantity of reports: } 227 \text { total contributions } \\
\text { Participation rate: } 2.5 \% \text { (contributions/unique visitors) }\end{array}$ \\
\hline $\begin{array}{l}\text { Management } \\
\text { (4.3.2) }\end{array}$ & $\begin{array}{l}\text { Organizational context: academic and DFPC } \\
\text { Contribution vetting: } 54 \text { of } 227 \text { contributions not used } \\
\text { Project timeframe: } 3 \text { months (February to May, 2015) } \\
\text { Data storage: cloud and local backup of data }\end{array}$ \\
\hline $\begin{array}{l}\text { Analysis } \\
\text { (4.3.3) }\end{array}$ & $\begin{array}{l}\text { Typology of contributions: locations, categorical observations, } \\
\text { numeric measurement, narratives, and opinions }\end{array}$ \\
\hline $\begin{array}{l}\text { Presentation } \\
(4.3 .4)\end{array}$ & $\begin{array}{l}\text { Report: created for the DFPC } \\
\text { Permanent map: VGI data repository }\end{array}$ \\
\hline
\end{tabular}

\subsection{Components}

The components within the system represent a complex arrangement between the project and its initiators, the participants, the Geoweb infrastructure, and VGI, which establish the conditions necessary to create a crowdsourced information product. 


\subsubsection{Project: Durham Food System}

Fundamental to the development of a VGI system is the underlying project and its purpose. This case study focused on the food system in Durham Region, a regional municipality consisting of eight lower-tier municipalities that contain a mix of rural and urban lands, and a population of approximately 650,000 people. Demographically, the population is concentrated in the south along Lake Ontario, with the large majority of the population living in urban areas. Durham has a strong agricultural base, which is threatened by the irrevocable loss of farmland with hundreds of thousands of acres going out of production between 1991 and 2001 (Walton, 2003). The threat continues with the majority of proposed and approved growth in the region occurring on prime agriculture land. Compounding this loss, much of the region's prime agricultural land is producing nursery stock, animal feed, and food for export, rather than food for local consumption (Contreras-Judge et al., 2013; Kubursi, Cummings, MacRae, \& Kanaroglou, 2015).

In response to these and other threats to Durham's long-term food security, the political climate in the Province of Ontario and Durham Region prioritizes local and sustainable food production. In addition to the provincially legislated Local Food Act, which aims to promote local food production, increase awareness of local food sources, and encourage the development of new local food initiatives (Bill 36, 2013), the region is responding to the heightening need to foster a sustainable local food economy. Prompted by the Durham Region Roundtable on Climate Change, Regional Council endorsed the Durham Region Food Charter in 2009, and the principles therein are now reflected in the region's Official Plan. The Charter reflects the "vision for a food secure community, focused toward building a just and sustainable local food system as a foundation for population and environmental health" (Contreras-Judge et al., 2013, p. 4). This Regional Charter also encourages municipalities to put local food provisions into their local policies and plans.

Following the endorsement of The Durham Region Food Charter, the Durham Food Policy Council (DFPC) was formed in 2010 to oversee its implementation. As part of their mandate, the DFPC commissioned the Durham Food System Environmental Scan (DFSES) to learn about the various food initiatives happening in the region (Contreras-Judge et al., 2013). The scan took an assets approach, which tends to build community development, 
rather than a needs approach, which tends to lead to community dependence (Kretzmann \& McKnight, 1993). The assets, categorized by food processing, distribution, procurement, recycling and waste, and consumption, were evaluated according to their interaction with the biological, economic, political, and social dimensions of the food system (ContrerasJudge et al., 2013). The DFPC is using the report to ensure that food policy accurately reflects, supports, and builds mutually beneficial relationships between the identified assets.

The scan provided key insights into Durham's food system. However, a major limitation identified in the report, and confirmed upon consultation with the DFPC, is the underrepresentation of the many local initiatives that comprise Durham's regional food system. Given there were no reporting mechanisms to capture the diverse and hyper-local food places, the scan missed what DFPC members describe as essential assets to the food system, as noted in the limitations section of the report:

"This report provides an overview of the existing food system environment in Durham Region, allowing for a high level scan of what is currently going on locally. A detailed analysis of the food system fell outside of the scope and scale of this project. However, the DFPC believes that such an analysis is important and, with appropriate partnerships and resourcing, should be considered as an important next step in this work.

Further, in completing this report, the DFPC noted several gaps in the available data. For example, a full analysis of food deserts, obesity and diabetes clusters was not included as the data required to do this was not available to our team within the timeframe of this project. Therefore, we do recommend that some analysis in these areas continue as new sources of data come available."

- Contreras-Judge et al., 2013, p. 6

The gap in existing data, coupled with the need to learn more about local food assets, shaped this project, which focused on creating the Durham Food Map, which a mapbased resource where local food stakeholders can actively contribute geographic information with the purpose of adding to the knowledge of food assets in the region. 


\subsubsection{Participants: Durham Local Map Actors}

Rooted in the project outlined above, the next step in setting up the VGI system is to coordinate the efforts of a large number of actors in this project and devise strategies to encourage the participation of local food stakeholders.

\subsubsection{Actors}

Three main groups, which are not mutually exclusive, were defined as the initiator, intermediary, and stakeholders. First, this project is initiated as an academic research study to apply the VGI systems framework to participatory food mapping. True to the active participant observation method (Jensen \& Glasmeier, 2010; Kearns, 2005), the socially situated researcher becomes actively involved in Durham's food system. Next, the intermediary facilitated the participation of the stakeholders and the connection to project initiators. While it is not always the case, in this study the academic research team was the initiator and intermediary.

Lastly, the stakeholders refer to participants selectively targeted because of their current and active involvement in the local food system, acting essentially as informants. Since motivation to participate is a key issue in VGI research (Elwood, 2008b; Goodchild, 2008) with contributors needing to understand 'why' their contribution matters (Coleman et al., 2009; Edwards, 2014; Elwood \& Leszczynski, 2013), the study targeted engaged food stakeholders through a purposeful promotional strategy consisting of preliminary meetings, emails, and presentations (explored in the next section), rather than broadly targeting all citizens using a extensive social media strategy. The purposeful sample, typical of exploratory research, has been shown to generate meaningful results (Newman et al., 2010), which can help move the local food system in new directions.

\subsubsection{Promotional Strategy}

Preliminary meetings were used to gain access and manage field relations (Kearns, 2005) with the local food community in Durham. Contact was first established with the region's climate change coordinator, who then facilitated contact with the Durham Region Roundtable on Climate Change, a committee of regional councillors and citizen members. A 
presentation to the Roundtable resulted in a list of key food stakeholders in the region, including the coordinator for the Durham Food Policy Council (DFPC). Immediately, the DFPC took a strong interest in the project because of the previously identified limitations of the DFSES, and the organization's overall mandate to foster greater communication among the various food system stakeholders in Durham Region.

Beyond the relationship building that occurred with the DFPC, other meetings and presentations were arranged to identify other stakeholders in the region, and to get stakeholders familiar with the goals of the participatory mapping project. In total, seven meetings occurred during the year leading up to the deployment of the Durham Food Map, providing valuable information about the state of the current food system.

In addition to the seven meetings, preliminary presentations were given to stakeholder groups outside of Durham Region, including the Toronto Food Policy Council, Clean Air Council, and Environmental Advisory Committees of Ontario. In doing so, it was decided the project be limited to the Durham Region, serving as a pilot before future expansion into provincial-level local food mapping.

Throughout the process of building a relationship between the researcher and the local food community, 30 key food stakeholders were identified in Durham Region and its eight lower-tier municipalities: one joint government and citizen group, four regional government agencies, eight municipal government agencies, six non-governmental agencies, six community groups, and two post secondary institutions. (See Appendix 4A for a complete list of stakeholder groups, and a summary of the promotional strategy employed for each.) The government agencies represented the environmental, climate change, and sustainability sectors, leaving out public health departments. Healthy food systems are crucial for a healthy population and as such, health department would be a valuable addition that was not included in this study. In future, gaining a better understanding of food systems from both an environmental and health point of view would further strengthen a food systems study. Community groups are broadly defined as being comprised by all volunteer work (i.e., no paid employees), compared to NGOs, which are more formalized organizations that have paid employee(s) and a board of directors. 
To facilitate participation, a member of each stakeholder group was contacted via email (see Appendix 4B for email text). The primary contact at each organization was often the climate change or environmental coordinator. Further, where time and scheduling permitted, a brief presentation was given to the organization, incorporated in the organization's existing meeting schedule, such as a monthly or annual meeting. When time or scheduling did not permit for a presentation, a three-minute video, uploaded to YouTube (see Appendix 4C for link and video script), was used to explain the project and efficiently support the understanding of 'why' participation was important. Initially, a webinar was planned for all groups, but given the time commitment required by participants (typically one hour at a set time), an email and video combination was deemed a more flexible option. Once the participants were aware of the project, their contribution was requested via the Geoweb infrastructure.

\subsubsection{Geoweb Infrastructure: Crowdmap}

Each VGI system has a specific set of hardware, software, and Web mapping infrastructure supporting the collection of volunteered content, herein referred to as the Geoweb. Among the many free pre-packaged Geoweb applications available, the Durham Food Map used the participatory mapping platform Crowdmap to support the system. Crowdmap is the hosted version (i.e., does not require installation on a local server) of the Ushahidi platform, which was initially designed to gather reports from citizens in times of crisis (Okolloh, 2009).

Crowdmap offers many customization options, including options for base map data (OpenStreetMap chosen), RSS feeds (all stakeholder websites added if they have RSS enabled), website appearance (title, tags, and about pages), and various contribution input types (reports, email). While the reports can be contributed by anyone, the default setting in Crowdmap required all contributions to be approved before becoming visible on the map. For this study, OpenStreetMap mapnik, an open source toolkit for rendering maps, was chosen as the base map because of its high level of detail. The standard and customizable options available through the Crowdmap platform, further discussed in Section 4.2.2, shape the functional considerations for the Durham Food Map. 


\subsubsection{VGI: Local Food Assets Data Collection}

The project, participants, and Geoweb construct an environment conducive to the creation of VGI. However, before VGI can be created by the identified food stakeholders, seed contents have been shown to encourage contributions (Sani \& Rinner, 2011). Seed contents are relevant data added to the map before seeking other contributions, in order to encourage participant contribution.

Resulting from the preliminary meetings, a preliminary dataset was acquired from the Durham Food System Environmental Scan (Contreras-Judge et al., 2013)—generously provided by the Durham Food Policy Council and Community Development Council of Durham-in order to seed contents to the map. While these data were not technically in the public realm, the partnership with the DFPC enabled access to the otherwise inaccessible dataset. To mitigate any potential risk related to sharing the dataset, it was provided under the context of free, prior, and informed consent (Williams \& Hardison, 2013); the DFPC consented, prior to sharing the data, to make the dataset available to the public for viewing and downloading within the Durham Food Map environment. This sizable dataset ensured future contributors are not looking at a blank map, wondering what they should contribute.

The content of the dataset represented what the DFPC already knew about food assets in the region; the categories within consisted of community gardens, community shared agriculture farms, farmers' markets, food banks, and supermarkets. The dataset also included latitude, longitude, name of asset, city, and description attributes. These data were used as a baseline to measure additional volunteered contributions. Five additional classifications were added based on asset categories stakeholders identified during the preliminary meetings: foodscapes (landscape with food), neighbourhood gardens, proposed gardens, events, and 'other' for contributions not represented by existing categories. The creation of the intended VGI is further explicated by considering the system functions for the Durham Food Map.

\subsection{Functions}

Building on the components of the system, the functional considerations shape the input, management, analysis, and presentation of VGI. 


\subsubsection{Input}

The input focused on who contributed the data. Geographic information was traditionally inputted by professionals but crowdsourcing relies more broadly on citizens to input data. In preparation for VGI collection in this project, students inputted seed content during a datathon, which is a variation of the more popular civic data hackathon; contest-based events that turn government open data into innovative applications that help deliver services to citizens (Johnson \& Robinson, 2014). The datathon, in contrast to data hackathons, only requires data input, rather than focusing on using the data for application development.

During the datathon, held February $4^{\text {th }} 2015$, six undergraduate and masters students volunteered to input the seed content. In addition to the data provided from the DFSES, students added a mandatory description to the report-a requirement of the Crowdmap platform-using information found on the web. Website links are added, if available. The student datathon also served as a test run of the Crowdmap application, proving its capacity to handle multiple reports simultaneously.

Once the seed content was added and the mapping platform performance tested, Crowdmap was ready for the direct input by local food stakeholders. A dedicated Durham Food Map email address was created for those wanting to ask questions, or submit addition report information. The SMS input option (phone-based text messaging), available through Crowdmap, was not enabled for this project because detailed contributions were sought. Ultimately, this decision limited contributions from those who do not have web-enabled phones or desktop computers. The lead researcher monitored contributions daily and tracked Web activity using Google Analytics to determine contribution and participation rates.

\subsubsection{Management}

Various administrative considerations have been identified for the effective management of VGI projects, including the composition of the organizational team, contribution vetting, data storage and download, and project timeframes. 
In larger projects, teams are often developed to achieve the various tasks required. Since this was a smaller research-based project, the lead researcher managed the project and was exclusively responsible for all Crowdmap administration. However, a higher level of oversight is a necessary part of project management. As such, the DFPC was invited to oversee the project, acting as an advisory committee. The advisory committee and project initiator collectively set the scope for the desired VGI, including the contribution vetting process. Various authors suggest that all contributions should be welcome (Coleman, Sabone, \& Nkhwanana, 2010; Hickling Arthurs Low, 2012). After consultation with literature and the advisory committee, we decided that all contributions be approved unless proven incorrect or defamatory information.

Once the Durham Food Map was ready for volunteered contributions, the 30 stakeholder groups were contacted to contribute to the map. While only those from the identified stakeholder groups were contacted, rather than employing a broad social media strategy, contributions were not restricted to this group only. Contributions from individuals outside of these groups were to be included on the map, again unless incorrect or defamatory. The 'about this project' page of the map included consent information, which stated that participants consent to participate by adding contributions to the map. If they chose not to consent, they are requested not to add content to the map.

Primary storage was in the cloud through the Crowdmap platform, with periodic backups of the data stored on a local computer. The Crowdmap environment offers a public data download option, which was activated to support the creation a food asset dataset that is accessible, usable, downloadable, and archivable. According to Sieber \& Johnson's (2015) classification of civic open data, the open dataset generated through this project fits into the participatory open data category. It represents a first attempt of data coproduction between authoritative and citizen-generated data in the regional food system, where stakeholder contributions are integrated and synthesized in the authoritative dataset provided by the DFPC. Overall, the co-production of data by multiple food stakeholders and open access improves the quality and utility of the data generated.

Timeframe was the final management consideration. While many notable examples of VGI systems are ongoing projects, including OSM and Wikimapia, staff and financial 
resources limit the operating time of a project. A constrained timeframe can help ensure the sustainable operation of a project. While there is no agreed upon timeframe for a study such as this, Haklay (2014) identified six to eight weeks as the ideal timeframe of a problem-oriented project, with a minimum lead time of three months. Neis \& Zipf (2012) also observed that the majority of OSM contributions occurred within three months of registration, before sharply declining. As such, the lead time for this project was one year, and the contribution timeframe was three months between February and April 2015.

\subsubsection{Analysis of VGI}

The analysis focused exclusively on the type of contributions generated, as contributor and contribution statistics are reported as part of the input results. There is currently limited capacity to analyze VGI datasets because it is not from a representative sample of the population. Given the challenges to measuring validity, objectivity, or other quantitative impacts of VGI, some have tried to measure usability of the mapping environment (G. Newman et al., 2010; Nivala, Brewster, \& Sarjakoski, 2008).

The study took a different approach by undertaking a thematic analysis of the participant contributions received from the Durham Food Map, categorized by the typology of user-generated content established by Rinner \& Fast (2015). Locations, categories, numeric, description, media, and opinion types classify the typologies. The analysis supported the categorization and interpretation of user contributions to the Durham Food Map, which enabled the subsequent organization and compilation of a centralized food assets dataset.

\subsubsection{Presentation}

Effectively synthesizing and presenting the food assets dataset ultimately supports the ongoing spatial understanding of the food environment in Durham. After compiling the data in a centralized dataset, an open dataset will be made available to the public. This dataset can then support a permanent Web map resource. A Web map ensures longer-term sustainability beyond the research project timeframe. The DFPC expressed interested in supporting the Durham Food Map after the active data collect phase, but requested to revisit the topic once the pilot project wrapped up. 
The outcomes of this study also need to be summarized in a way that is easily comprehended and communicated with the DFPC and other food system stakeholders. As such, a report summarizing findings of the study is an important resource to supplement the Web map. This report is intended to build on the assets identified in the existing Food System Scan, with a particular focus on what was learned about the regional food system through participant contributions. As discussed with the DFPC in preliminary meetings, this report is viewed as a project deliverable and as such, was requested to be made publicly available on the DFPC's website.

\subsection{Conclusion}

It is under the conditions presented in this chapter that the VGI system on Durham's food assets is established. The next step of this research is to understand the outcomes associated with following this process. 
Appendix 4A: Summary of Stakeholder Groups, Contact, and Outreach

\begin{tabular}{|c|c|c|c|c|}
\hline STAKEHOLDER GROUP & PRIMARY CONTACT & $\begin{array}{c}\text { PRELIMINARY } \\
\text { MEETING } \\
\end{array}$ & EMAIL & PRESENTATION \\
\hline \multicolumn{5}{|c|}{ GOVERNMENT AND COMMUNITY COUNCILS } \\
\hline Durham Food Policy Council & Coordinator & $\checkmark$ & $\checkmark$ & $\checkmark$ \\
\hline \multicolumn{5}{|l|}{ REGIONAL GOVERNMENT } \\
\hline $\begin{array}{l}\text { Durham Regional Roundtable on } \\
\text { Climate Change }\end{array}$ & Coordinator & $\checkmark$ & $\sqrt{ }$ & $\sqrt{ }$ \\
\hline $\begin{array}{l}\text { Durham Tourism, Planning, and } \\
\text { Economic Development }\end{array}$ & Director & & $\sqrt{ }$ & \\
\hline Parks and Environmental Services & Senior Staff & $\checkmark$ & $\checkmark$ & \\
\hline $\begin{array}{l}\text { Climate Change Adaptation Food } \\
\text { Security Task Force }\end{array}$ & Coordinator & $\checkmark$ & $\checkmark$ & \\
\hline \multicolumn{5}{|l|}{ MUNICIPAL GOVERNMENT } \\
\hline $\begin{array}{l}\text { Environmental Coordinators from } \\
\text { Durham municipalities ( } 8 \text { total) }\end{array}$ & $\begin{array}{l}\text { Environmental } \\
\text { Coordinators }\end{array}$ & & $\checkmark$ & \\
\hline \multicolumn{5}{|c|}{ NON-GOVERNMENTAL ORGANIZATIONS } \\
\hline Durham Integrated Growers & Communications Director & $\checkmark$ & $\checkmark$ & $\checkmark$ \\
\hline Durham Farm Fresh & Executive Director & $\checkmark$ & $\checkmark$ & \\
\hline EcoSource & School Food Coordinator & $\checkmark$ & $\checkmark$ & \\
\hline Oshawa Public Library & Service Director & & $\sqrt{ }$ & \\
\hline $\begin{array}{l}\text { Toronto and Region Conservation } \\
\text { Authority - Durham }\end{array}$ & Durham Director & & $\sqrt{ }$ & \\
\hline Durham Sustainability & Program Manager & $\sqrt{ }$ & $\checkmark$ & \\
\hline \multicolumn{5}{|l|}{ COMMUNITY GROUPS } \\
\hline $\begin{array}{l}\text { Durham Environmental Advisory } \\
\text { Committee }\end{array}$ & Members & & & $\sqrt{ }$ \\
\hline $\begin{array}{l}\text { Ajax Environmental Advisory } \\
\text { Committee }\end{array}$ & Chair & & & $\checkmark$ \\
\hline $\begin{array}{l}\text { Oshawa Environmental Advisory } \\
\text { Committee }\end{array}$ & Members & & & $\checkmark$ \\
\hline We Grow Food & Coordinator & $\checkmark$ & $\checkmark$ & $\checkmark$ \\
\hline Canadian Victory Garden Project & Executive Director & & $\checkmark$ & \\
\hline Durham Master Gardeners & Executive Director & & $\checkmark$ & \\
\hline $\begin{array}{l}\text { Durham Agricultural Advisory } \\
\text { Committee }\end{array}$ & Chair & & $\sqrt{ }$ & \\
\hline Oshawa Garden Club & President & $\checkmark$ & $\checkmark$ & \\
\hline \multicolumn{5}{|l|}{ POST-SECONDARY INSTITUTIONS } \\
\hline $\begin{array}{l}\text { University of Ontario Institute of } \\
\text { Technology }\end{array}$ & Sustainability Coordinator & & $\checkmark$ & \\
\hline Durham College & Sustainability Coordinator & & $\sqrt{ }$ & \\
\hline
\end{tabular}




\section{Appendix 4B: Email to Local Food Stakeholders}

Dear $<$ insert contact $>$,

As you know from your work with <insert association>, there are many great local food assets in Durham Region, including community gardens, school greenhouses, local food procurement, harvest trading tables, foodscapes, gardening workshops, and more!

To learn more about these food assets, the Durham Food Policy Council partnered with Ryerson University to develop the Durham Food Map. Please see our short 3-minute video about the Durham Food Map: https://youtu.be/UOg5GZLP w

Building on the Durham Food System Environmental Scan, there are already many food assets on the map. However, there are many more to add, especially from municipalities in Northern Durham. If you have initiated, participated in, or know about food assets in the Region, you can help in 1 of 3 ways:

1. Please go to https://durhamfood.crowdmap.com and check to see if your food asset is on the map, and if all of the information is correct. If you would like to add anything (photos, links, news stories, updated information), leave a comment on the report or send an email to durhamfoodmap@yahoo.ca and it will be added to the map. Please upvote it if it's correct, too.

2. If your initiative isn't already on the map, please add it by clicking "Create Report". You can report the title, location, description, websites, photos, and more.

3. If you know of anyone working toward strengthening food assets in Durham Region, please forward this email to them. The more contributions we get on the Durham Food Map the better!

The map will be open for contributions until April 30th, 2015. After this date, the contributions will be incorporated into a report for the Durham Food Policy Council.

Sharing information about your food events, community initiatives, and other food assets helps shape future food policies and planning in Durham Region. In particular, this map resource will be used by the Durham Food Policy Council in support of the Durham Food Charter, in addition to building an online community of local food advocates.

Please reply to this email DurhamFoodMap@yahoo.ca if you have any questions, comments, or general inquiries. Also, send an email if you would like to share information about your food asset without adding it to the map.

Thank you for helping us crowdsource Durham's food secure future!

Sincerely,

Victoria ...on behalf of the Durham Food Map.

Victoria Fast

PhD Candidate, Ryerson University,

Environmental Applied Science and Management

If you would prefer not to receive information on the Durham Food Map, please reply with unsubscribe. 


\section{Appendix 4C: Promotional YouTube Video Script}

Title: Durham Food Story(Map) Link: https://youtu.be/UOg5GZLP_w

1. Hi, I'm Victoria Fast and I'm going to share Durham's Food Story... using the Geoweb

2. Maps are increasingly online and interactive. If you use Google Maps, you've used the Geoweb.

3. This Google map, in particular, shows the Durham Region, which is just east of Toronto.

4. Local Food system stakeholders in Durham are already using the Geoweb to share spatial information, including:

5. The Durham Farm Fresh map of farm locations; and,

6. Durham Integrated Growers map of community gardens.

7. Our research partner, the Neptis Foundation, developed a specialized Geoweb designed to visualize how regional and municipal plans connect-or more accurately, do not connect-with each other, helping us tell a STORY about growth in Durham.

8. Focusing on southern Durham, purple shows current built up areas.

9. Next, we add surrounding protected areas (green) and prime agricultural land (yellow). Here's where the story gets interesting. Let's add urban expansion.

10. The 2 shades of pink show where the Region plans to grow...

11. ...which is concentrated over prime agricultural land.

12. The story we're starting to tell...

13. ...Is that we're prioritizing growth over food security.

14. But these maps only tell part of the food story; the part that's in official planning documents.

15. Traditional ways of mapping don't show the diverse and hyper-local places of food that are also contributing to Durham's food story.

16. In fact, there are thousands of people tweeting about local food. What are they saying?

17. They're talking about: the Tuesday Trading Table, where inner city residents traded surplus produce with other gardeners.

By the end of the season, food was so plentiful it was given away to those in need.

18. They're talking about: the Neighbourhood garden started on a vacant downtown property by the We Grow Food community group.

19. The garden supplied 30 families with over " 25 " hundred pounds of food.

20. And a place for neighbours to meet.

21. They're talking about: Beautiful food planted alongside flowers, which was harvested and donated to the local food bank.

22. Building sustainable and regenerative local food systems require bringing these diverse food initiatives together.

23. This research is dedicated to giving citizens a platform to share their food stories. Think Google maps meets Wikipedia. We're crowdsourcing food resources.

24. The custom build Geoweb allows anyone with an Internet connection to report locations, photos, links, and videos of food resources, initiatives, and events.

25. It enables local food stakeholders-including individuals, community groups, non-profits, and government-to share their successes \& add to Durham's food story.

26. Overall, this research highlights citizen-led initiatives, ultimately supporting community driven food policies.

27. Maps can tell a story. Participatory mapping can change a story!

28. And there's so much to add to this story. Please visit: durhamfood.crowdmap.com to learn more.

29. Thank you to our funders, partners, and you for watching. 


\title{
5. ReSults ANd Discussion: Reporting Food AsSets in Durham Region
}

\begin{abstract}
Applying the VGI systems framework, the results in this chapter report on the process of implementing a VGI system framework to support the participatory mapping of Durham's local food assets, organized by input, management, analysis, and presentation functions. The discussion elaborates on the engagement of the various stakeholder groups and the pivotal role of the intermediary. Overall, this project served as a test implementation of the VGI system framework, while contributing new information about food assets in Durham's regional food system.
\end{abstract}

\subsection{Input}

This study began with no publicly available data on Durham's regional or local food system, other than disconnected pieces of spatial data online, such as the locations of community gardens maintained by Durham Integrated Growers and farms that hold Durham Farm Fresh memberships. The study focused exclusively on data that were actively volunteered by the identified stakeholders (i.e., contributions), rather than passively collected from various online sources.

In total, volunteers contributed 227 data points (Table 5.1), 54 of which were not used (contribution vetting explored in Section 5.2.2). The first contribution was the dataset gathered and used in the Durham Food System Environmental Scan (DFSES), which was previously inaccessible and stored privately. The dataset contained 130 data points, 22 of which were not used. Beyond this initial dataset, contributions were divided into three input types: individual contributions added directly to the map (12), individual contributions emailed and added by the intermediary (8), and dataset contributions (3 datasets, 77 total data points). Based on a tally of those who contributed via email and an 
estimate of online contributors, approximately 23 unique participants contributed these data. The three most significant findings are the mode of input, access rates, and contribution of entire datasets.

Table 5.1: Summary of volunteered contributions, contributions vetted, and primary mode of input

\begin{tabular}{|l|c|c|l|}
\hline \multicolumn{1}{|c|}{ SOURCE } & $\begin{array}{c}\text { \# OF } \\
\text { POINTS }\end{array}$ & $\begin{array}{c}\text { CONTRIBUTIONS } \\
\text { NOT USED }\end{array}$ & MODE OF INPUT \\
\hline Dataset from DFSES & 130 & 22 & Email delivery \\
\hline $\begin{array}{l}\text { Individual contributions } \\
\text { added directly to map }\end{array}$ & 12 & $\mathrm{n} / \mathrm{a}$ & Direct map input \\
\hline $\begin{array}{l}\text { Individual contributions } \\
\text { emailed and added by } \\
\text { intermediary }\end{array}$ & 8 & 4 & Email \\
\hline $\begin{array}{l}\text { Contribution of entire } \\
\text { dataset (3 total) }\end{array}$ & 77 & 23 & Email delivery \\
\hline \multicolumn{1}{|c|}{ Total: } & $\mathbf{2 2 7}$ & $\mathbf{5 4}$ & \\
\hline
\end{tabular}

\subsubsection{Email}

Only 12 of the 227 data points were added directly to the map. The remaining 215 data points were contributed via email, including eight individual contributions as well as the remaining dataset contributions. Both individual contributions and dataset contributions sent via email relied heavily on the intermediary to input the contributions to the map. However, the eight individual contributions that were emailed contained the most detailed information about food system assets, and included information on inspiration, status, and connections to other food stakeholders (further analyzed in Section 5.3).

Coleman, Sabone, \& Nkhwanana (2010) suggest that participation rates could be related to program effectiveness (i.e., user friendliness of the map application), however a mechanism to test Crowdmap effectiveness was not part of this study. While it was not possible to confirm why email input is preferred, this finding highlighted the need for the intermediary to take an active role in project management and, among other responsibilities, mediate the map contributions. 


\subsubsection{Access Rates}

In comparison to the low rate of active contributions, the number of people viewing the site was high, according to the sessions recorded by Google Analytics (Figure 5.1). Google Analytics recorded 1011 sessions from 893 users during the three-month timeframe, indicating that $88 \%$ of the sessions were by new users (these statistics also included researcher activity). Interestingly, sessions peaked immediately following two mass email events. The initial email, sent after receiving approval from the DFPC on March 15 ${ }^{\text {th }}, 2015$, generated 134 new sessions. The email sent April 26 $6^{\text {th }}, 2015$, reminding participants that the data collection would close April 30th 2015 , generated the highest peak of 197 sessions (see Appendix 5A for detailed Google Analytics reporting).

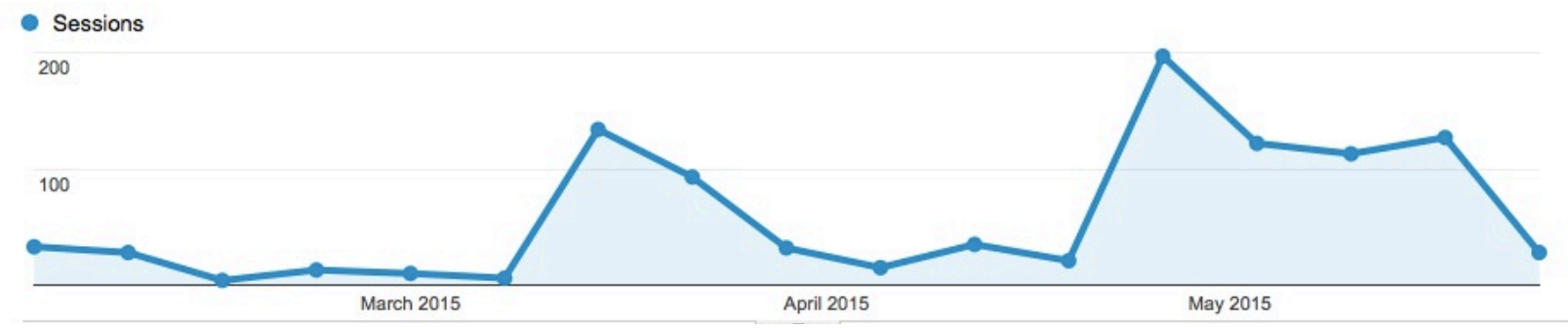

Figure 5.1: Sessions recorded via Google Analytics from February to May 2015

The 23 active contributors out of 893 unique users led to a participation rate of approximately 2.5\%. As reported by Neis \& Zielstra (2014), OpenStreetMap demonstrates similarly skewed participation rates, with only 20,000 of the 1.3 million registered users, or approximately $1.5 \%$, actively contributing VGI in 2013. Further, within the group of active contributors, there are significant differences in the level of activity, with the majority of contributors only being active for three months after registration (Neis \& Zipf, 2012). Given the three-month timeframe of this project, the $2.5 \%$ participation rate was likely the peak of participation. The February to April timeframe proved adequate, although multiple contributions were received (and accepted) during the month of May.

\subsubsection{Volunteered Datasets}

In addition to the initial dataset contributed by the DFPC, three stakeholder groups opted to share dataset contributions rather than individual contributions. The groups, 
representing two NGOs and one community group, previously held the datasets privately but expressed an interest to increase accessibility of their information through the mapping interface. Overall, the datasets-containing information on farms, farmers' markets, and community gardens-were more detailed (i.e., containing attributes such as contact information, operating hours, and produce available), up-to-date (i.e., two of the three datasets updated in 2015), and complete (i.e., containing all of the farms and community gardens operating in 2015) than the information initially contributed by the DFPC. In order to integrate these datasets into the Durham Food Map, the datasets were manually cleaned of duplicate records, keeping the most up-to-date contributions, and then uploaded to the Durham Food Map.

Interestingly, volunteered dataset contributions are not typically associated with VGI, nor do they qualify as open data, which is typically gathered from government sources, because of the authority and availability of the data. Rather, the volunteering of entire datasets created and maintained by NGOs and community groups occupies an unexplored area somewhere between the two. While there are challenges to realizing the value of these datasets-including establishing data standards, mechanisms for sharing, and intermediary facilitation-the NGOs and community groups who were part of this study demonstrated a willingness to share their fastidiously maintained datasets for the benefit of the broader food system. The contributions from these non-government groups, when effectively combined and presented, is a source of current and relevant data that was not previously integrated into regional decision-making.

\subsection{Management}

The prominent aspects of the management of VGI systems relates to the organizational context, contributor vetting process, and data download considerations.

\subsubsection{Organizational Context}

The project employed a small research team. Since the researcher group represented both the initiator and intermediary, communication was not an issue. The advisory committee, introduced in section 4.3.2, also worked well as part of the organizational team. They were given agency to define various elements in the 
participatory mapping process, including which stakeholders to contact, information to include in the email, and contributions to vet. In some instances, the decision-making agency shared with the advisory group led to delays in project deployment. However, the delays were eclipsed by the value of the DFPC's advocacy for the mapping project, facilitating support from other local food stakeholders.

\subsubsection{Contributor Vetting}

In total, 54 of the 227 contributions received were not included on the map. This high vetting rate was attributed to different reasons than initially expected. Originally, the advisory committee discussed removing contributions that were incorrect or inappropriate. In practice, most contributions that did not make it to the map contained either sensitive or inadequate spatial information.

The vast majority of vetting occurred because it contained sensitive spatial information. For example, in the initial DFSES dataset, the food banks category contained 45 entries. However, 22 of the 45 data points were not included because they contained information related to shelters and support services, which is information not currently publically available (i.e., emergency women's shelters). The other 23 data points related to food banks were added to the map because this information is available online through disparate websites. Also, contributions that contain food assets reported at private residences were withheld to protect individual privacy. Lastly, related to privacy, tensions arose between government and citizens regarding bylaws regulating locations where food can and cannot be grown. Given the ongoing nature of this issue, names and affiliations of the contributors are removed from the data.

Contributions were also excluded if they lacked adequate location information. All 12 contributions added directly to the map were included, because the pre-set input options within the mapping application required contributors to include adequate spatial information. In contrast, only four of the eight contributions inputted via email made it to the map because they did not contain adequate spatial information. In the following example sent via email, the contributor shared information on a food asset in the region, but the contribution was missing adequate spatial information to add it to the map: 
"The Big 6: DDSB Cafeterias are sourcing local carrots, cooking onions, mushrooms, red peppers, apples, and cucumbers for this entire school year."

It was impossible to know which six schools within the Durham District School Board this contribution refers to. While this type of contribution cannot be added to the map because of the ambiguity of the spatial information, local food procurement initiatives are valuable information about food assets in the region.

The next example, also sent by email, did not include explicit location information and focused on a range of food strategies, rather than food assets. This highlights the difference between assets that are typically location-based, compared to strategies that broadly operationalize food policies. The latter does not lend itself to mapping because strategies do not relate to a feature on the earth's surface.

“Aside from our Farmers' Market and healthy diet initiatives (part of our Health Workplace Program), we don't have any other food strategies in place yet. The development of programs to encourage local food procurement and community involvement is included as a strategy in Phase 1 of our 5-year strategic plan, which was just approved at the Senior Leadership Level. If we can find a way to align the strategy with our academic programs then it may accelerate implementation."

\subsubsection{Data Download}

The data download option, unfortunately, excluded the photo, video, or Web links that many contributors provided. This is considered a major limitation of Crowdmap's data download function because the photos and links enrich the reporting of food assets. As a result, the lead researcher manually gathered these data from email contributions and known food system stakeholder so they can be included in the final report.

In addition, the individual contributions reported directly to Crowdmap contained optional fields for first name, last name, and email address of the contributor, in which approximately half of those who reported chose to include their personal information. These data are included (i.e., cannot be excluded) in the public data download function in Crowdmap. As a result, the data download function had to be disabled part way through the project to protect the privacy of individual contributors. As an alternative, other open data repositories were investigated and CartoDB was chosen (explored in Section 5.4). 


\subsection{Analysis}

The analysis supported the categorization of data attributes according to the typology of user contribution, which includes location, categorical and numeric data, descriptions, media, and opinions (Table 5.2). The typology was applied to all contributions gathered in this study, which included the individual contributions (IC) and the dataset contributions collected from the Durham Food System Environmental Scan (DFSES), Durham Farm Fresh (DFF), We Grow Food (WGF), and the Durham Integrated Growers (DIG). The analysis of the attributes supported the integration of these diverse datasets in a common database to be subsequently repurposed for further use.

Table 5.2: Typology of volunteered contributions to the Durham Food Map

\begin{tabular}{|l|l|l|l|l|l|l|}
\hline SECTION & DATA TYPES & IC & DFSES & DFF & WGF & DIG \\
\hline \multicolumn{2}{|c|}{ \# of data points: } & 20 & 130 & 42 & 23 & 13 \\
\hline 5.3 .1 & Locations & $\checkmark$ & $\checkmark$ & $\checkmark$ & $\checkmark$ & $\checkmark$ \\
\hline 5.3 .2 & Categorical & $\checkmark$ & $\checkmark$ & $\checkmark$ & $\checkmark$ & $\checkmark$ \\
\hline 5.3 .3 & Numeric & & & & $\checkmark$ & $\checkmark$ \\
\hline 5.3 .4 & Description & $\checkmark$ & $\checkmark$ & $\checkmark$ & & \\
\hline 5.3 .5 & Media & $\checkmark$ & & & & \\
\hline 5.3 .6 & Opinions & $\checkmark$ & & & \\
\hline
\end{tabular}

\subsubsection{Locations}

The location represents the spatial dimension of the data. All of the data contains explicit or implicit location information, which is a necessary requirement for the data to be mapped. The explicit location data, expressed in latitude and longitude coordinates, is used less frequently than the implicit content of addresses or features (e.g., road intersection). Crowdmap was able to handle implicit location information in the form of a postal address, but other implicit location data required manual interpretation by the intermediary in order to input the data to the map. For example, the primary location information of one contribution was 'NW corner of Port Perry fairgrounds', which the map platform is unable to recognize. The project intermediary identified the location using satellite imagery and then manually inputted it as a point on the map. 
Spatial data can be represented using point, line, or polygon (area) feature classes. While the map was able to handle all three classes, points were used most often. Only three of the contributions were polygons, despite community gardens, farmers' markets, farms, and other food assets covering larger geographic areas that are better represented using polygons. As such, no analysis on size of assets could be performed on these data.

\subsubsection{Categorical Observations}

The initial dataset from the DFSES contained five categories, with four other categories added based on early meetings with food stakeholders (5.3). The 'other' category also gained insightful contributions, which are collectively referred to as innovative food assets.

Table 5.3: Categorical contributions

\begin{tabular}{|l|l|}
\hline FOOD SYSTEM & CONSULTATION WITH \\
ENVIRONMENTAL SCAN & STAKEHOLDERS \\
\hline Farms & Foodscapes \\
\hline Farmers' markets & Neighbourhood gardens \\
\hline Community gardens & Proposed community gardens \\
\hline Supermarkets & Events \\
\hline Food banks & Other (Innovative Food Assets) \\
\hline
\end{tabular}

Farms, the most abundant contribution on the map, are concentrated in the rural locations throughout the region. The data on farms was initially available in the DFSES, however the contribution by DFF contained more detailed and up-to-date information. Farmers' markets are distributed throughout the region, with each municipality having as least one market. These data came from DFSES and DFF, again with DFF providing more complete and current data that subsequently replaced the data from the DFSES. There are dozens of community gardens in the dataset, which were added through a combination of DFSES, DIG, and individual garden coordinators' contributions.

Supermarkets and food banks were contributed exclusively by the DFSES, not receiving any contributions from stakeholders. Both categories are underrepresented in the dataset, with many key retailers and services missing. Smaller supermarkets, specialty stores (e.g., bakeries), prepared food (e.g., fast food and other restaurants), and corner 
stores are not represented by the supermarkets category. Similarly, certain food bank services were repressed in the dataset to protect privacy. These data would be necessary for detailed analyses of food access and food deserts.

The above contributions-farms, markets, gardens, supermarkets, and food banksrepresent knowledge that the DFPC already had, with the contributions from DFF, DIG, and select individual contributions supporting the update of the dataset. In contrast, the following individual contributions-foodscapes, neighbourhood gardens, trading tables, seed libraries, and other innovative food assets-represent assets not addressed in the DFSES.

Foodscapes, which is understood as landscaping with food-based plant material, demonstrates the functional and beautiful aspects of food production. Stakeholders were keen to share their experiences of planting food outside of traditional vegetable gardens, which included incorporating food in planters, front gardens, boulevards, and City and Regional flowerbeds. Most of the experiences were positive:

"Oshawa has been planting food alongside flowers, creating beautiful foodscapes." "Kale planted in the botanical gardens in Valleyview gardens, downtown Oshawa."

However, one contributor reported (off the map) bylaw conflicts when they planted vegetables on the boulevard in front of their property. Unfortunately, this contribution was not added to the map because it contains sensitive location and personal information. While not mappable, it brought forth an interesting conflict between Regional and City policies that support urban food production and bylaws that prohibit food production for public safety or aesthetic concerns. Both government and citizens are promoting producing food locally, so this ongoing issue requires continued attention in order to come up with a resolution that meets the needs of all parties involved. This issue is addressed in detail in the project report (presented in Section 5.4.2).

Three neighbourhood gardens were added to the map. These gardens are distinguished from community gardens. In traditional community gardens, residents pay and manage an allotment. Neighbourhood gardens, also referred to as communal gardens, are established as a common resource for the immediate neighbourhood, and local 
residents are expected to take no more than they can eat in one day. The three neighbourhood gardens reported on the map-Carol's Neighbourhood Garden, Pepper Patch Garden, and Cordova Street Garden-are community initiatives where the City approved the use of public or parklands, volunteers donated plants and time, and neighbours maintain their new communal resource. These gardens are celebrated (and awarded) for building strong communities in what is defined as Oshawa's most underprivileged neighbourhoods. The 'proposed community gardens' category was added initially because there were new gardens in the planning phase. However, once the map was ready for stakeholder input, the proposed gardens were reported as neighbourhood gardens. As such, all neighbourhood gardens are grouped together in the final dataset.

The events category was added to the map because various stakeholders identified multiple food-related events happening in the region (e.g., seed swaps, gardening workshops, and food events), but a common resource to share that information does not currently exist. While a few events were added to the map, it was not ideal because there was no specific location, date, or time fields to include information related to the event. Recognizing this as a limitation of the map, the We Grow Food community group created an events calendar, available on their website, to supplement the Durham Food Map. The calendar is currently being updated semi-regularly to keep residents informed about food events happening in the region.

The other category received unique contributions, which are labeled as innovative food assets. These assets include harvest trading tables, seed libraries, greenhouses, and pollinator gardens. The Tuesday trading table is an initiative started by a local restaurant in Oshawa:

"Local gardeners are getting together to swap vegetables every Tuesday outside of the Table restaurant on Simcoe Street in Oshawa. No cash allowed... only trading vegetables and other edibles/seeds."

The Oshawa Public Library started the seed library:

"The library is helping your garden grow this year! Have a look for the Need a Seed, Leave a Seed display at any branch and you may find just the seeds you need for planting this spring. 
The Oshawa Public Libraries, in support of agricultural sharing and preservation, will be hosting a Need a Seed, Leave a Seed display at all branches beginning this April, and running until the end of June.

If you have extra seeds at home, you can share them with fellow community members by leaving them with the display. Simply ensure they are in a sealed and labelled envelope.

This is a great way to try growing something new, or to share seeds of your own with others.

Together, we can take this step towards preserving and promoting community sustainability and beauty!

Take part in our Need a Seed, Leave a Seed program, and get growing!"

The local community identified public greenhouses as a need, rather than an asset. Multiple members of the community indicated they need access to a place to start their seedlings in the winter and early spring. Only one greenhouse, which does not have public access, was reported on the map:

"Henry Street High School has a greenhouse and a garden that is brand new this year (2015). They are working on various initiatives related to connecting the garden with the hospitality program/cafeteria."

Lastly, pollinator gardens were reported as an important food asset:

"The Town of Ajax, along with the TRCA, is about to install a pollinator garden on the berm located on the south-east corner of the [St. Andrew's] park. There are plans to install bee habitats and a bat box in that same location. As well, the Town will be installing a small public orchard, located just north of the garden plots, which includes apple and pear trees."

"We are in the process of working with a volunteer group who have received a donation of pollinator plants. They are working with the Legends Community Garden to undertake a planting at the garden."

\subsubsection{Numeric Measurements}

Collecting volunteered contributions in the form of numeric measurements was not the goal of this study. However, multiple contributions were received that contained attribute information related to the number of plots within community. These data were included in the description because the map environment was unable to individually handle numeric measurements. 
In addition, one dataset contained the names of gardens, their addresses, size, and number of pounds of food grown in 2014. The dataset collectively reported on 23 private gardens that covered 11,500 square feet and grew an estimated 20,500 pounds of fresh produce. This is valuable information, as there are few studies on urban food production capacity, however the personal and location information in the dataset was deemed too detailed to release to the public. It is important to note that government and decisionmakers are looking for quantified benefits to justify further support of urban food, so we will be able to repurpose these data for other uses in the future.

\subsubsection{Descriptions}

The descriptions, many of which have already been shared in this paper, are the most substantial contributions. The descriptions include annotations, narratives, stories, and other details about the food asset being reported. Many food stakeholders wanted to share the story of their particular food asset, including details on the origin, motivation, current status, and future development potential. The community garden category contains the most detailed descriptions, as demonstrated by contributions from the Care and Share, Hebron, Whitby-Ajax, and Salvation Army Community Gardens.

\section{Care and Share Community Garden:}

"Inspiration for Starting It: A few of us attended "The Place to Bee: A Pollination Event" - at Lunar Rhythms CSA (just outside of Blackstock - I think the address is Janetville, so they are officially within the City of Kawartha Lakes region). A specialist had come to talk about her work in encouraging farmers to plant pollinators along ditches, between crops, etc. After attending this event, I volunteered at Happy Farm and started to learn about sustainable farming practices. And learned so much. At the same time, I read a book called, "The Stop".

By late August 2013, fearing that our local fairgrounds would be re-developed into housing in the near future, I approached the Port Perry Agricultural Society, who hold the lease for this land (from the Township of Scugog). I was granted permission to start a project on a small parcel of land $(1 / 3$ of an acre) on the Northwest corner of the grounds.

SO, LONG STORY SHORT - OUR GROWING KNOWLEDGE OF FOOD SECURITY AND FOOD JUSTICE, ALONG WITH CONCERNS ABOUT THE PHYSICAL AND MENTAL 
HEALTH OF LOCAL SCHOOL CHILDREN AND LONELY SENIORS ENCOURAGED US FORWARD.

At this point, we have a core of passionate volunteers. We have decided that we can best serve the community by providing a demonstration garden that showcases sustainable methods of growing food, caring for others, and sharing our excitement with others!"

\section{Hebron Community Garden:}

"Just a few years old and growing (pun intended) the Hebron Community Garden is a place for Green Thumbs of all ages. Starting out with just 20 plots and a passion for growing things, the Hebron Community Garden has doubled in size over the past year and is fast becoming a hub of activity for passionate gardeners. Some of the growing season highlights include a spring seed starting workshop where you can start to get your seeds germinated, seminars from the Durham Digs society, and a year end BBQ with fresh vegetables from the gardens. The Garden plot sizes range from $5 \mathrm{ft} \times 10 \mathrm{ft}$ to $5 \mathrm{x} 20 \mathrm{ft}$ and grow anything and everything from sweet corn to eggplant."

\section{Whitby Ajax Community Garden Project:}

"The Whitby Ajax Garden Project was founded in 2001 by Celebration! Presbyterian Church as a place where individuals, families, and organizations could work shoulder to shoulder, raising fruit and vegetables for those in need. It believes that by growing together that we can heal our selves, others, our community and the world.

The Whitby Ajax Garden Project has continued to grow and expand over the years on its five acre site under the care of Crossroads Community Church, which adopted it when the founding church closed in 2004. The Whitby Ajax Garden Project now encompasses: a communal garden (where fresh produce is grown for those in need); a community garden (where individuals and families can grow and learn to grow their own produce); and the Lynde Creek Tributary Restoration Project all creating a sense of sanctuary.

With the dedicated support of our Garden Members and Community Volunteers the Whitby Ajax Garden Project was able to donate 7000 pounds of fresh produce annually for each of the last three years $(2010,2011,2012)$ a significant increase on previous year donations. In addition, the Whitby Ajax Garden Project continues to provide leadership in development of other urban agriculture initiatives and with other food security organizations in Durham Region and beyond. 
At the end of 2012 the Whitby Ajax Garden Project entered a new chapter in its life becoming an independent not-for-profit organization working toward registration as a charity.

As we move forward we are reminded that WAGP is so much more than a garden. It gives us the opportunity to be truer stewards of the earth. Looking out over the garden we are filled with a sense of hope in the future and the presence of something and someone much greater than ourselves."

\section{Salvation Army Garden}

"The Salvation Army's Community Garden currently has 19 plots. Each Garden Plot is $5 \times 15$. All Garden soil, seeds and plants are provided to get you started. Access to Garden is Combination Lock Entry. Garden tools are provided on site. We are currently looking for anyone interested in acquiring a plot within our Garden community. If you have any questions or you would like to visit the Garden please feel free to contact the Community Garden Coordinator."

While many contributors shared illuminating descriptions, not everyone shared this level of detail in writing. For example, the description for the Tuesday Trading Table and neighbourhood garden contained only a few short sentences. Instead, these groups opted to share their story-history, motivation, challenges, opportunities, and more-in person during meetings, presentations, and other contact time with the researcher. These details are captured using the supplemental field notes, and the report to the DFPC allows the opportunity to share the details of both the written and oral descriptions of assets.

\subsubsection{Media}

Media is a type of volunteered contribution gaining particular importance. Almost all of the data acquired contained links to websites, email addresses of the primary contact, and social media links, like Facebook and Twitter. While none of the dataset contributions contained photos, many individual contributions contained photos. However, the photo upload function only worked selectively, so many who intended to share photos either did not upload them or submitted them via email. Adding further restrictions on the media typology, photos were not available in the data download function. To supplement the limited photos, some photos were taken of reported assets by the researcher to include in the final report. 


\subsubsection{Opinions}

Opinions, including ratings and comments, were not regularly used in this study, despite the option to do so. Up voting and down voting a report (i.e., thumbs up, thumbs down) and comment functions were made available but not used by participants. There was also a verify function, but it was used inconsistently, which led to arbitrary distinctions between contributions that were and were not verified. As a result, none of the contributions were verified.

While the comment, voting, and verify functions were underutilized in the Crowdmap platform, other opinion-type contributions were received off the map. There was one comment on the YouTube video, which identified multiple assets and suggestions for action in the community:

"Did you know there is a seed exchange initiative at the Oshawa Downtown Library? Or, perhaps you are part of this. The work you are doing is great, and much needed.

There is a real issue of food security with many South Oshawa residents on disability. The food banks do the best they can; but often, fresh produce is difficult to come by. Is there anyone connecting the Oshawa food banks to D.I.G and the "We grow Food" movement?

Additionally, someone needs to liaise with the Oshawa/Durham based ODSP case workers. Is it possible to get an insert in the statements that go out each month, to let recipients know about their local community garden project, where they can participate/connect?

Another liaison point: Canadian Mental Health Association - Durham.

Thank you for the work you are doing."

- Local resident, YouTube comment

Another opinion, sent via email, identified an incorrect location of a garden on the map:

"the location on the map for is a little off...instead of being situated on Rideout, as shown on the map, our garden's main entrance is located off the parking lot on the west side of the park (pretty well where the lower ' $\mathrm{P}$ ' is). The garden itself takes up the space formerly occupied by what is shown to be a baseball diamond in the park."

The project intermediary corrected the location manually on the map. Lastly, one contributor emailed to explain a browser compatibility issue. After investigation, it was 
determined that the browser issue was isolated to this user's computer, so no further action was taken. Since these opinion-type contributions were resolved, they are not included in the final food assets dataset.

\subsection{Presentation}

Synthesizing the above typology, prominent types, fields, and subfields emerge from the contributions that are relevant to all data gathered in this study (Table 5.4; also see Appendix 5B for a detailed breakdown of attributes from each contributor group and a link to the open dataset). This dataset is used to support the creation of the Food Assets in Durham Region map and the Crowdsourcing Urban Food Assets report.

Table 5.4: Types, fields, and subfields in Durham's food asset dataset

\begin{tabular}{|l|l|l|}
\hline TYPE & FIELD NAME & SuBFIELDS \\
\hline \multirow{2}{*}{ Location } & Geometry & Latitude/longitude \\
\cline { 2 - 3 } Category & Address & Postal Address \\
\hline \multirow{2}{*}{ Description } & Asset & $\begin{array}{l}\text { Farm, Farmers' Market, Community Garden, Food } \\
\text { Bank, Supermarket, Foodscape, Innovative Food Asset }\end{array}$ \\
\hline \multirow{3}{*}{ Media } & Name & Business/feature name \\
\hline \multirow{2}{*}{ Metadata } & Links & Short description \\
\cline { 2 - 3 } & $\begin{array}{l}\text { Contact } \\
\text { information }\end{array}$ & Website, Twitter, Facebook \\
\cline { 2 - 3 } & Timestamp & Name, email \\
\cline { 2 - 3 } & Origin & Date data created \\
\hline
\end{tabular}

In particular, the final dataset includes location, category, description, media, and metadata types. The numeric and opinion types were not used enough to justify their inclusion, and thus, not included in the dataset. Links and social media are included as field in the media feature class, but photos are not included because of issues with uploading photos into the reports and downloading photos from the dataset.

Lastly, a metadata feature class was added to the dataset. Metadata, defined as data about data, include details related to who created the data, when the data were created, and other data quality information, which helps to assess its fitness for use (Devillers et al., 2010). While there have been improvements in spatial data quality over the last 30 years, there are very little, if any, metadata associated with most volunteered datasets. Coleman 
(2010) noted that the lack of metadata in volunteered datasets-in particular, information on sources of data and subsequent edits of OpenStreetMap data-makes it challenging to identify why some data may be more accurate than others.

To maintain the quality of the food assets dataset, which was acquired from multiple sources (individual contributions, DFSES, DFF, and DIG) with data created at different times, origin and timestamp details are included as fields. In the data gathered in this study, less than half contained a timestamp (i.e., when the data were created). In contrast, almost all of the data could be attributed to the source, whether an individual contribution or dataset contribution. However, in an attempt to capture the origin of data in the final dataset without identifying individual contributors, the origin field is generalized to the dataset it came from, which is sub-categorized as IC, DFSES, DFF, and DIG. On a similar privacy note, if an individual contributor could be identified from their affiliation, the affiliation was also removed from the examples presented in this research.

\subsubsection{Food Assets in Durham Region Map}

Crowdmap was ideal for actively collecting VGI within the scope of the Durham Food Map project because the platform is designed to gather reports from the public. However, because of the constant and continued reliance on the intermediary to support the system-promoting the project, mediating the input, and approving the reports, among many other tasks - the reporting function is only ideal during data collection. To support a permanent map resource using the data generated in this study, a new mapping platform is needed that requires less maintenance while still offering data download functions.

While Geoweb options able to create interactive online maps are constantly expanding, potential mapping applications are limited to free online mapping tools because proprietary GIS software is expensive and open source options have steep learning curves. Bartlett \& Rivard (2014) compared nine free online mapping tools, including GeoCommons, MapBox, and CartoDB. While there are many considerations that went into the selection of an online mapping tool, CartoDB was chosen because the software is free, the database management system allows for easy data updates, the map can be managed by multiple users and is easily embedded into a separate website, and the data are open and 
downloadable in multiple formats. The downside to this platform is the limits to the amount of data that can be entered; only four individual layers totalling no more than 50 megabytes of data can be entered. While the dataset generated in this study is within these limits, it potentially restricts future expansion to provincial or national level food mapping.

The permanent map—called Food Assets in Durham Region in order to distinguish it from the Crowdmap-based Durham Food Map - will be embedded on the DFPC website once their new website goes live. In the meantime, the map and the data are publically available on CartoDB: http://cdb.io/1Ljjx18.

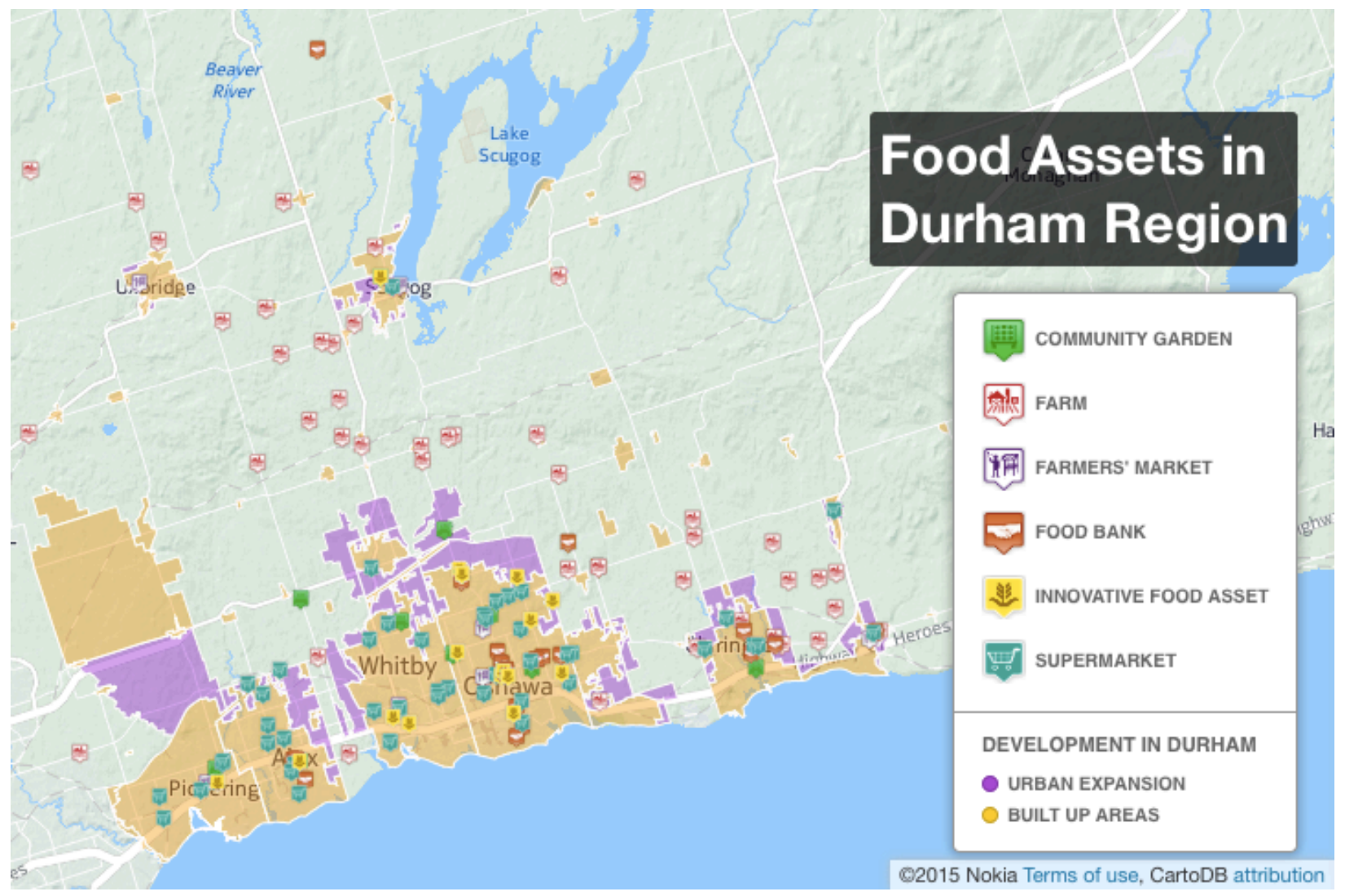

Figure 5.2: Food Assets in Durham Region map created using CartoDB and data volunteered by Durham's food community

\subsubsection{Report}

The report, intended for the DFPC, can be seen as an extension of the initial Durham Food System Environmental Scan. In the scan, urban food assets were largely underrepresented in favour of a broader food industry focus (e.g., agricultural production, 
food process, distribution, and retail). While this study targeted a broad spectrum of local food stakeholders, representing rural and urban interests, the most active contributions were from the urban food community. As such, the report resulting from this study (Appendix 5C) focuses on urban food assets that are central to the food communities hosting them. The food stakeholders engaged in this study have clearly demonstrated that urban food is going beyond backyard gardens, pointing to new trends in urban food production. These urban assets identified by the community add to an emerging field of studying how cities can become more food secure, given the shift from rural to urban living.

The report is supported by the data collected from the food stakeholders in Durham Region. However, the time the researcher spent with the food community led to a detailed, cross-sector view of the regional food system, enriched by the narratives shared during stakeholder meetings and presentations. These narratives are essential to understanding the context around many of the regional food assets reported. As such, the report goes beyond the content of the contributions and draws on field experience (field notes) to further reflect on the value of the food assets identified to the urban food system. Further, it also includes recommendations to support, strengthen, and encourage growth of Durham's urban food assets.

\subsection{Process Benefits: Engaging the Regional Food Community}

The outcomes of the research are an up-to-date food assets database that was contributed by the regional food community, which then supported the creation of an online interactive food map and a report on urban food assets. In addition to these outcome benefits of enacting a VGI system, there were also process benefits that are challenging to objectively measure and report. This research aimed to engage local food actors in the fundamentally social participatory mapping process by getting them to share their location-based food assets. While there is a growing understanding of the societal implications of this new social practice on the networked publics (N. Chrisman, 2005; Elwood et al., 2012; Elwood, 2009a; Lin, 2013), it is still a challenge to tangibly measure the impact the Geoweb and VGI have on networking, advocacy, and collaboration efforts toward building a food community. According to Schaffer (2007, p. 3), "most citizen sites 
don't use traditional metrics - unique visitors, page views or revenues - to measure their success." Rather, success is more often determined by the impact the site has on the community.

We suspect the impact of this research and engagement far surpassed the numbers reported above. Beyond the stakeholders engaged and data created, the discussion reflects upon the engagement among the stakeholder groups and the role of the intermediary. Overall, the bottom-up (involvement of the food community) and top-down (involvement of the researcher) design of this project enabled the limited but meaningful engagement of participants.

\subsubsection{Stakeholders}

Durham Region encompasses a diverse set of local food champions that represent government, NGOs, community groups, and individuals working tirelessly to support a secure food system, 30 of which were identified and contacted in this research. These stakeholders represent people and organizations already engaged in local food issues, and vested in the various outcomes of regional and local food decision-making. Individually, they possess fragments of valuable information about the local food system in Durham; fragments that, put together, provide a dataset to better understand what food assets are important to the regional food community.

Overall, the participants volunteered a mix of datasets and individual contributions, supporting learning about the local food assets within the region. Particularly active engagement came from the NGO and community group participants, compared to the more limited engagement of government stakeholders. The individuals within these groups were more inclined to actively and meaningfully contribute data, both individual contributions and larger datasets. Many noted that they were already trying to work toward better collaboration (especially online) with other food system stakeholders, so the map provided a medium to support their pre-existing goals. The lesson here is to harness existing food champions, targeting those already engaged as an entry point to more meaningful reporting and dialogue. 
At the time of writing of this thesis, the metropolis of Milan in Italy released their first, and perhaps one of the world's most comprehensive guides on supporting a sustainable food system (Barilla Centre for Food and Nutrition Foundation, 2015). The strength of the "Milan Protocol on Food and Nutrition" revolves around the hundreds of signatories who have committed to a more sustainable food system. The signatories are from a wide-range of food system stakeholders, just like the ones targeted in this research. Their collective strength and action is what can make a difference in the food system. Better tools and resources for collaboration are essential, and participatory mapping proved to be one of them.

\subsubsection{Intermediary}

The engagement of the stakeholder groups could not be realized without the active contribution of an intermediary. The researcher facilitated the cross-sector sharing of stories, resources, and initiatives throughout the preliminary meetings, formal presentations, video, and follow-up contact. In this project, like many others conducting participatory mapping, crowdsourcing, or citizen science, the mediation was central to the deployment of the VGI system. As such, it is important to further refine this role, and its effectiveness, to continue developing VGI systems to connect decision-makers with civil society.

There is a growing need for intermediaries who can bridge the gap between experts in the subject matter (i.e., food stakeholders) and experts in a digitally enabled approach (i.e., trained mapmakers). This became strikingly obvious in this project. The intermediary, who was also the initiator, established the technical side of the Durham Food Map. The map functioning properly was essential for participation. The role of the intermediary is a point worth further exploration.

The process of gaining both knowledge and trust within the local food system through preliminary meetings, gathering contributions, and following up with the stakeholders enriched the researcher's knowledge and involvement in the local food system. This contact and subsequent familiarity of the domain was of utmost value to building trust among the existing community, highlighting the necessity of the extensive 
lead-time. Further, the researcher became regarded as a local food champion. This position allowed the researcher to work across the fragmented local food groups with the purpose of advocating various assets across the region. Thus, resulting from the active engagement of the initiator, the impact of this project extended far beyond the participatory mapping environment. Results like these would not be expected if the VGI systems framework had been applied to a project aiming at collecting passive VGI, highlighting that the VGI system perspective is not exclusively about the mapping technology; it is equally about the project and participants it supports and shapes.

\subsection{Limitations}

The decisions made during the study about how to establish the VGI system represent uncontrolled variables; it is impossible to determine the impact that choosing a different variable would have had on the study's outcome. The two major limiting choices that likely had the greatest impact on this study are related to targeting active food system stakeholders, rather than conducting a broad social media campaign, and selecting the Crowdmap application from the host of Web map options.

Targeting engaged food stakeholders led to few, but meaningful contributions, suggesting that it was an effective strategy to upgrade the information known about assets within the regional food system. However, it was not representative, nor comprehensive. The relatively small number of participants $(n=23)$ and contributions $(n=227)$ in this study created a dataset that is not representative of all food assets in the region. This limits further analysis of the data related to the distribution of assets throughout the region, such as locating food deserts, food swaps, or healthy food communities. In addition, limiting the scope of contributions to food assets potentially excluded those who do not identify their contribution to the food system as an asset, while the PAR approach potentially overemphasised desirable (i.e., positive) response as no negative responses were received. In light of these limitations, the contributions gathered from this small group of informants add new information about the regional food system; information that was not previously accounted for in provincial or regional asset mapping. 
The limitations imposed by the Crowdmap application are, similar to other methodological choices, impossible to measure because there are no control variables. The challenges related to uploading photos in Crowdmap discouraged some residents from sharing their photos. While some chose to email these separately, it is impossible to know who wanted to share photos but did not end up doing so. Similarly, the reliance on email for individual contributions suggests that the stakeholders may not yet be comfortable submitting reports directly to the map. Presumably, larger datasets were sent via email because it would be too time consuming to upload them as individual contributions. For both individual and dataset contributions, the role of the intermediary is necessary for the development of a participatory VGI system. In addition, as addressed in section 5.3.1, the majority of the contributions were point based geographic features, with no lines and few polygons used to represent various features of food assets. This oversimplifies food assets, such as farms, to points, thus eliminating elements of spatial coverage.

Lastly, this participatory mapping project in Durham Region was hoped to provide a foundation for provincial- and national-level food asset mapping, ultimately supporting the widespread information sharing necessary for building more resilient food systems that are strongly linked to the assets in each community. However, by its very nature, this research is rooted in developing a relationship with the local food community in order to connect to what they identify as assets and priorities moving forward. It would be challenging to develop similar multi-stakeholder alliances at the provincial- or nationallevel. As such, scaling up participatory food mapping would require connecting to the organizations and institutions (government, NGO, community, and academic) currently maintaining datasets on the regional, provincial, and national food system. If they are willing to share their data, like the food stakeholders who maintain data on Durham's food system did for this study, it would be a strong starting point for the expansion of local food mapping.

\subsection{Conclusion: Synthesizing the Durham Food VGI System}

This study focused on using VGI to engage multi-sector food system stakeholders to create new information on regional food assets. Structured by the VGI systems approach, 
and under the conditions of the methodology developed in this research, new knowledge on food assets was generated. This knowledge went beyond what was previously available to regional food decision-makers from the DFSES or OpenStreetMap. The new knowledge highlights citizen-identified assets, suggesting new directions to strengthen the regional food system. In particular, urban food assets were identified as a priority for many citizens in Durham Region.

The resources created from this study, specifically the map and urban food assets report, have the potential to inform future regional and municipal food policy and planning. It is now up to the regional food community to utilize these new resources to develop regional food policies, programs, and regulations that support these community identified assets. The impact of this policy-relevant research on regional and municipal food policy, and program and regulation development that come with it, will be determined through the continued commitment of the actors engaged in this research. In particular, the Durham Food Policy Council plays a central role in using these resources to support stronger food policy. While the scope of this study ends here, the primary recommendation moving forward is to mobilize the cross-sector network of engaged food stakeholders to develop regional food policies, to be adopted by each municipality, that support strong urban food systems. Currently, an urban food policy working group, comprised of government and citizen members under the mandate of the DFPC, is being formed to work toward realizing this recommendation.

Overall, the Durham Food Policy Council gained a uniquely local and communitydriven perspective about food system assets within the region using the VGI system. Knowledge of community-identified food assets is a central element of a regional food system that is economically viable, ecologically sound, and socially just. 
Appendix 5A: Google Analytics

- Sessions

200
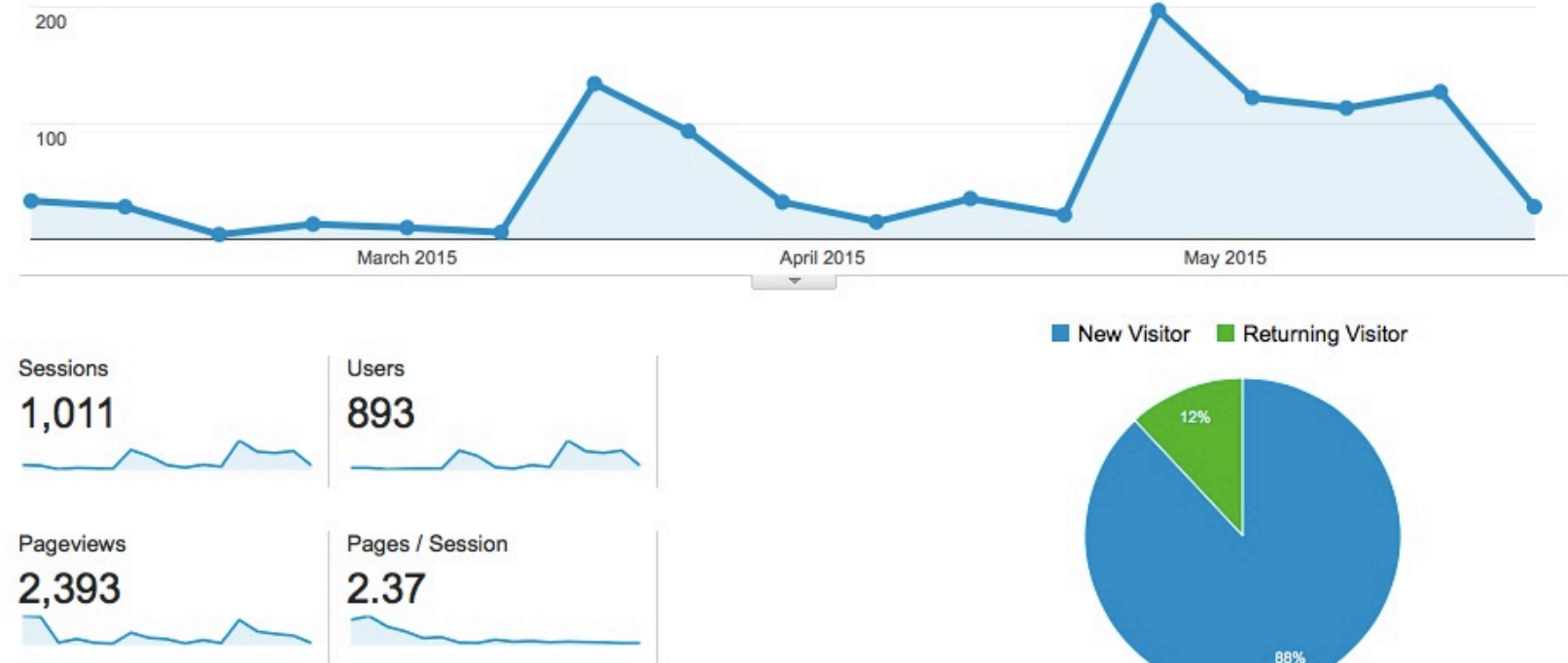

Avg. Session Duration

00:01:52

Bounce Rate

$\quad 72.40 \%$

$\%$ New Sessions

$88.03 \%$ 
Appendix 5B: Detailed Contribution Types Receiving from Each Contributor Group

\begin{tabular}{|c|c|c|c|c|c|}
\hline FEATURE CLASS & DFPC & DFF & WGF & DIG & VGI \\
\hline Location & $\begin{array}{l}\text { Lat/long, } \\
\text { address of } \\
\text { feature }\end{array}$ & $\begin{array}{l}\text { Lat/long, } \\
\text { address of } \\
\text { farm, city, } \\
\text { province, } \\
\text { postal code }\end{array}$ & $\begin{array}{l}\text { Address of } \\
\text { garden }\end{array}$ & $\begin{array}{l}\text { Address of } \\
\text { garden }\end{array}$ & $\begin{array}{l}\text { Lat/long, } \\
\text { address of } \\
\text { report }\end{array}$ \\
\hline Category & $\begin{array}{l}\text { Community } \\
\text { gardens, } \\
\text { farmers' } \\
\text { markets, } \\
\text { farms, } \\
\text { food banks, } \\
\text { supermarkets }\end{array}$ & Farms & Gardens & $\begin{array}{l}\text { Community } \\
\text { gardens }\end{array}$ & $\begin{array}{l}\text { Foodscapes, } \\
\text { local food } \\
\text { procurement, } \\
\text { seed library, } \\
\text { greenhouses, } \\
\text { events }\end{array}$ \\
\hline Numeric & & & $\begin{array}{l}\text { Square feet } \\
\text { of garden, } \\
\text { pounds of } \\
\text { food grown }\end{array}$ & $\begin{array}{l}\text { Number of } \\
\text { plots, year } \\
\text { garden } \\
\text { established }\end{array}$ & \\
\hline Description & $\begin{array}{l}\text { Name of } \\
\text { feature }\end{array}$ & $\begin{array}{l}\text { Business } \\
\text { name, } \\
\text { product list, } \\
\text { icons }\end{array}$ & $\begin{array}{l}\text { Name of } \\
\text { garden } \\
\text { owner }\end{array}$ & $\begin{array}{l}\text { A short } \\
\text { description of } \\
\text { your garden } \\
\text { (unrestricted) }\end{array}$ & $\begin{array}{l}\text { Description of } \\
\text { feature } \\
\text { (unrestricted) }\end{array}$ \\
\hline Media & & & & $\begin{array}{l}\text { Facebook, } \\
\text { website, email, } \\
\text { Twitter, }\end{array}$ & Photos, links \\
\hline Opinions & & & & & Corrections \\
\hline Metadata & & $\begin{array}{l}\text { Primary } \\
\text { contact, } \\
\text { contact } \\
\text { information, } \\
\text { timestamp }\end{array}$ & & $\begin{array}{l}\text { Primary } \\
\text { contact, } \\
\text { contact } \\
\text { information, } \\
\text { timestamp }\end{array}$ & $\begin{array}{l}\text { Name of } \\
\text { contributor } \\
\text { (optional), } \\
\text { timestamp }\end{array}$ \\
\hline
\end{tabular}

In recognition of the importance of open data, the complete dataset is available for viewing and download on CartoDB. These data are available in conjunction with the Food Asset in Durham Region map: http://cdb.io/1Ljjx18 


\section{Appendix 5C: Crowdsourcing Urban Food Assets}

The following report is a white paper intended to summarize and present the findings from the Durham Food Map project. The emphasis is on information the Durham Food Policy Council (DFPC) and other food system stakeholders can use to further support regional food system development. The report will be made available on the DFPC website when the site redesign is complete. In addition, the Urban Food Policy working group is currently using a draft copy of the report, as they work toward integrating urban food assets into the regional food system. 


\section{DURHAM FOOD MAP REPORT:}

\section{Crowdsourcing \\ Urban Food Assets}
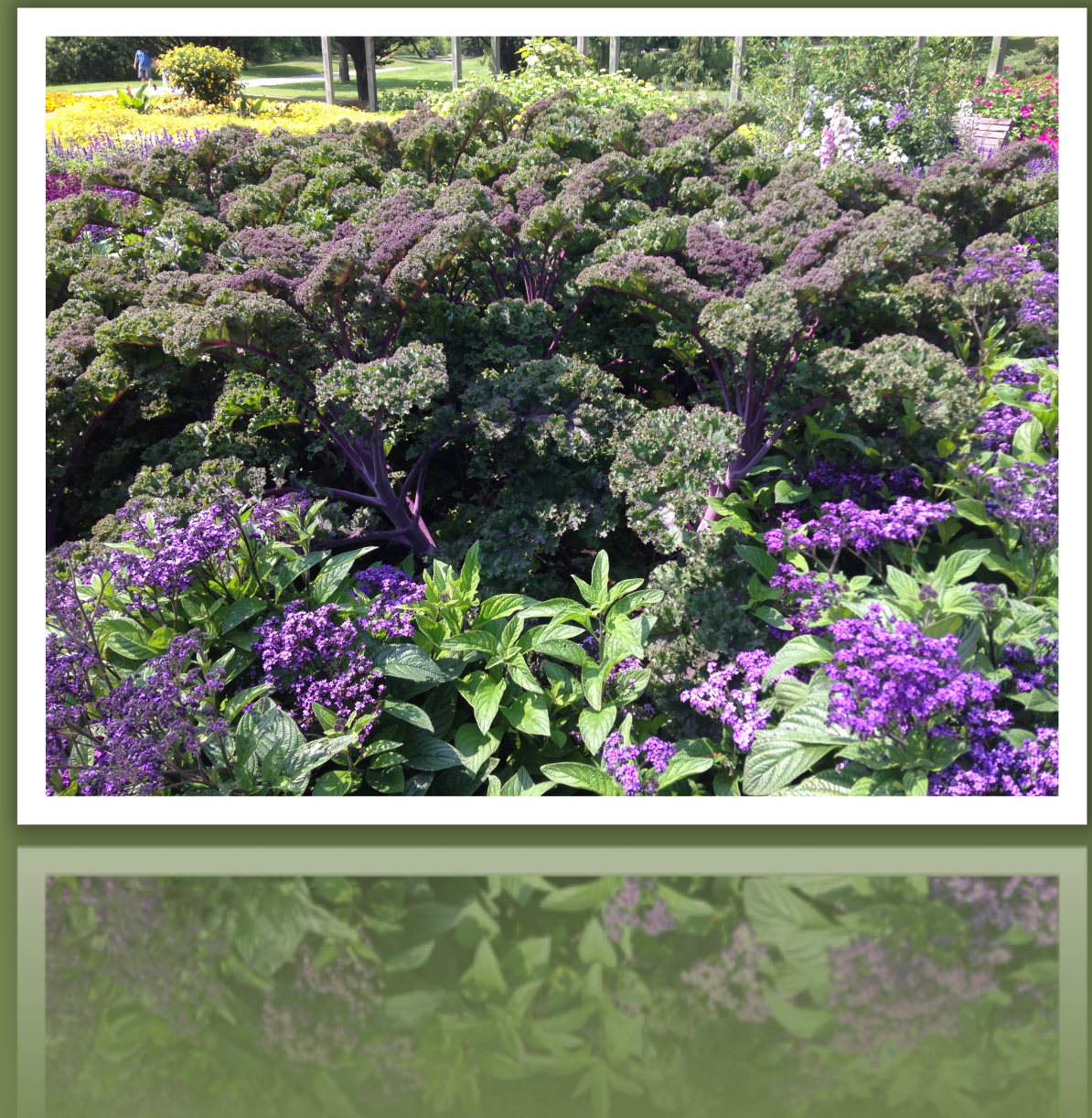

Victoria Fast 
Durham Food Map Report: Crowdsourcing Urban Food Assets

A report for the Durham Food Policy Council

Draft publication date: July 2015

Author:

Victoria Fast, $\mathrm{PhD}$ Candidate,

Environmental Applied Science and Management,

Ryerson University

vfast@ryerson.ca

Project support provided by:

- Durham Food Policy Council

- Social Sciences and Humanities Research Council of Canada

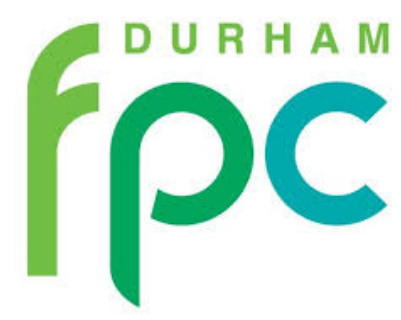

Social Sciences and Humanities Research Council of Canada
Conseil de recherches en sciences humaines du Canada 


\section{Table of Contents}

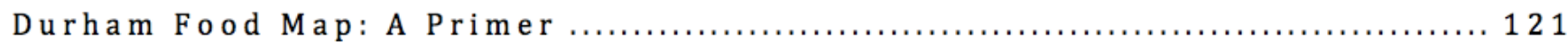

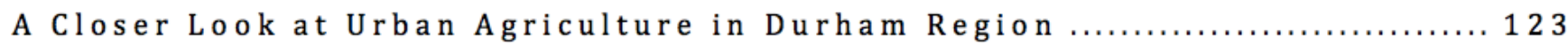

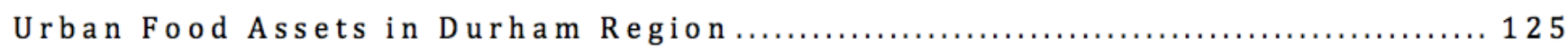

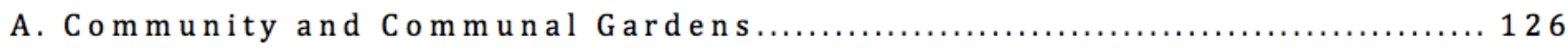

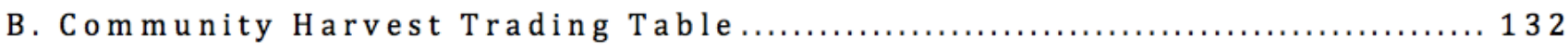

C. Food-related Events in Durham ...................................... 133

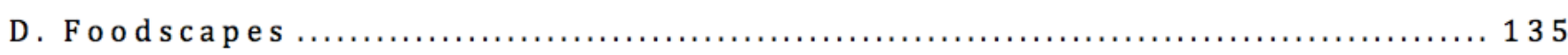

E. Permaculture: Pollinator Gardens and Public Orchards .................. 138

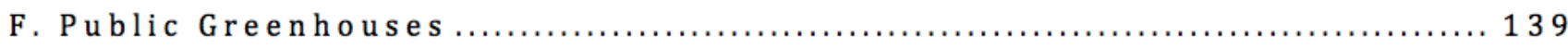

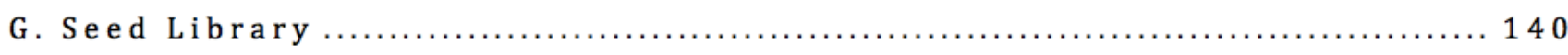

Supporting Urban Food Assets in Durham Region ............................ 141

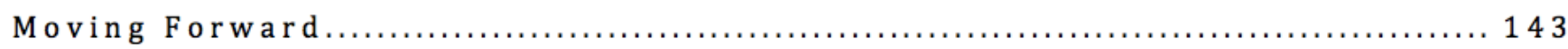

Appendix A: Food Policies In Durham Region Municipalities ................... 144

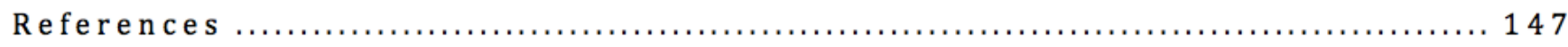




\section{Durham Food Map: A Primer}

The participatory mapping of regional food assets, dubbed the "Durham Food Map", was initiated to enable knowledge sharing, promote community engagement, and support policy-relevant research related to Durham's regional food system.

The Durham Food Map responded to the limitations highlighted in the Durham Food System Environmental Scan, which called for a more detailed (local) analysis of the existing food environment in Durham Region (Contreras-Judge et al., 2013). The scan took an assets-based approach, exploring the strengths of the regional food system. However, at the time of the scan, there was no mechanism for the local food community to share what they identified as food assets.

Given that the local food community is central to the regional food system, this project developed a Web map platform that enabled the regional food community to share food assets with other food system stakeholders, regional councils, and decision-makers. As a part of this study, food system stakeholders from various sectors in the regionincluding government, NGO, and community groups-were identified, contacted, and asked to report known food assets in an online mapping environment.

Individually, these stakeholders possess fragments of valuable information about urban food assets. Collectively, they serve as a mechanism to learn more about communityidentified strengths within the regional food system, effectively capturing the distributed intelligence of those who are active in Durham's food system.

This study is built on the concept of crowdsourcing, where information is obtained by enlisting the participation of the public (Brabham, 2009; Lauriault \& Mooney, 2014). Crowdsourcing map-based information is more specifically known as volunteered geographic information because the public, in this case food system stakeholders, are volunteering information about food assets to an online map.

Overall, better tools and resources for collaboration are essential, and participatory mapping proves to be one of them. 
In summary, over 200 contributions were gathered from Durham's food community and added to the Durham Food Map (Figure 1). These contributions represent a broad spectrum of diverse and hyper-local food assets, including neighbourhood gardens, permaculture, and foodscapes. In addition, the Durham Food Mapsite attracted over 1000 unique visitors between February and April 2015, serving as a valuable resource for the food community, even if many viewers did not actively contribute.

While this study targeted a broad spectrum of local food stakeholders, representing rural and urban interests, the most active contributions came from the urban food community. This is not surprising, as many urban food assets are community-driven. The food stakeholders engaged in this study have clearly demonstrated that urban food is going beyond backyard gardens, pointing to new trends in urban food production. The emphasis on urban food assets adds to an emerging field of studying how, given the shift from rural to urban living, cities can become more food-secure. This report presents and expands upon the assets that the community has identified as central to their food system.
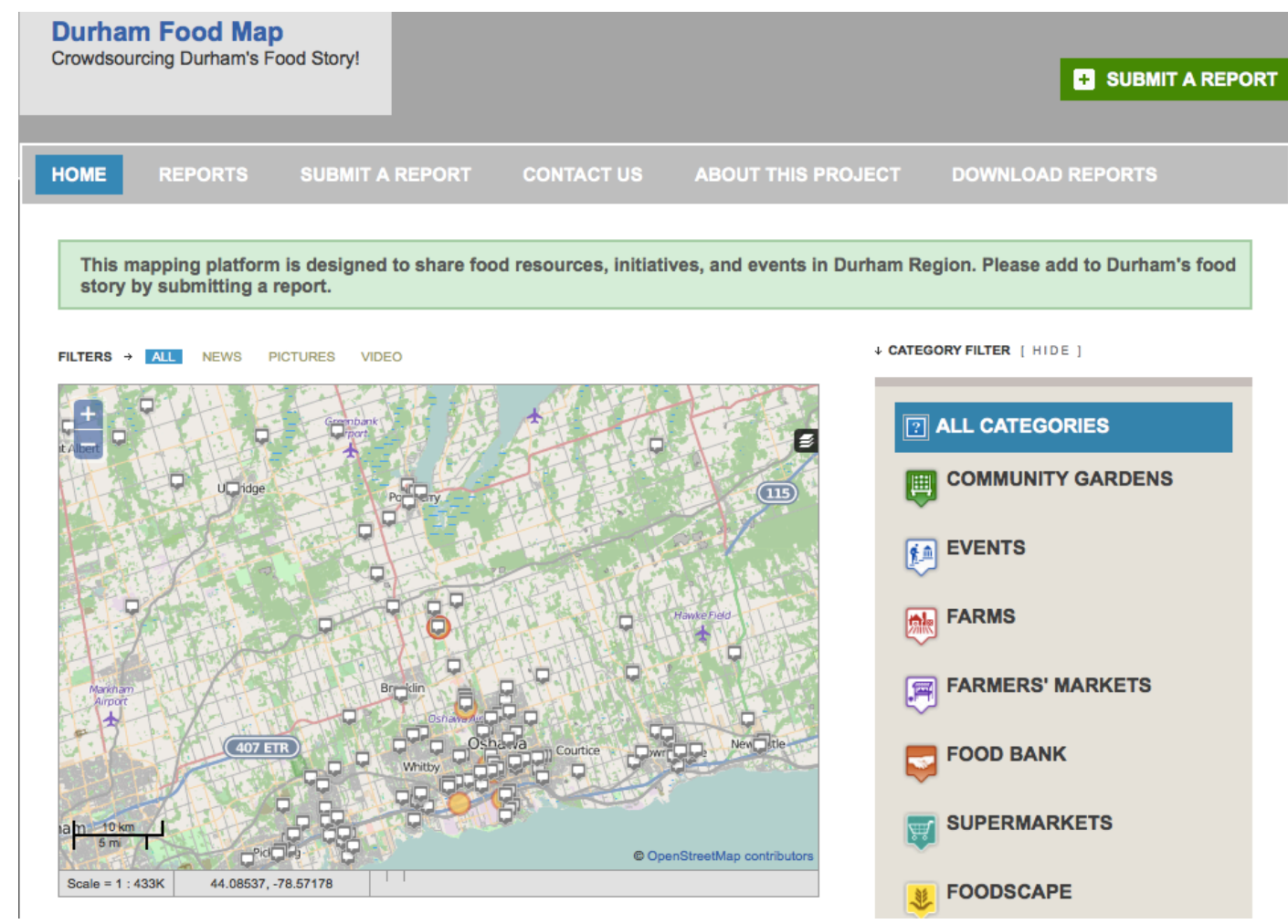

Figure 1: A Screenshot of the Durham Food Map 


\section{A Closer Look at Urban Agriculture in Durham Region}

The Regional Municipality of Durham and its eight member municipalities (Ajax, Brock, Clarington, Oshawa, Pickering, Scugog, Uxbridge, and Whitby) contain a unique mix of urban and rural lands (Figure 2). The Greenbelt Act, enacted in 2005, protects some of the rural land from future development by (shown as protected area in green on the map). However, large swaths of rural lands that are classified as prime agricultural land are not protected (shown as prime agricultural land in yellow on the map). Large chunks of these unprotected lands have already been approved for development (shown as urban expansion pre-2006 and post-2006, in light and dark pink on the map).

This planned urban expansion is compounded by the hundreds of thousands of acres of farmland that already went out of production between 1991 and 2001 due to urban development (Walton, 2003). Further, much of Durham Region's prime agricultural land is producing nursery stock, animal feed, and food for export, rather than food for local consumption (Contreras-Judge et al., 2013; Kubursi et al., 2015). The loss of agricultural land and the lack of local food production threaten the region's ability to feed its growing population.

\section{Urban Expansion in Durham Region}

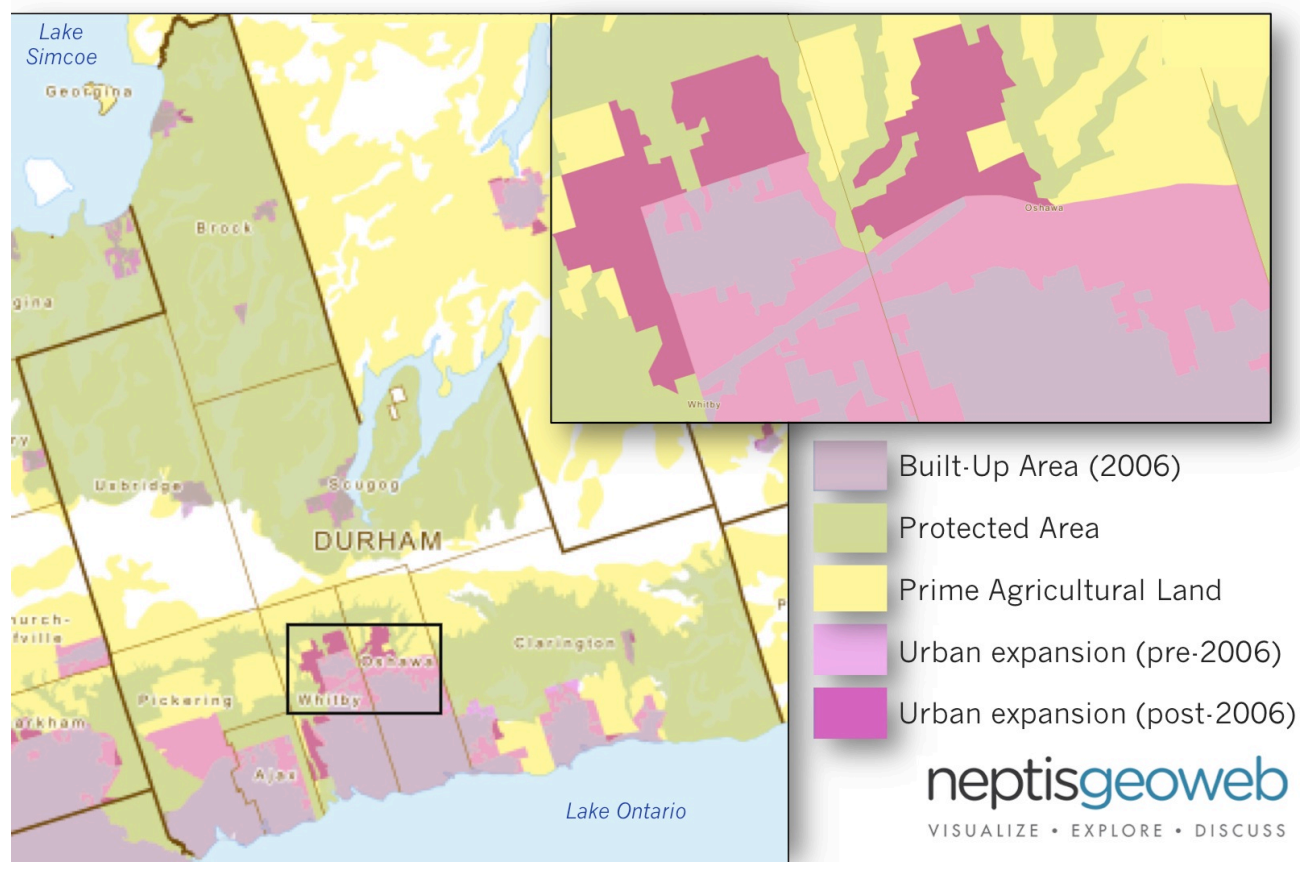

Figure 2: Approved Urban Expansion in Durham Region 
While more can (and should) be done to protect the region's agricultural land, the fact remains that more of Durham is becoming urban land. As such, it is necessary to learn how to optimally support the growing of food in urban regions. This phenomenon is broadly understood as urban agriculture.

Urban agriculture denotes such urban food assets as backyard gardens, community gardens, farmers' markets, and other community and institutional initiatives such as seed swaps. Urban food is produced, processed, and consumed locally. This process engages diverse communities, builds strong neighbourhoods, and increases access to healthy local food. Urban agriculture is, by nature, integrated in the social, economic, ecological, and cultural systems of the local community and as such, has the potential to achieve greater local food system sustainability than its rural counterpart (Dubbeling, Renting, \& Hoekstra, 2015; Jarosz, 2008; Sonnino \& Spade, 2014).

In short, urban agriculture is contributing resilience, security, and sustainability to local food systems all over the world.

It is important to note that urban agriculture is part of, but different than, local food. Local food systems broadly encompass all aspects of food designated for local consumption, including production, distribution, processing, and retail. The boundary of local food is both permeable and variable, but focuses on agri-business and the food industry, which has been historically focused on food from rural origins.

The local food movement, which is gaining momentum, has many positive effects on urban food systems. The Province of Ontario's Local Food Act (Bill 36, 2013) and the auxiliary Local Food Fund (Rural Economic Development Program, 2013) support a strong local food economy, increasing both the supply and demand for locally produced food. The first annual progress report on the Local Food Act, focused on benchmarking growth in the industry, reported a 34 billion dollar contribution to Ontario's economy (Leal, 2015).

While the Local Food Act is progressive and a significant shift toward supporting stronger food systems, it does not adequately address food assets outside of the agriindustrial focus. The food community in Durham has identified urban food assets as a pillar of the regional food system. As such, it is necessary to learn more about urban agriculture and its assets, in order to better support these in the future. 


\section{Urban Food Assets in Durham Region}

Underscoring the urban food assets presented in this report is the food system stakeholders. Collectively, they are the greatest asset within the food system because they are initiating, operating, supporting, and reporting the food initiatives presented in this study. The community is made up of multi-sectorial food stakeholders, which includes community members, grass-roots community organizations, not-for-profits, and municipal and regional government agencies.

The urbanfood community is acting as a catalyst for change, increasing the supply, security, and sovereignty of local food systems.

The Durham Food Map project provided insight into both key food system stakeholders, and related food assets in Durham Region. This report focuses on the urban food assets that were identified by local food stakeholders, categorized as:
A. Community and Communal Gardens
B. Community Harvest Trading Tables
C. Food-related Events in Durham
D. Foodscapes
E. Permaculture
F. Public Greenhouses
G. Seed Library

Each urban food asset category presents information that was shared by food stakeholders. In addition, this information is supplemented with information gathered online and from field notes, and through interpretation of stories told by the local food community. Collectively, the categories highlight community-identified urban food assets, and serve as examples of programs and regulations that exist to support the regional food system. Where applicable, the categories include a recommendation to the Durham Food Policy Council. 


\section{A. Community and Communal Gardens}

Community gardens are most closely associated with traditional notions of urban agriculture, where gardens are established, managed, and maintained by a group of people. These people are often associated through an organization, such as a church, school, or retirement residence. Durham Integrated Growers (DIG) maintains a dataset on current gardens, which they generously volunteered to the map (Figure 3). Community gardens are currently receiving the greatest recognition and support as an urban food asset from community groups (e.g., DIG) and government. The Township of Uxbridge, for example, has a community

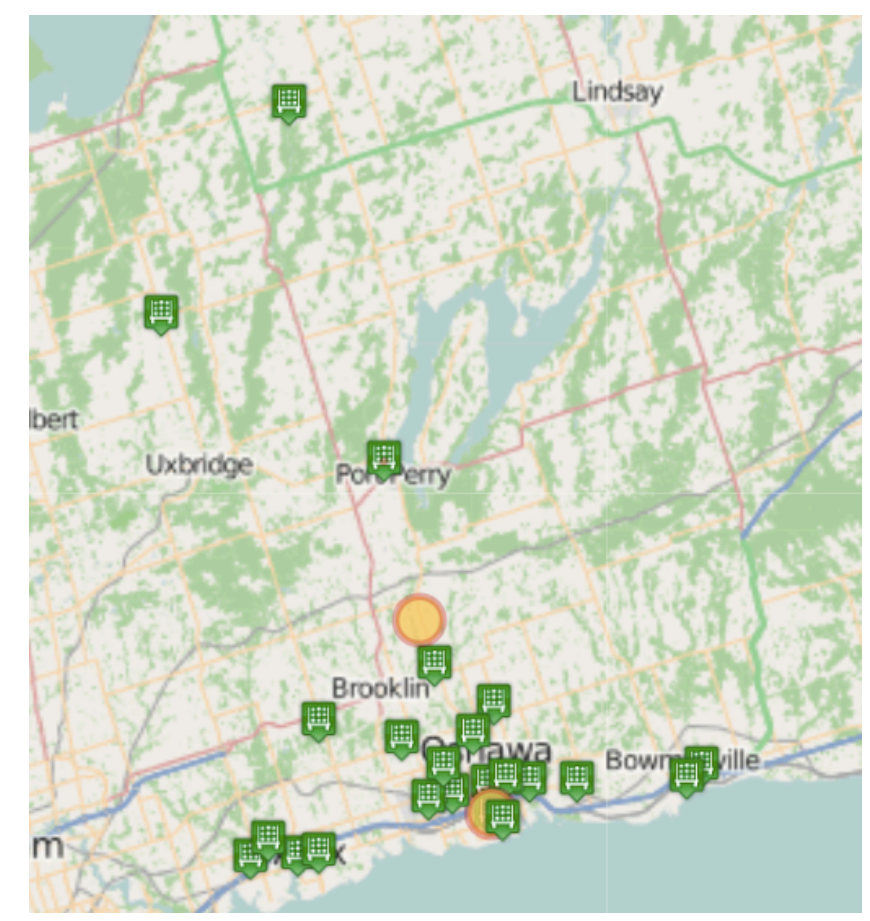

Figure 3: Community gardens located throughout Durham garden policy in their Official plan:

"Community gardens help to support people who could not otherwise afford the time, effort and land, and may not possess the skills or experience to maintain gardens on their own property. The Township supports the creation of community gardens, which contribute to community food security. Community gardens shall be permitted in any area of the Township where agriculture operations are permitted, provided they are outside of key natural heritage and hydrological features and related vegetative protection zones and any area, which may have soil contamination. They shall also be permitted in the hamlets and in the Uxbridge Urban Area."

- Township of Uxbridge, 2014

Overall, community gardens are well established, supported, and understood as a central asset of the urban food community. 
Communal or neighbourhood gardens are a type of community garden. However, instead of a traditional plot-based model, communal gardens are established as a shared resource for the surrounding neighbourhood. Where community gardens are created and maintained by an existing community (e.g., church congregation), communal gardens create a new community who converge around the garden. While less is known about this garden model, contributors have reported very successful neighbourhood gardens. One advantage is that since there are no plots, the management of the garden is shared among the community, which puts less pressure on any one individual, including persons with disabilities. The Care and Share Permaculture Garden, reported by the garden coordinator, is an example of a communal garden that was established next to a senior's residence, encouraging them to participate without committing to exclusively managing a plot:

"Inspiration for Starting It: A few of us attended "The Place to Bee: A Pollination Event" - at Lunar Rhythms CSA (just outside of Blackstock - I think the address is Janetville, so they are officially within the City of Kawartha Lakes region). A specialist had come to talk about her work in encouraging farmers to plant pollinators along ditches, between crops, etc. After attending this event, I volunteered at Happy Farm to learn about sustainable farming practices. At the same time, I read a book called, "The Stop". By late August 2013, fearing that our local fairgrounds would be re-developed into housing in the near future, I approached the Port Perry Agricultural Society, who hold the lease for this land (from the Township of Scugog). I was granted permission to start a project on a small parcel of land ( $1 / 3$ of an acre) on the Northwest corner of the grounds.

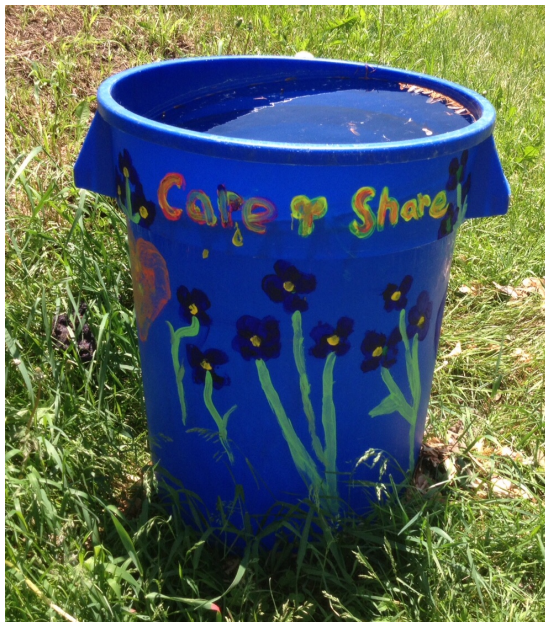

Figure 4: A beautiful and cost effective rain barrel painted by a young girl who happily volunteers in the Care and Share Garden
SO, LONG STORY SHORT - OUR GROWING KNOWLEDGE OF FOOD SECURITY AND FOOD JUSTICE, ALONG WITH CONCERNS ABOUT THE PHYSICAL AND MENTAL HEALTH OF LOCAL SCHOOL CHILDREN AND LONELY SENIORS ENCOURAGED US FORWARD. At this point, we have a core of passionate volunteers. We have decided that we can best serve the community by providing a demonstration garden that showcases sustainable methods of growing food, caring for others, and sharing our excitement with others!"

- Care and Share Community Garden Coordinator Photos by: Care and Share Community Garden Coordinator 
The We Grow Food (WGF) community group has also successfully established three neighbourhood gardens, where no 'community' previously existed. The first garden reported was the Pepper Patch:

\section{Pepper Patch Garden}

"We Grow Food's first neighbourhood garden. In its first year (2014), 30 families worked in the garden and produced over 2500 pounds of food."

- We Grow Food Communications Coordinator

The land in which the Pepper Patch Garden was built is owned by the City of Oshawa. The city approved the development of the garden, and the local restaurant, The Table, paid the necessary insurance. Neighbours were instructed to take only enough food to feed their family for one day. Moving into its second year, the garden was expanded and is now independently operated by a community coalition of local residents.

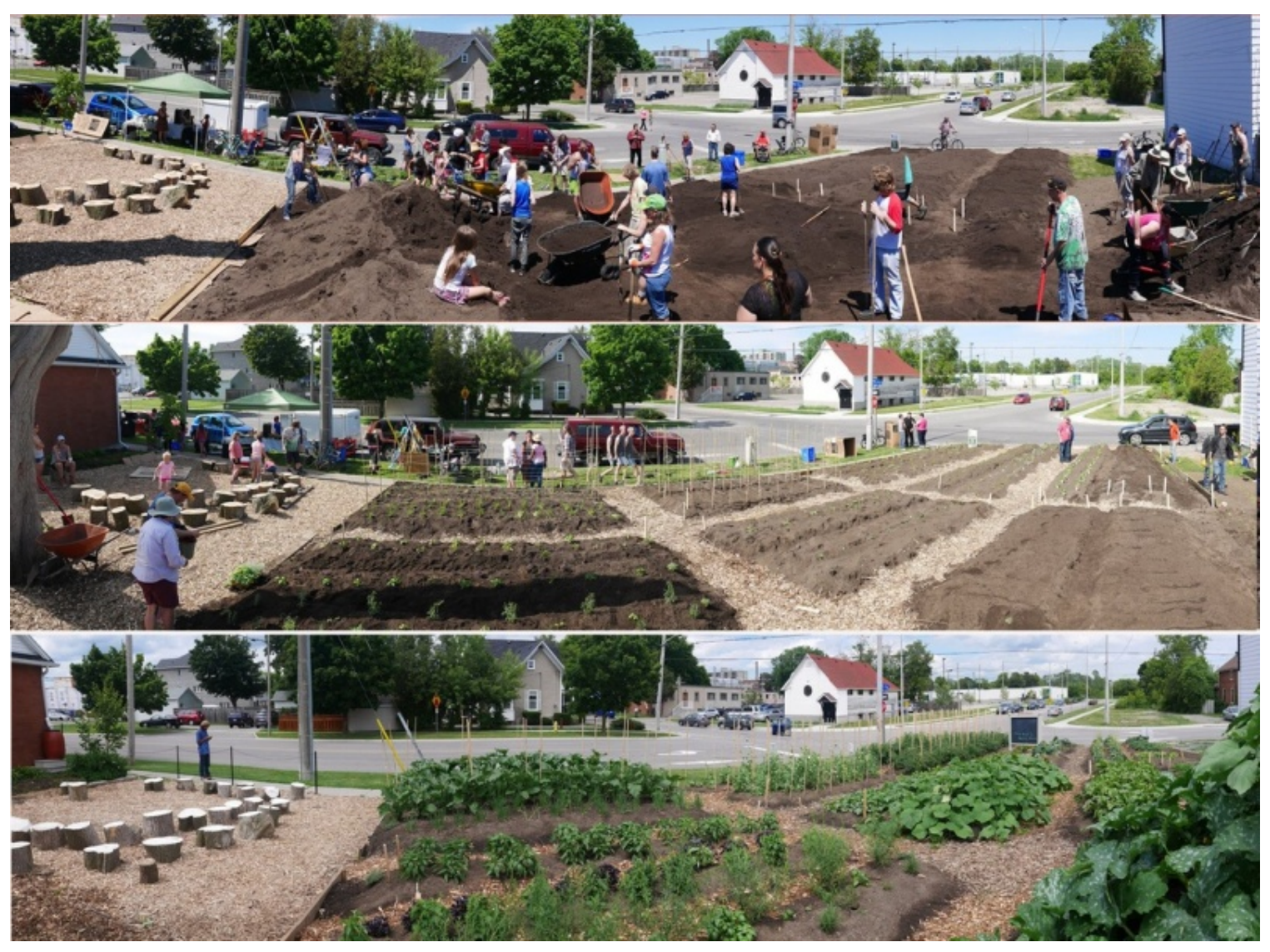

Photos by: Rich Fletcher

Figure 5: The creation of the Pepper Patch Neighbourhood Garden 
The second garden reported by the We Grow Food team is Carol's Neighbourhood Garden. The contributor shared the local newspaper article written about the garden, which demonstrates the broader community interest in the neighbourhood garden model:

\section{Carol's Neighbourhood Garden}

“You can't miss Carol Cavallari's house. The Oshawa business owner's front yard stands a few feet taller than the neighbouring lawns on Grandview Street.

From an apple tree to a kale patch, roughly 1,500 square feet of Ms. Cavallari's property has been transformed into a community garden that she refers to as her humble garden. A sign at the top of the yard reads, "This humble garden, plus three fruit trees out back, will produce about 1,000 pounds of food. That is 250 four-pound meals for a family." Located south of the Olive and Grandview intersection in Oshawa, the garden holds an open-door policy. With about 10 people taking and contributing, there are no permanent rules or fees.

In fact, neighbours pop in and out as they please.

"I've been eating her lettuce all summer," said Rose McIntosh, who lives two doors down. Ms. McIntosh regularly visits the garden and loves the kale, which overflows from its raised bed.

Ms. Cavallari is the owner of The Table, a downtown Oshawa restaurant that serves dishes made of locally grown ingredients. Half of the yield of her garden goes to her restaurant, while the rest is offered free to the public. Since health and sustainability are a focus of her business, non-genetically modified and organic seeds are used in the community garden.

...see News Source Link for the rest of the article!"

News Source Link: http://www.durhamregion.com/news-story/4029723-oshawarestaurant-owner-grows-food-for-community/

- Reported by: We Grow Food Communications Coordinator

The final garden, reported as the Cordova Street Neighbourhood Garden, is the newest of the We Grow Food neighbourhood gardens implemented:

"It's happening! The Cordova Street garden is well underway. Follow http://www.wegrowfood.org to learn more."

- Reported by: We Grow Food Communications Coordinator

The Cordova Street garden was established in spring 2015, following the same implementation model as the previous gardens. It is already proving to be a success, as a community is forming among the neighbours living in the high-density area (Figure 6). 


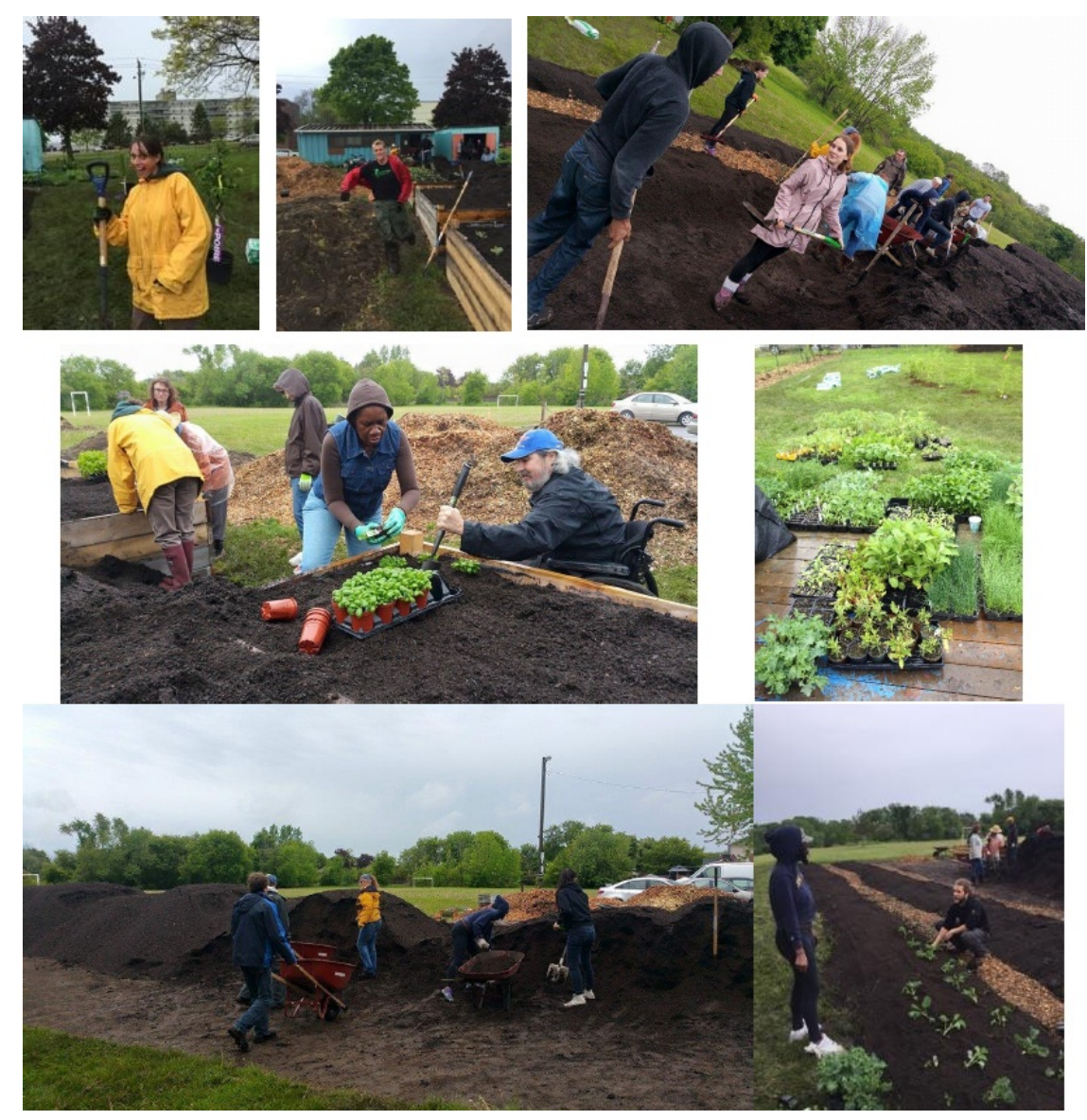

Photos by: Rich Fletcher

Figure 6: Beginning the new Cordova neighbourhood garden

The neighbourhood garden model implemented by We Grow Food has been incredibly successful in these three instances, establishing both a garden and a community of gardeners where neither existed previously. To better understand how these neighbourhood gardens came into being, it is important to recognize the community group initiating them.

We Grow Food (WGF) is a community organization that was started by a group of enthusiastic gardeners in Fall 2013, who decided to install a series of public vegetable gardens. The group decided to focus their energies in disproportionally underserved neighbourhoods when they became aware of the food security issues in Oshawa. In one short year, the WGF community group imagined and implemented 26 family garden plots and two large neighbourhood gardens. In doing so, over 100 volunteers transformed over 11,500 square feet of empty space into a place where an estimated 20,500 pounds of food 
were grown. The garden engaged over 160 families, educating them to sustainably grow healthy food with their community. What started as an idea has sprouted into a blooming food community.

Now entering the second year, WGF created another large neighbourhood garden, the Cordova Garden, which also includes a pollinator garden and public orchard. The neighbourhood garden model established by WGF is having a significant impact on urban food security. Moving forward, the process of establishing these gardens in neighbourhoods where no previous community existed needs to be better understood so it can be implemented more broadly in the Region and beyond. To expand the work of WGF and other innovative community groups, support from government and other community agencies is necessary. 


\section{B. Community Harvest Trading Table}

An interesting asset reported is the community harvest trading table (Figure 7), or more commonly referred to as the Tuesday Trading Table:

"Local gardeners are getting together to swap vegetables every Tuesday outside of the Table restaurant on Simcoe Street in Oshawa. No cash allowed... only trading vegetables and other edibles/seeds."

To elaborate on this report, Carol Vandersanden started the Tuesday Trading Table outside of her restaurant, The Table. She wanted to provide local urban vegetable gardeners the opportunity to share and trade their fresh produce, and build a sense of community among the urban food community. The Trading Table ran every Tuesday from August to October, from noon to 6 PM. Each week, dozens of people attended, with the numbers increasing as awareness spread. Surplus produce, in which there was plenty, was donated to local charities. No cash was allowed, as the initiative operated strictly by trade only. However, in many instances, food was given away to anyone who expressed interest. This initiative creates opportunities to build capacity around food and community through educating, growing, consuming, sharing, and trading the harvest.
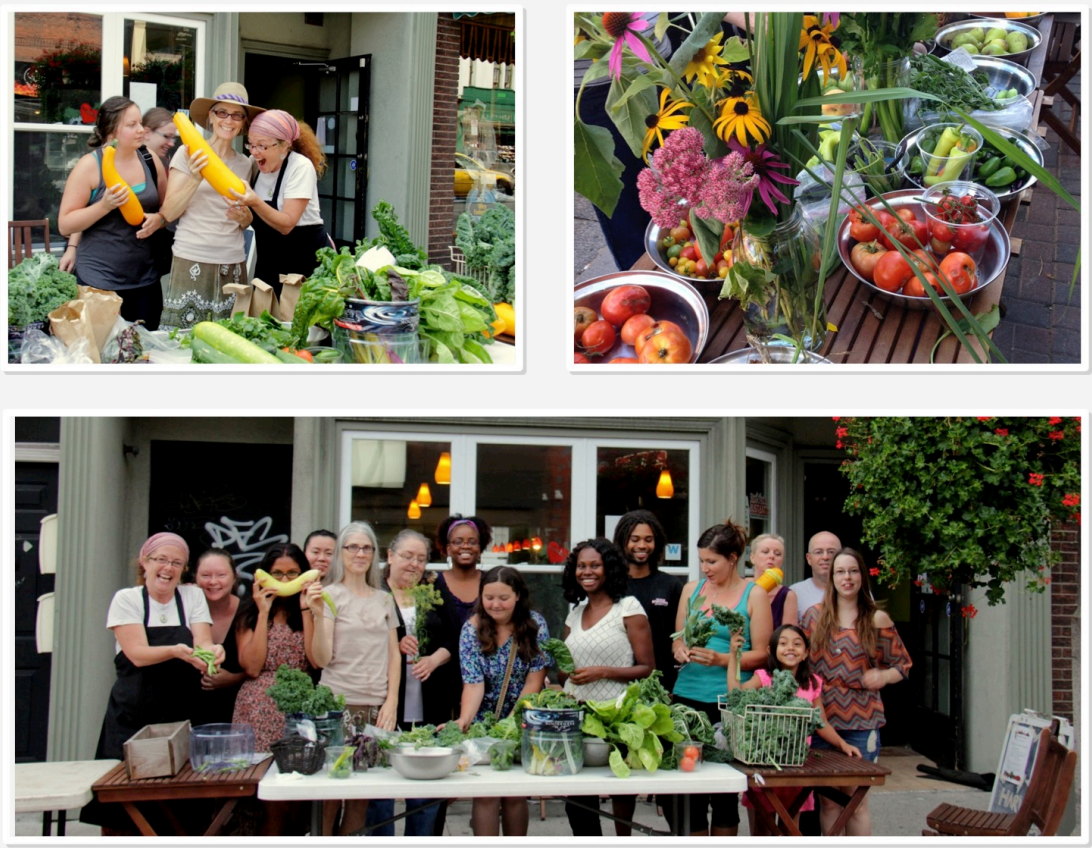

Photos by: Rich Fletcher

Figure 7: A bountiful harvest at the Tuesday Trading Table 


\section{Food-related Events in Durham}

Multiple food-related events reported to the Durham Food Map. For example, a member of Durham Integrated Growers shared the Table Talk event series (Figure 8):

"Want to get your vegetable seeds off to a good start? Join experienced market gardener John Nowakowski and learn his seed starting tips! Get practical and helpful advice regarding seed starting Soil Mediums, seeds, seed sources and timing."

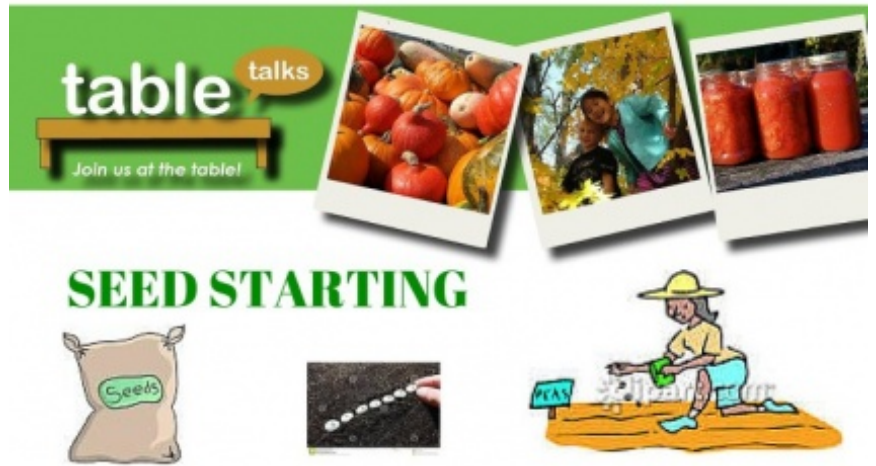

When: Tuesday February 17th @ 6:30

Where: The Nourish \& Develop Foundation

33 Cameron St. E. Cannington 705-432-2444

What: Want to get your vegetable seeds off to a good start? Join experienced market gardener John Nowakowski and learn his seed starting tips! Get practical and helpful advice regarding seed starting soil mediums, seeds, seed sources and timing.

Next Table Talks: Tuesday March 17th "Dirt the movie"

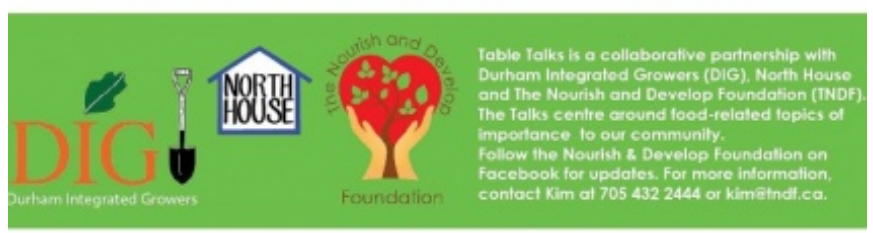

Poster by: Durham Integrated Growers

Figure 8: Event poster

The Table Talks series, which was initiated by Durham Integrated Growers in partnership with various community groups, have occurred at various locations throughout the region. In addition to seed starting, topics have included bee keeping, composting, growing indoors, and integrated pest management. The events draw a wide 
audience of community members, representing a range of novice to expert food growing skills. These events are central to supporting the community of urban food growers.

Unfortunately, the Durham Food Map was not optimally designed to report events because there was no specific location, date, or time fields to include information related to the event. Recognizing the need for a central repository for food-related events beyond the functions offered by the Durham Food Map, the We Grow Food community group created an events calendar, available on their website, to supplement the Durham Food Map, which is currently being updated regularly to keep residents up-to-date on food events happening in the Region (Figure 9). This calendar was a good first step toward an integrated resource for community food events and initiatives that had strong early usage. However, contributions to the calendar are waning. The calendar needs to be linked to a more active online environment.

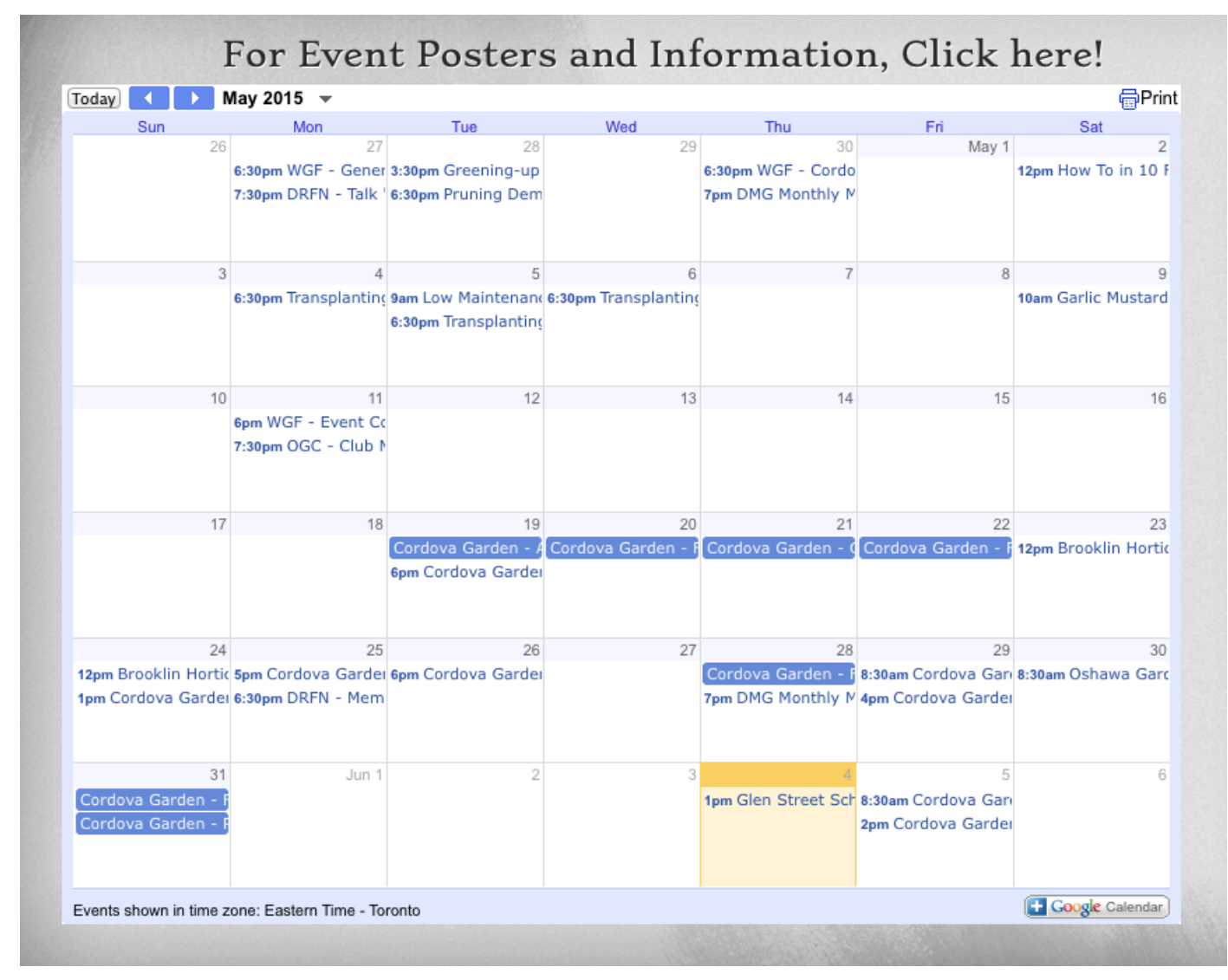

Source: http://www.wegrowfood.org/calendar.html

Figure 9: We Grow Food events calendar 


\section{Foodscapes}

Landscaping with edible plant material is a unique and beautiful way to intensify growing food in urban spaces (Figure 10). While few residential foodscapes were added to the map because of the privacy concerns, there were two contributions about food grown on public lands:

Foodscapes in Oshawa public gardens! "Oshawa has been planting food alongside flowers, creating beautiful foodscapes."

More foodscapes: Oshawa Valley Botanical Gardens "Kale planted in the botanical gardens in Valleyview gardens, downtown Oshawa."

The kale planted in the gardens was harvested and donated to Feed the Need in Durham, where staff processed and distributed the kale to various food banks throughout the Region. Planting food in existing flowerbeds did not require major changes to how the city operationalizes the management of the flowerbeds (i.e., acquiring seedlings, planting and watering schedules) other than the harvest going to a food bank rather than to compost. The next step would be to review management practices to determine how to maximize the quantity and quality (e.g., fertilizer and pest management that is safe for use of vegetables) of this source of food.

Beyond the limited contribution gathered here, there is still much to explore when it comes to foodscapes. Todmorden, a town in England, is a brilliant example of a community successfully embracing foodscapes. The motto of Incredible Edible Todmorden: "if you eat, you're in"; everyone is a stakeholder in producing food in the town (McDougall, 2015). The food, which is available to anyone who wants it, is grown along the main walking route to school, at the local police and fire stations, and tucked in corners of parking lots, among many others locations. By involving all members of the community in the growing and consuming of food produced in town, Todmorden experienced a changing culture toward growing food in the urban environment.

It should also be noted that growing food in non-traditional farm or backyard garden locations is leading to issues under certain conditions. Bylaw conflicts prohibit residents from growing food in certain areas, such as boulevards. These present legitimate 
concerns for officials, because in some instances, it can be a public safety hazard when large plants take over the sidewalk (Figure 11). The next step is to gain a better understanding of the potential problems and benefits to residents and officials in order to work toward accommodating growing food in unconventional urban spaces while minimizing potential health or safety concerns.
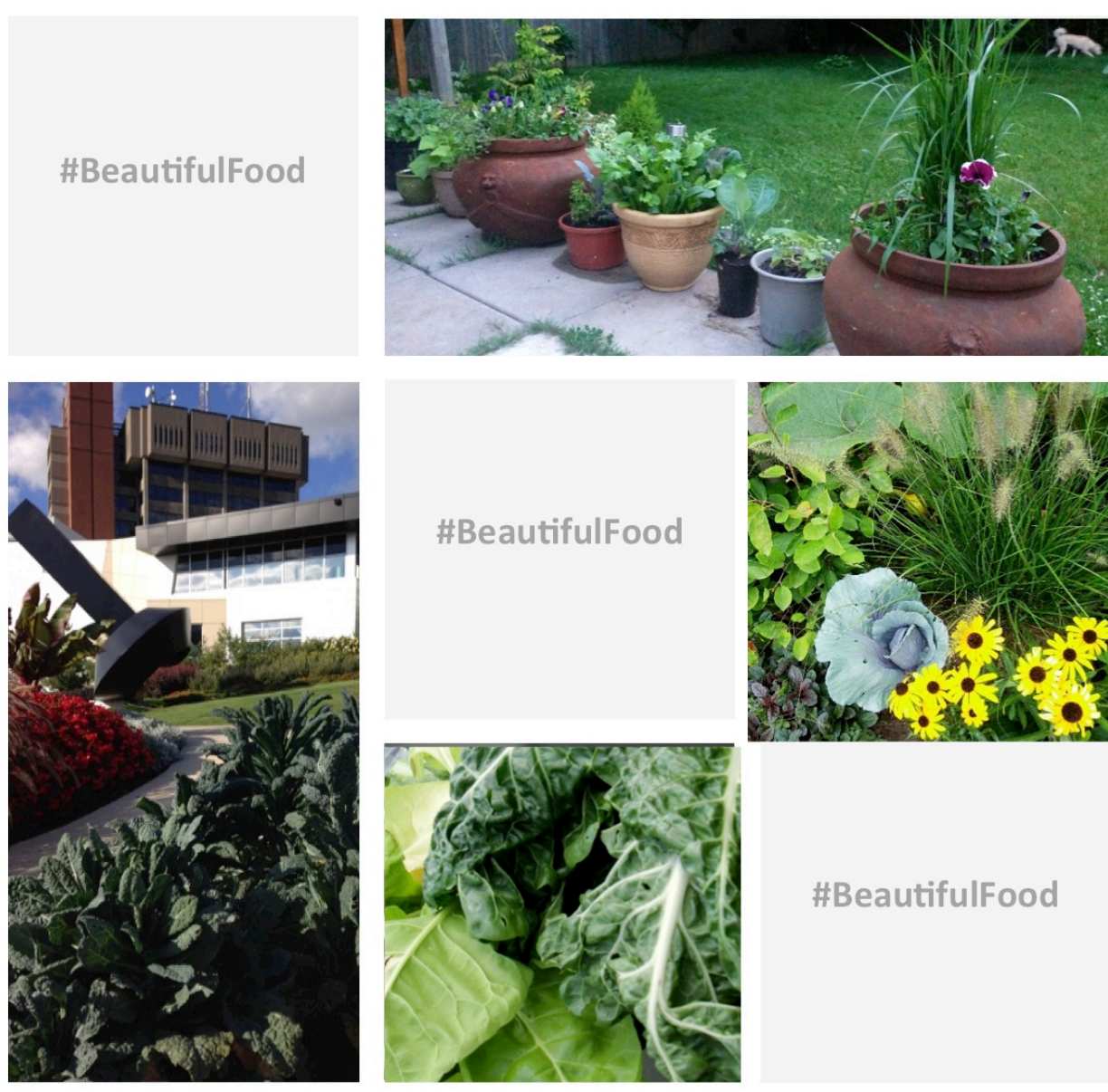

\section{\#BeautifulFood}

Photos by: Victoria Fast, Rich Fletcher, and Durham Resident Anne-Marie
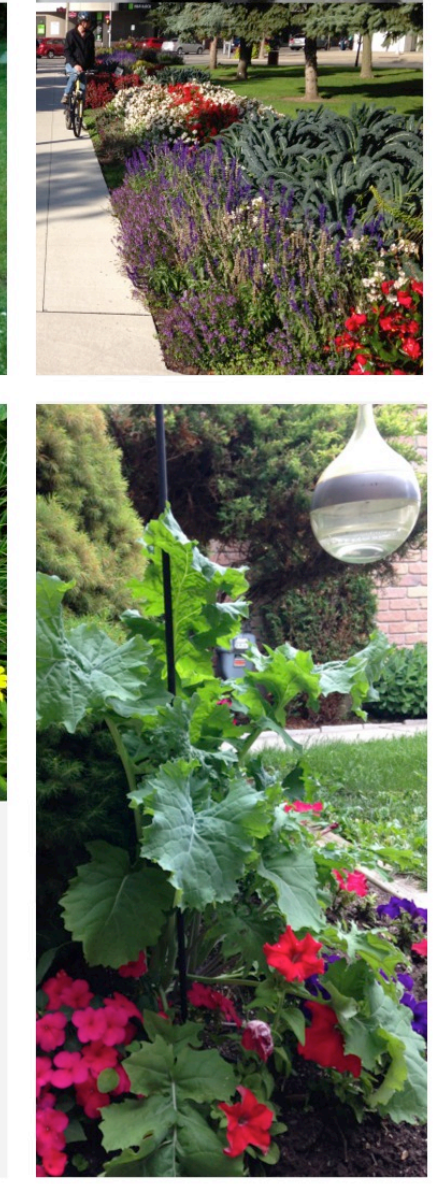

ate gardens 


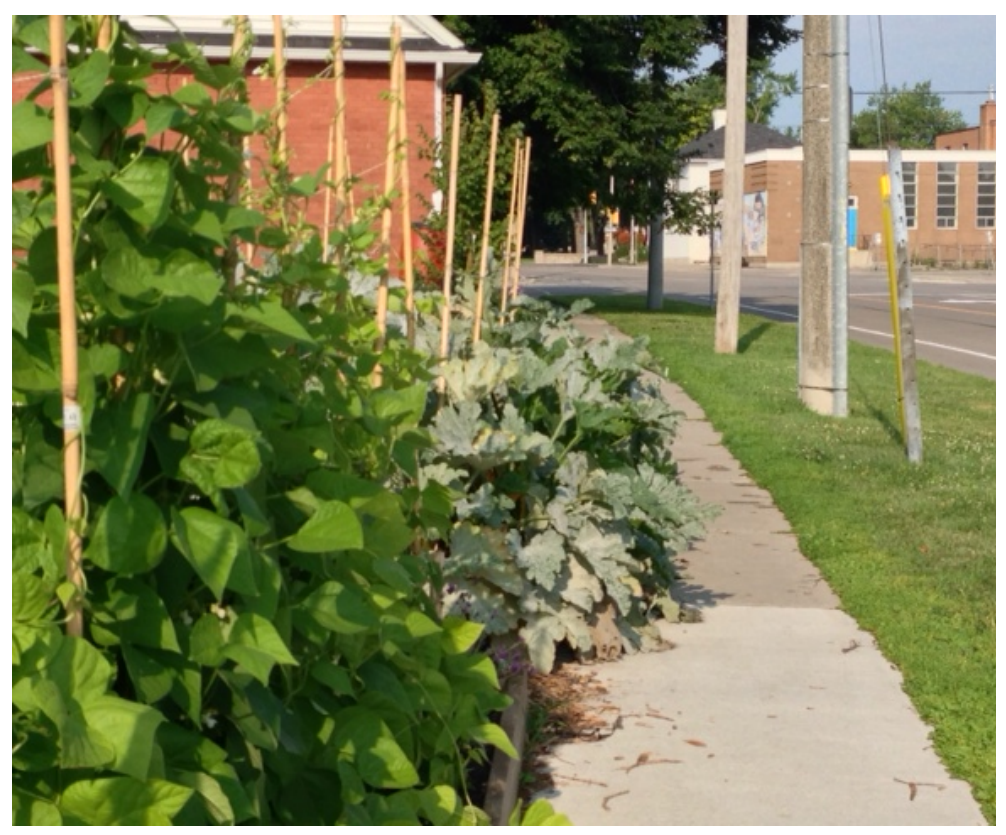

Photo by: Suzanne Elston

Figure 11: Vegetable garden creating trip hazard on sidewalk 


\section{E. Permaculture: Pollinator Gardens and Public Orchards}

Permaculture, broadly understood as permanent agriculture, refers to an edible ecosystem that relies on natural earth system cycles and ecosystem interactions to support itself (L. Newman \& Dale, 2009). The urban food community identified pollinator gardens and public orchards as permaculture-related assets that are contributing to the regional food system. Pollinator gardens incorporate flowering plants into gardens to attract, and create a habitat for, bees and other pollinating insects (Figure 11). This urban food asset also adds to the beauty of gardens and other food growing spaces. Public orchards were also reported as a permanent source of food, however they are in the process of being developed and as such, photos and best practice have not been developed yet.

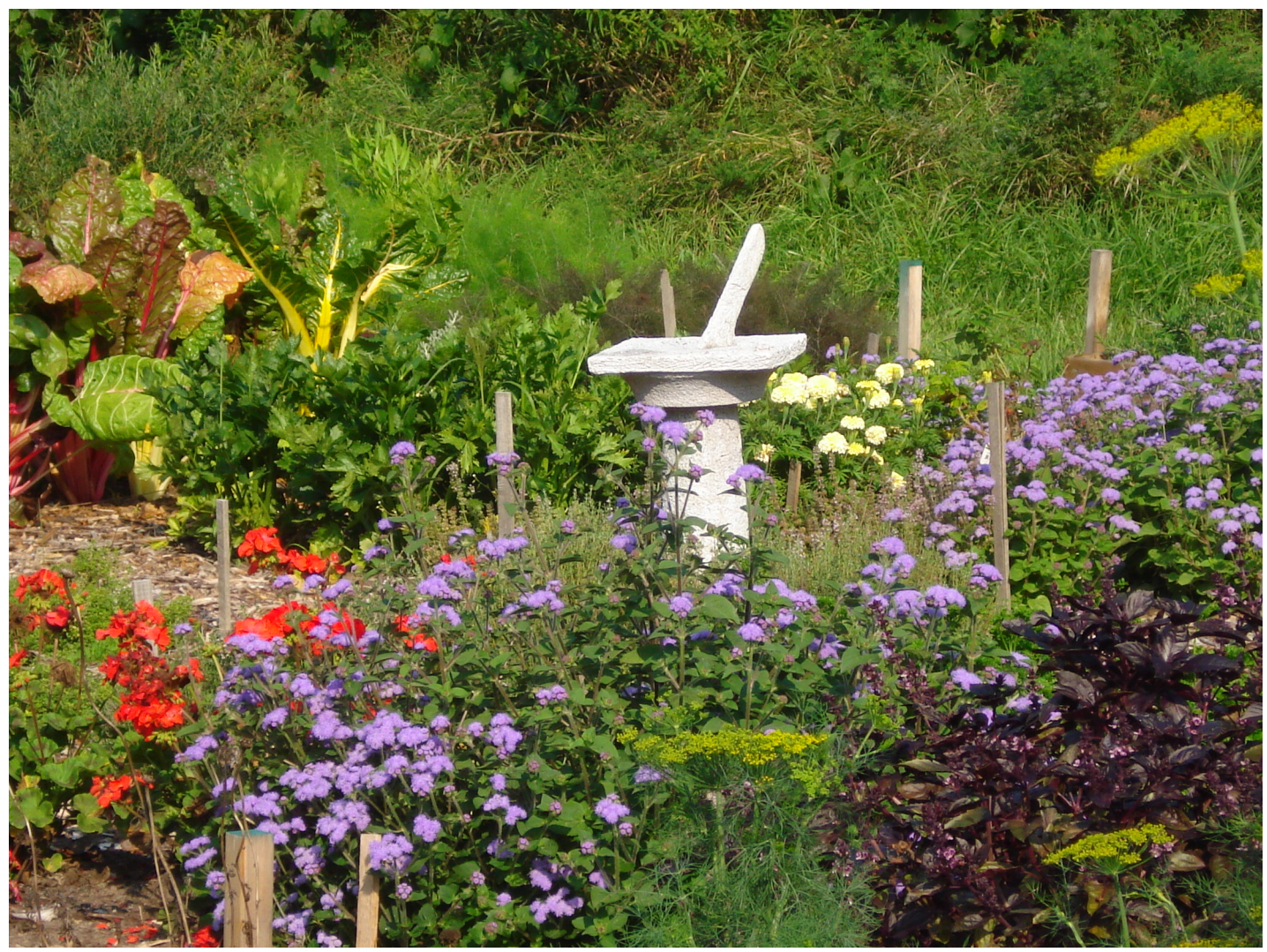

Photo by: Whitby Ajax Garden Project coordinator

Figure 11: Pollinator Gardens incorporated into the Whitby Ajax Community Garden 


\section{F. Public Greenhouses}

One greenhouse, which was initiated by and built at a school in Durham, was reported to the map. However, the need for public greenhouse space was expressed multiple times by multiple stakeholders. In one example, a stakeholder acquired Milkweed seeds and wanted to start seedlings to give out free during various community events. Milkweed is not edible by humans, but it is necessary food and habitat for Monarch butterflies. After a lengthy process of finding greenhouse space, the individual borrowed space in a private greenhouse and grew over 1000 Milkweed plants that were distributed to the local community. Public greenhouses are a new idea that requires further investigation, including an assessment of feasibility, including who is going to establish and manage such an asset. Overall, the food community expressed public greenhouses as a central need to better support urban food production. 


\section{G. Seed Library}

Evolving from decades of successful seed swaps, seed libraries are starting in many communities. The local library often manages seed libraries, relying in their established base of patrons to donate, borrow, and return seeds. One such library was reported in Durham Region at the Oshawa Public Library:

"The library is helping your garden grow this year! Have a look for the Need a Seed, Leave a Seed display at any branch and you may find just the seeds you need for planting this spring. The Oshawa Public Libraries, in support of agricultural sharing and preservation, will be hosting a Need a Seed, Leave a Seed display at all branches beginning this April, and running until the end of June. If you have extra seeds at home, you can share them with fellow community members by leaving them with the display. Simply ensure they are in a sealed and labelled envelope.

This is a great way to try growing something new, or to share seeds of your own with others. Together, we can take this step towards preserving and promoting community sustainability and beauty! Take part in Need a Seed, Leave a Seed, and get growing!"

To expand on the information provided for the Durham Food Map, the Seed Library program was established as a pilot project in 2015. Each of the 4 libraries in Oshawa set up a display close to the front entrance with seeds and other resources to support urban vegetable growing (Figure 12). Library officials are reporting that the pilot, while still ongoing, is considered a success and will likely run again in 2016. The library has learned important lessons that they are currently documenting. In information could help other municipalities in the region, and elsewhere, establish similar programs.

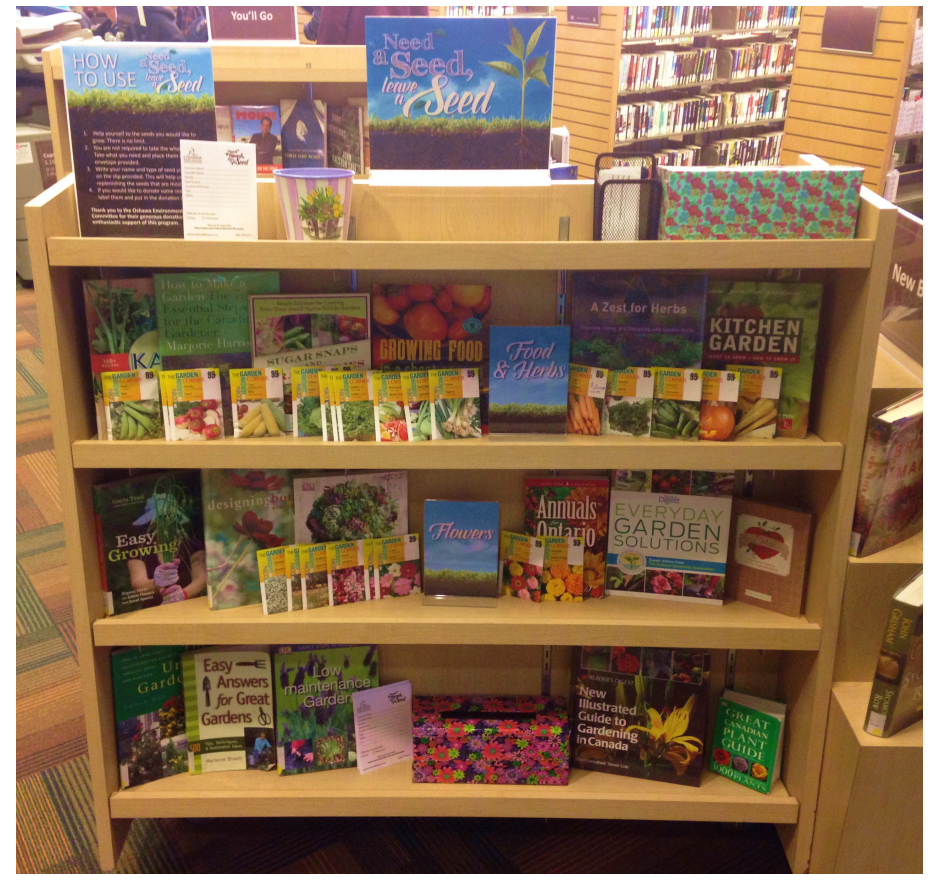

Figure 12: The "Need a Seed, Leave a Seed" display at the Oshawa Public Library 


\section{Supporting Urban Food Assets in Durham Region}

The food community has identified urban food assets as an important part of the overall strength and resiliency of the regional food system. This community consists of individuals, community groups, not-for-profits, and government agencies. Collectively, they reported on community harvest events, foodscapes, neighbourhood gardens, permaculture, and seed libraries as the strengths of their urban food system. The urban food community also reported on their needs and challenges, as they work toward innovating the local food system.

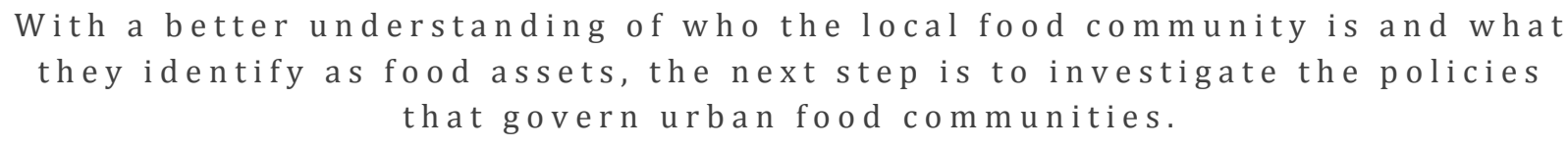

Current policies are generally supportive of local food, but do not always explicitly address urban food. Provincially, the Local Food Act, enacted November 2013, is beginning to influence the local food system but does not have an urban food focus (Leal, 2015). Regionally, the Durham Food Charter was endorsed by Regional Council in November 2009 and is currently administered by the Durham Food Policy Council. This Charter broadly supports local food in the region but similar to the provincial legislations, does not focus on urban food. The "Region of Durham Community Climate Change Local Action Plan" (Durham Region, 2012), which was written three years after the endorsement of the Durham Food Charter but before the provincial Local Food Act, identifies urban agriculture as one of the three potential programs recommended for future development in the Local Action Plan:

"Urban Agriculture Program:

Develop a thriving urban agriculture community within Durham with an emphasis on garden plots, community gardens, backyard gardening, sustainable agriculture, education, and community engagement. The Urban Agriculture Program would initially offer:

- Educational farming fields located onsite at partner elementary schools, secondary schools, community centres, other community institutions, and interested residents' backyards.

- Urban farming internships, workshops and volunteer opportunities.

- A local compost program.

- The opportunity to buy shares in the harvest. Harvest Festivals, Open Farm Days and other opportunities for broad community engagement. 
The Urban Agriculture Program would also increase the carbon sequestration capacity of Durham's built environment, reduce food miles and implement key provisions of the Food Charter."

- Durham Region, 2012

Municipally, the eight municipalities in the region do not universally implement urban food policies (Appendix A). In fact, only three of the municipalities do have urban food policy. The Town of Ajax has the strongest and most detailed urban food policies. Under "Theme 2.1: Climate Change Context" in the official plan, the Town addresses the goal of promoting the growing of food, which explicitly addresses urban agriculture. It contains both permissive policies (e.g., allowing growing on public and private lands) and restrictive policies (e.g., excludes raising animals).

The Township of Uxbridge is the only other municipality to have urban food policy in their official plan, but it only addresses the provision of community gardens.

The City of Oshawa does not have urban food policy in their official plan. However, the Creating Our Sustainable Tomorrow Strategic Plan 2013-2018 (City of Oshawa, 2012), which was written and endorsed by city council contains a "Resilient Local Food System" theme under the environmental responsibility category. The strategy promotes and encourages urban agriculture, as well as backyard and community gardening, but does not contain specific programs or regulations.

The remaining five municipalities do not have urban agriculture policies at the municipal level; instead, they rely exclusively on regional policies to govern urban food. Given the community-identified importance of urban food assets, coupled with the growing support of local food at provincial and regional levels, it is timely to pursue the universal adoption of strong urban food policy in all municipalities in the region. The lower-tier municipal governments have the greatest impact on what happens inside of the urban boundary, and are responsible for building permits, animal control, bylaws, street and sidewalk maintenance, parks and recreation, and the bylaws that regulate these aspects of municipal management. At the time of writing this, both Clarington and Whitby were undergoing Official Plan reviews, pointing to the timeliness, and time-sensitivity of this issue. 
In addition to strong urban food policies, permissive regulations and supportive programs need to be developed to enable the policy intent. Urban food assets need to be fostered, encouraged, and continuously innovated to significantly contribute to the resiliency of the regional food system.

Thus, it is recommended that:

- Durham Region and each of its member Municipalities, in partnership with the urban food community, review existing plans and make appropriate changes to inform policy intent on urban agriculture.

- A working group, comprised of a range of government and citizen stakeholders, be formed to support the creation of urban food policy, which is to be adopted by all eight municipalities in Durham Region.

- The Region and each of its member Municipalities develop programs and regulations that support urban agriculture initiatives, including community gardens on both public and private lands, harvest trading events, permaculture, neighbourhood gardens, pollinator gardens, public greenhouses, seed libraries, among other assets still to be identified.

- Bylaws and Official Plans be amended to authorize urban agricultural assets.

\section{Moving Forward}

As reported in this study, urban food assets resonate with the community of food stakeholders in the region. Overall, urban agriculture is a key resource for nutritious food that supports the health and well-being of the population, reduces emissions influencing climate change, builds communities among those who engage in urban food initiatives, and enables greater food supply, security, and sovereignty. As a community, we need to encourage and support the expansion of food grown in urban areas. 


\section{Appendix A: Food Policies In Durham Region Municipalities}

\begin{tabular}{|c|c|c|}
\hline MUNiCIPALITY & $\begin{array}{l}\text { DOCUMENT \& } \\
\text { DATE }\end{array}$ & URBAN FOOD-RELATED POLICY \\
\hline Town of Ajax & $\begin{array}{l}\text { Official plan: } \\
\text { February } \\
2012 ; \\
\text { Consolidation } \\
\text { January } 2015\end{array}$ & $\begin{array}{l}\text { Theme: 2.1. CLIMATE CHANGE CONTEXT AND GENERAL } \\
\text { ENVIRONMENT POLICIES } \\
\text { The Town recognizes that clean water, clean air, safe and } \\
\text { secure shelter and infrastructure, employment, community } \\
\text { facilities and programs, public open space, a protected } \\
\text { natural heritage system, protected agricultural land, and } \\
\text { locally grown foods are needed to sustain a healthy } \\
\text { community. } \\
\text { GOAL: Promote the growing of food, and support protection } \\
\text { of agricultural land, to enhance food security and support } \\
\text { community interaction; } \\
\text { 2.1.7 Urban Agriculture } \\
\text { Urban agriculture shall mean the growing of produce (i.e., } \\
\text { fruits and vegetables) and flowers in community gardens, } \\
\text { and smaller scale gardening on public and private land, } \\
\text { yards, and structures, such as rooftops, but shall exclude the } \\
\text { raising of any animals, livestock or poultry, including } \\
\text { chickens. } \\
\text { The Town's goal is to promote agriculture activities within } \\
\text { the Urban Area that are compatible with planned land uses, } \\
\text { while enhancing access to locally grown produce, lowering } \\
\text { energy consumption, reducing transportation costs and } \\
\text { greenhouse gas emissions, and augmenting supplies of fresh } \\
\text { and preserved foods. } \\
\text { To achieve this goal, the Town shall: } \\
\text { a) Promote the growing and sharing of a wide variety of } \\
\text { local produce and preserved foods and flowers; } \\
\text { b) Encourage the establishment of community gardens in } \\
\text { suitable locations having maximum exposure to sunlight. } \\
\text { Community gardens shall not be permitted in the } \\
\text { Environmental Protection designation and in areas } \\
\text { contaminated by existing or previous land uses. Community } \\
\text { gardens and associated accessory structures, such as garden } \\
\text { sheds, shall be minor in scale and secondary to the primary } \\
\text { permitted land use(s); } \\
\text { c) Require proponents of community gardens, on privately } \\
\text { and publicly owned land, that are to be open to public use, to } \\
\text { enter into an agreement with the Town, including addressing } \\
\text { the requirements, if any, of the owner(s) of the land on } \\
\text { which such a garden is to be located. This agreement would } \\
\text { include, as a minimum, the following: }\end{array}$ \\
\hline
\end{tabular}




\begin{tabular}{|c|c|c|}
\hline & & $\begin{array}{l}\text { i) the organizational structure for those persons or } \\
\text { groups proposing to manage the garden; } \\
\text { ii) a concept sketch of the garden, indicating provision of } \\
\text { adequate parking, drainage, and access for the location and } \\
\text { scope of operation; } \\
\text { iii) the source of water for irrigation, with preference for } \\
\text { efficient use of precipitation captured in rain barrels and } \\
\text { cisterns, rather than municipally- treated water, whenever } \\
\text { possible; } \\
\text { iv) the prohibition of lighting; } \\
\text { v) a maintenance plan detailing daily and seasonal } \\
\text { operations, procedures, and requirements, for spring start- } \\
\text { up, the growing season, and garden closure in the fall; and, } \\
\text { vi) indication that there will be no adverse effects on the } \\
\text { enjoyment of nearby properties; } \\
\text { d) Encourage gardens on public and private lands designed } \\
\text { to capture and infiltrate surface runoff; } \\
\text { e) Require the use of clean topsoil, compost and mulch; } \\
\text { f) Encourage gardens to be designed with elements, such as } \\
\text { elevated or tiered planting beds with wide aisles/paths } \\
\text { between plots, that accommodate access by gardeners with } \\
\text { disabilities and situational impairment; } \\
\text { g) Promote fruit and vegetable gardening in the yards of } \\
\text { residential, "clean" commercial and "clean" industrial } \\
\text { properties, greenhouses, and containers on balconies and } \\
\text { porches, and on rooftops; } \\
\text { h) Support the establishment of seasonal or year-round } \\
\text { marketplaces in key locations where locally grown and } \\
\text { preserved foods can be sold, and function as places of social } \\
\text { interaction; and, } \\
\text { i) Consider establishing permanent agricultural easements to } \\
\text { secure lands for community gardens in perpetuity. }\end{array}$ \\
\hline $\begin{array}{l}\text { Township of } \\
\text { Brock }\end{array}$ & $\begin{array}{l}\text { Official Plan: } \\
\text { June } 2006\end{array}$ & Agricultural / rural only \\
\hline $\begin{array}{l}\text { Municipality } \\
\text { of Clarington }\end{array}$ & $\begin{array}{l}\text { Official Plan: } \\
1996\end{array}$ & $\begin{array}{l}\text { Agricultural / rural only } \\
\text { Encourage and support the agricultural industry as an } \\
\text { important part of the Municipality's economic base and as a } \\
\text { valuable contribution to Ontario's food supply. } \\
{ }^{*} \text { Undergoing OP review; no new food provisions in draft }\end{array}$ \\
\hline $\begin{array}{l}\text { City of } \\
\text { Oshawa }\end{array}$ & $\begin{array}{l}\text { Creating Our } \\
\text { Sustainable } \\
\text { Tomorrow } \\
\text { Strategic Plan } \\
\text { 2013-2018 }\end{array}$ & $\begin{array}{l}\text { Category: Environmental Responsibility } \\
\text { Theme: Resilient Local Food System Strategies } \\
\text { 1. Promote and encourage backyard and community } \\
\text { gardening, and urban agriculture } \\
\text { 2. Educate the public about the value and importance of } \\
\text { buying locally grown food }\end{array}$ \\
\hline
\end{tabular}




\begin{tabular}{|l|l|l|}
\hline $\begin{array}{l}\text { City of } \\
\text { Pickering }\end{array}$ & $\begin{array}{l}\text { Official Plan: } \\
\text { March 1997; } \\
\text { Consolidation } \\
\text { February } \\
2010\end{array}$ & Agricultural / rural only \\
\hline $\begin{array}{l}\text { Township of } \\
\text { Scugog }\end{array}$ & $\begin{array}{l}\text { Official Plan: } \\
2009 ; \\
\text { Consolidation } \\
\text { November } \\
2014\end{array}$ & Agricultural / rural only \\
\hline $\begin{array}{l}\text { Township of } \\
\text { Uxbridge }\end{array}$ & $\begin{array}{l}\text { Consolidation } \\
\text { January 2014 }\end{array}$ & $\begin{array}{l}\text { 1.8.6 Community Gardens } \\
\text { Community gardens help to support people who could not } \\
\text { otherwise afford the time, effort and land, and may not } \\
\text { possess the skills or experience to maintain gardens on their } \\
\text { own property. The Township supports the creation of } \\
\text { community gardens which contribute to community food } \\
\text { security. Community gardens shall be permitted in any area } \\
\text { of the Township where agriculture operations are permitted, } \\
\text { provided they are outside of key natural heritage and } \\
\text { hydrological features and related vegetative protection } \\
\text { zones and any area which may have soil contamination. They } \\
\text { shall also be permitted in the hamlets and in the Uxbridge } \\
\text { Urban Area. }\end{array}$ \\
\hline $\begin{array}{l}\text { Town of } \\
\text { Whitby }\end{array}$ & $\begin{array}{l}\text { Official plan: } \\
1995\end{array}$ & $\begin{array}{l}\text { Agricultural / rural only } \\
\text { * Undergoing OP review; no new food provisions in draft }\end{array}$ \\
\hline
\end{tabular}




\title{
6. CONCLUSION: LEARNING FROM VGI SYSTEMS
}

\begin{abstract}
This chapter summarizes the major findings of this research. Since the significance of the findings for the regional food system are presented in detail in Chapter 5 and in the Crowdsourcing Urban Food Assets report (Appendix 5C), the conclusion focuses primarily on the relevance of this work to the VGI and Geoweb areas of research.
\end{abstract}

Overall, this research provides a guideline for implementing VGI systems and applied it to Durham Region's food system. The first part of this research (Chapter 2) establishes a working framework for the process of creating VGI. In this VGI systems framework, the project, participants, and Geoweb coalesce with the input, management, analysis, and presentation of VGI. In identifying the project and purpose as a crucial component of the system, the second part of this research (Chapter 3) explores how mapping has been used in food systems. The examples contained in this chapter reflects on the impact mapping can have on understanding the food system, and concludes that increased engagement in the mapping process leads to noteworthy food mapping projects.

The third part of this research (Chapters 4 and 5) implements a VGI system to support the participatory mapping of regional food assets in Durham. Engaging local food stakeholders to actively contribute information on food assets enabled the creation of an open dataset on food assets in Durham Region, a public Web-based food map resource, an urban food assets report, and an urban food policy working group. The implementation of a VGI system made a significant contribution to the regional understanding of urban food assets. Overall, the VGI systems framework was used to engage a wide range of food system 
stakeholders while creating new, and previously unavailable information about diverse and hyper-local food assets.

Beyond the benefits realized by local food stakeholders, the process of establishing a VGI system addresses important topics that can be broadly related to geographic information science. This final chapter concludes the research with a series of reflections, lessons learned, and areas for future research that are especially timely as research related to VGI continues to evolve rapidly. In fact, many VGI and Geoweb projects currently under development have not yet been formally published. Given this publication lag, these lessons are rooted in current literature but inspired by conversations at conferences, research meetings, networking events, and social media. The following lessons, traversing a range of significance for future research, are related to: conceptualizing VGI, building and democratizing the Geoweb, investigating the impact of data driven geography, exploring the intersection of VGI and citizen science, advancing VGI systems applications, and finally, considering the ethical implications of this research.

\subsection{Conceptualizing VGI and the Geoweb}

The growing pragmatic influence of VGI and the Geoweb on academic, government, and societal decision-making is evident from the examples and case studies highlighted in this thesis. In addition to the empirical application of the VGI systems framework, this research attempts to make a contribution to the conceptual understanding of VGI, which is an area of research still in its infancy. This work on the conceptualization of VGI systems contributes to ongoing work that theorizes the profound shift in mapping, data generation, and community engagement (Haklay, 2013a; Leszczynski \& Wilson, 2013; Rinner \& Fast, 2015). Building on these conceptualizations, this work developed a VGI system framework to propose the process of creating VGI. The inherent variability in crowdmapping projects-active, passive, citizen science-challenges the notion of a one-size-fits-all VGI system. As such, this research began to understand the relationships and connections between the various components and functions of VGI systems. With further refinement and application, this framework can be applied to support the development and deployment of a range of crowdmapping projects. 
In addition to the contribution to theoretical considerations of VGI, the VGI systems framework helped to clarify the (often ambiguous) differences between VGI and the Geoweb. Through this research process, it became clear that VGI and the Geoweb are very different phenomena, despite being used interchangeably to refer to the same phenomenon in some instances (Leszczynski \& Wilson, 2013). The process of establishing a system capable of collecting VGI is much different than that of establishing a Geoweb environment. VGI is created using project, participant, and Geoweb components for the input, management, analysis, and presentation of volunteered geographic content. Conversely, the Geoweb is created through programming, coding, and website development (to name only a few of the tasks involved).

While VGI and the Geoweb are not the same thing, they are complementary in nature. The online mapping infrastructure, applications, services, and platforms encompassed by the Geoweb can be used to support the creation of VGI. Similarly, VGI is often collected by way of the Geoweb. Despite this symbiotic relationship, not all Geoweb environments are capable of collecting VGI, and not all VGI is collected via the Geoweb. The remaining conclusions in this chapter are organized according to lessons learned relating to mapping and the Geoweb domain (lessons 6.2 and 6.3) and the VGI systems and data domain (lessons 6.4 to 6.7).

\subsection{Think Before you Build}

A main lesson related to the Geoweb was that developing a custom Geoweb application is not easy. Initially, this research started as a collaboration with the Neptis Foundation, a not-for-profit foundation that conducts mapping, research, and analysis related to growth management in Canada's urban regions. Neptis developed a Geoweb tool to support planning and policy in the Greater Toronto and Hamilton Area (Neptis Foundation, 2015). Dubbed 'engagement by visualization', the Neptis Geoweb integrates an online Web mapping environment with hundreds of municipal, regional, and provincial planning documents and data. The data include urban rural settlement, historic built-up areas, political boundaries, and provincial plans including the Greenbelt (2005), Oak Ridges Moraine (2002), and Niagara Escarpment (1973) planning areas. While not previously 
available together, these data tell a story of unprecedented growth across the Greater Toronto and Hamilton Area, highlighting both the connections and incompatibilities between plans.

The Neptis Geoweb has many interactive features, including the ability to turn map layers on/off, zoom to predefined geographic areas, query data, and draw features on the map. The tool was also designed to support map-based comments and conversations. However, the VGI capabilities to gather and display crowdsourced contributions on the map remained underdeveloped, and did not sufficiently address the requirements of the Durham Food Map. While the Neptis Geoweb continues to be developed, it highlights the challenges of developing a custom build Geoweb in a research-based, time-sensitive, or time-limited research project. In lieu of a custom-built Geoweb environment, multiple free and open source Geoweb environments are capable of collecting VGI (explored in the next lesson), which adequately served the case study in this research.

The challenges related to developing a custom-built Geoweb application emphasized the divide between trained mappers (geographers, cartographers, GIScientists, spatial analysts) and computer scientists. Software development (i.e., coding, programming) and other skills necessary for Geoweb development are not typically taught as part of geographic training, despite becoming increasingly important in research related to the Geoweb. The lack of programming skills in university and college level geography programs leaves those with computer science skills, whether trained or self-taught, to design and develop Geoweb environments, regardless of cartographic skill or training. The rapid and continued development of the Geoweb, largely by individuals not trained in geography or cartography, emphasizes the role trained mappers can, and should, play in the future of Geoweb development to ensure the cartographic integrity of this prolific source of maps being used by society.

\subsection{Negotiating Access to the Geoweb}

Contrasting the challenges surrounding Geoweb development is the ease of use and accessibility of publicly available Geoweb applications. The Geoweb is having a profound impact on how we create, use, and distribute maps, formally and informally (Haklay, 
Singleton and Parker, 2008). This research is evidence of that: as part of the research process, dozens of maps were used in community and academic presentations, community outreach, map-based storytelling, and promotional material. Despite prolific map use, traditional GIS, whether proprietary or open source, was not used at all in this project. Instead, this entire study was completed using freely available and hosted Geoweb environments; most notably, the Neptis Geoweb, Ushahidi, and CartoDB. This is evidence that mapping is becoming more accessible to the broader public, with minimal to no software costs, and ever increasing functionality.

With the growing number of free and open source Geoweb platforms available, one area of applied research worth pursuing is a review of Geoweb mapping options and their functionality. These include commercial applications, such as ArcGIS Online, CartoDB, and GeoCommons, which have both free and paid functionality. There are also privately developed Geoweb environments, such as Argoomap (Ryerson University), GeoLive (University of British Columbia), and GeoKey (University College London), that are open source and available for download or hosted deployment. These options require more knowledge of computer programming, and are not as accessible/usable as the commercial options, but available no less. More research is needed to understand the suite of options available, as the list is constantly expanding. Despite the range of accessibility, usability, and functionality, these Geoweb options are typically more feasible compared to a custombuilt Geoweb application. Knowing what is available is the first step toward choosing a Geoweb app that best fits the project at hand.

\subsubsection{Democracy and the Geoweb}

Accompanying recent mapping and Geoweb developments are growing implications on society. As such, it is necessary to continue to learn about the social implications of its influence. Chrisman (2005) described this as tracing full circle when contending with the social influence of GIS. For research into the Geoweb and VGI systems to come full circle, there is a continued need to explore the implications of their use.

Beyond the pragmatic side of map access without traditional GIS, this discussion fits into more theoretical conversations about neogeography (Connors et al., 2012; M. W. 
Wilson \& Graham, 2013), democracy (Haklay, 2013b), and the accessibility of mapping and Geoweb tools (Cinnamon \& Schuurman, 2012; Johnson \& Sieber, 2012a). Neogeography, in contrast to academic geography, refers to the use of mapping technologies by non-expert communities and is touted for disrupting traditional authority and potentially achieving greater democracy in mapping (Connors, Lei and Kelly, 2012; Crampton, 2009; Goodchild, 2009; Haklay, Singleton and Parker, 2008). The expectations for mapping are changing. The public now understands maps as inherently interactive and a valuable tool for locating, visualizing, and storytelling (Schuurman, 2009).

While there is evidence that maps are being developed and used by more people than ever because of the Geoweb and open source developments, Haklay (2013) rightfully regarded increased map development and use as a delusion of democracy. The delusion was also evident in this study. As previously stated, the project was completed using only free and publicly accessible Geoweb services. However, and in sharp contrast, none of the stakeholders engaged in the process knew what mapping resources were available to them or how to use them. Further, three of the organizations engaged in this study expressed an interest in acquiring a Geoweb for their personal sites, using a mix of in-house data and data generated from this study. However, as smaller not-for-profit organizations and community groups with no dedicated technical or mapping staff, none were able to develop their own map despite the desire to do so. Rather, an intermediary would be necessary to support map development and maintenance, even using free and publically available Web mapping applications.

\subsubsection{Role of the Intermediary}

The Geoweb is enabling greater accessibility to mapping, but it is not universally accessible, calling for a better understanding of what barriers exist that limit widespread access to mapping tools. This research highlighted the necessity of the intermediary. In particular, what role does the intermediary play, and in what context?

Increasingly, geographers, cartographers, and spatial analysts seem well positioned to facilitate this role. In a 2008 interview with Dr. Michael Goodchild, Dr. Nadine Schuurman asked "does the changing authority of geographic information and its emphasis 
on representation somehow change the authority of GIS specialists in geography?" Goodchild responds, "I think it will eventually. I think there's always going to be room for the qualified professional" (Schuurman, 2009, pp. 573-574). That 'eventually' is now. In government and citizen interaction using the Geoweb and VGI... A recent report from the government of Canada highlighted the role of the intermediary for government agencies to realize the benefits of VGI: "cost reduction and efficiency requirements will see more government Geomatics organizations outsourcing processes to the private sector, partnering with VGI data providers and others, and focusing on the roles of commissioning and managing the delivery of a complete location information framework" (Hickling Arthurs Low, 2013, p. 40).

\subsection{Data-Driven Geography}

Transitioning to lessons related to VGI, this research highlighted the relevance of data-driven geography. Geographic information studies typically operated in a data-scarce environment, and as such, many GIScientists focused on creating new algorithms and methods to support the analytical capabilities with the data that was available (Miller, 2004; Unwin, 1996). However, the ways in which geographic data are accessed, analyzed, and presented is changing due to the influence of Web 2.0 technologies, the Geoweb, and other forms of media and technology that are capable of collecting geographic information, leading to a data-rich environment (Miller \& Goodchild, 2014). It is necessary to investigate the types of data emerging from this data-rich environment, which are grouped into big data, open data, and data-information-knowledge discussions.

\subsubsection{Big Data}

Big data is categorized according to the Vs: volume, velocity, and variety; and the more recently added, value and veracity (Miller \& Goodchild, 2014). Big data most often has a location component (i.e., geographic coordinates, address information, or city name), making it relevant to geographic information studies. While the limits of big data are still being debated and contested, Graser (2014) defined the threshold of big data as data that analysts, computers, or GIS software do not yet know how to handle. Thus, the threshold is a moving target. Once we are able to handle and extract information from the data, it no 
longer is big data. Adhering to this definition, the active VGI studied in this project does not cross the big data threshold. In fact, very few if any projects that collect active VGI are big data projects, not even OpenStreetMap because, given Graser's definition, we know how to manage and use the data.

Where big data does seem more relevant to VGI is when users contribute digital footprint and passive VGI. These types of passive VGI are most closely associated with Goodchild's (2007) 'citizens as sensors' perspective. Fischer (2012) referred to this type of data as 'involuntary geographic information', while Stefanidis, Crooks, \& Radzikowski (2011) called it ambient geospatial information. More research needs to be done on the contribution of VGI to big data.

\subsubsection{Open Data}

Open data are defined as the provision of raw data by government, in which governments provide the data that are licensed to share (more) freely with citizens (Johnson \& Robinson, 2014; Lauriault \& Mooney, 2014). Sieber \& Johnson (2015) identify four models of open data. The first is simple data provision, where governments are providers of data. This is a big step for many governments, as they need to consider legal, ethical, accessibility, data standards, and other considerations before freely providing raw data (Lauriault \& Mooney, 2014; Scassa, 2014). Next is the code exchange model, where governments support data use and benefits through interactive approaches, such as civic hackathons (Johnson \& Robinson, 2014).

Third, Sieber \& Johnson (2015) identify civic tracker issue as a model for open data where governments accept feedback (i.e., crowdsourcing) on a limited range of issues to maintain and improve existing data. Finally, the participatory open data model denotes the co-production of data between authoritative sources (i.e., government) and new citizen generated data (i.e., VGI). The participatory open data model is going beyond simple data provision to opening new channels for citizen engagement with governments and integration into the decision-making environment in order to achieve various outcomes, policy or otherwise (Sieber \& Johnson, 2015). 
Given these various models, the data generated by this research fit into the participatory open data model, albeit with one major exception: the open data generated did not come exclusively from a mix of government and citizen sources. Rather, the largest data contributions came from the private sector, which included NGOs and community groups. Sieber \& Johnson (2015) only very briefly indicate the potential to extend citizengovernment data co-production to private or not-for-profit actors.

This research uncovered an unexplored, and largely untapped, source of data. These data were previously gathered, managed, and housed by local NGOs and community groups, and contained information on various elements of their area of specialty. The coproduction between various NGOs and community groups, a hybrid existing somewhere between authoritative and citizen-generated data, tapped into an existing network of actors and existing data resources. In addition to the data generated in this study now being publicly viewable and downloadable (i.e., open), it connected the actors by engaging them to share their information with each other and the Durham Food Policy Council. It is important to further explore how to foster contributions from NGOs and community groups and incorporate them into the open data arena for maximum benefit to government, NGOs, and the community.

\subsubsection{Data, Information, and Knowledge in VGI}

The term 'VGI' is most often used to refer to the data or the dataset generated, and is inaccurately referred to as 'VGI data' (Cinnamon \& Schuurman, 2012; Connors, Lei, \& Kelly, 2012; Fischer, 2012; Haklay, Antoniou, Basiouka, Soden, \& Mooney, 2014; Hickling Arthurs Low, 2012; Lauriault \& Mooney, 2014; Neis \& Zielstra, 2014; Seeger, 2008; and many others). However, in the context of the data-information-knowledge hierarchy (Poore \& Chrisman, 2006), what the public is contributing contains elements of data (e.g., latitude/longitude), information (e.g., points of interest), and knowledge (e.g., value statement about point of interest). As such, user contributions on the participatory Geoweb can be more accurately described as content (Rinner \& Fast, 2015). To avoid a neologistic debate, in this research, VGI is used to refer to the full range of user contributions. 
While data (or more specifically, datasets) and information are important for VGI, the knowledge of the contributor can be particularly relevant when trying to understand the origins, authority, and impact of VGI. VGI contributions can be broadly thought of in two dimensions: professional and local (Figure 6.1). For example, OpenStreetMap contributors can be professionals; such as when a trained cartographer with photogrammetry experience digitizes features on the earth's surface from a satellite image of an area he/she does not know. They can be local; for example, an individual adds local shops while walking around his/her neighbourhood. To borrow from Coleman, Georgiadou, \& Labonte (2009), contributions can be neophytic; new to the subject and the skill. For example, untrained individuals contribute to disaster relief efforts by adding roads, buildings, and other features of places they are not familiar with. Finally, they can be professional and local if an individual with map training contributes content to an area he/she knows.

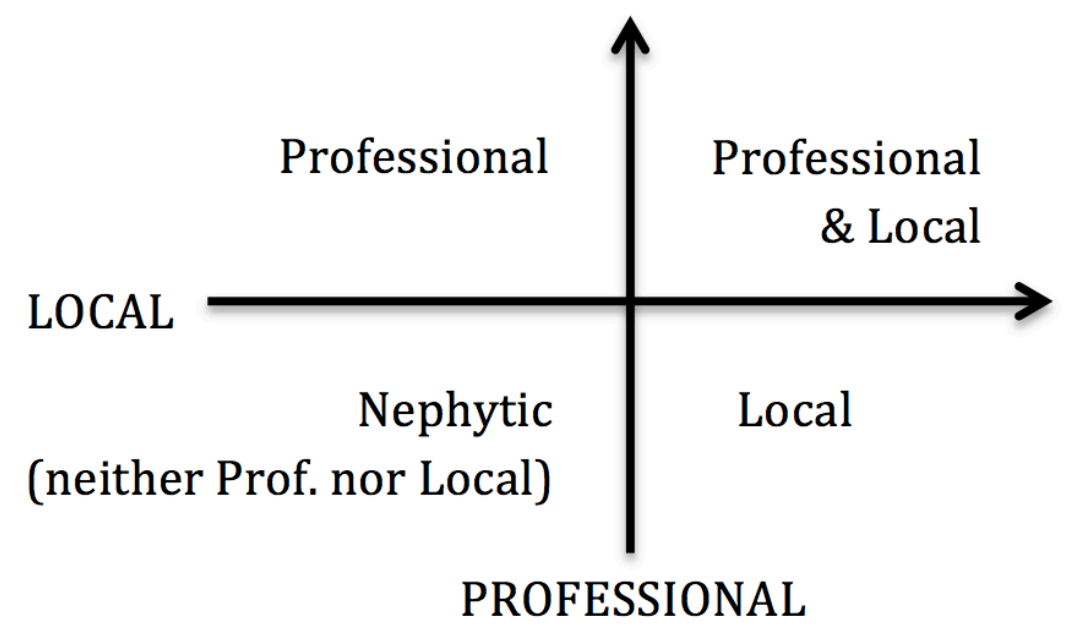

Figure 6.1: The range of VGI contributor characteristics

These distinctions become important when working on disaster relief efforts. When mapping a new area from satellite imagery to aid in relief efforts, there could be significant variation between the contribution of locals in their neighbourhoods, mapping professionals without personal knowledge of the area, and untrained non-local individuals.

In this research, contributions were always from participants in Durham Region (local), were sometimes from experts in the food system (professional), but given the 
methodology employed in this study, were not neophytic. However, these distinctions in contributor knowledge were not conveyed in the final VGI dataset. Further, despite the varying degrees of knowledge represented in the content, the entire dataset was classed as VGI. Now that the dataset is open and available for download by the public, it is not entirely distinguishable from traditional geographic information. Rarely is there data about the creator, or any other metadata (data about data) for that fact. It raises the question: should data about the contributor's knowledge or skill be included in VGI?

The range of contributor characteristics in VGI, yet lack of metadata to convey the distinctions in contribution knowledge, can be related to the ongoing debate around the concept of authority in VGI (Flanagin \& Metzger, 2008; Goodchild, 2008). Arguably, the origins of the creation are relevant once the VGI is presented as an integrated dataset, further reinforcing the imperative to start thinking of the systems, perhaps even the science, which support the creation of VGI. Getting to know the process that creates VGI can help understand ongoing issues instigated by its creation and use, such as metadata and data quality, role of intermediary, participant inequality, and use in government, to name a few.

\subsection{VGI and Citizen Science}

There are a growing number of comparisons between VGI and citizen science. While each has a unique set of processes, methods, outcomes, and implications, there are many overlapping themes between the two. This most notably includes the broader public's participation in something that was typically reserved for professionals. In some cases, VGI and citizen science are used interchangeably, and they often appear as keywords together. Despite their similarities, VGI and citizen science are indeed different. Citizen science focuses on the publics' contribution to more traditional notions of science, and the contributions may or may not include a 'geographic' component. VGI focuses on volunteers' contribution to geographic information, which may or may not have a 'scientific' component.

Research in both of these areas is expanding, but it seems many more researchers are working toward understanding the process of citizen science given its broad public 
appeal (Wiggins \& Crowston, 2015), whereas the study of VGI has remained largely contained within the academic discipline of geography. While the research contained in this dissertation only briefly addressed citizen science as an example of VGI, there is far more to learn from citizen science. Citizen science is further strengthened by the wellestablished Citizen Science Association, the Citizen Science: Theory and Practice journal, and research projects that are engaging sizable communities all over the world. Given the similarity between citizen science and VGI, and the well-established citizen science paradigm, an important area of research would be to understand how VGI and citizen science intersect. The interconnection between citizen science and VGI could be an important step to unlocking their potential in both the traditional science and geographic information science spheres.

\subsection{VGI systems: Beyond Food to Mental Health and Air Quality Monitoring}

Relatively few organizations outside of the academic discipline of geography government, business, or community-use the term VGI. However there is a growing demand for VGI services among these groups. They want to employ online mapping tools and engage in crowdmapping and citizen science for both data generation and community engagement purposes. While there are many organizations wanting and choosing to employ these tools, few have the expertise or experience to operate such tools. Two organizations in Toronto that are currently implementing VGI systems are the Centre for Addiction and Mental Health and the Clean Air Partnership. There is much to learn from the processes they have undertaken to achieve public engagement through crowdsourcing. The following two subsections introduce their projects, and the challenges and opportunities presented within. It is with continued refinement of the VGI systems framework that better processes can be designed to meet the growing need for crowdmapping within these organizations.

\subsubsection{Crowdsourcing Mental Health Resources}

The Centre for Addiction and Mental Health (CAMH) recently prioritized alternative approaches to engaging more people, especially youth, in mental health advocacy, policy, and research development. One particular impactful alternative approach was a 
participatory mapping project that brought together post-secondary students from the University of Toronto, Ryerson University, and the Ontario College of Art and Design. Together, they created Thought Spot: a crowdsourced map of mental health and wellness services in Toronto (Hart \& Fast, 2015). The goal of the project was to empower postsecondary students to build their own mental health-promoting interactive Geoweb that supports improved awareness of services in the Toronto area.

The initiators at CAMH wanted the project to be led by students, which was further reinforced by the original 'For Students, By Students' project name, later changed to 'Thought Spot' by the students who took lead on the project. Since the initiators wanted students to take ownership of the project, they did not interfere with project development. Instead, to mediate between CAMH and the student group, they hired an intermediary, a digital media consultant, to manage the project. The intermediary gathered the team of student volunteers from the various universities, but provided only minimal guidance regarding the development and direction of the project. The hands-off approached initially proved to be a challenge for the students involved because they did not fully understand the purpose of the project and needed stronger guidance before they were able to take ownership of the Through Spot project. However, in the end, a valuable map resource was created that supported the accessibility of mental health and wellness resources relevant for post secondary students.

Active project development is completed, but the map resource and various maintenance tasks persist, which are sustained by students paid for by CAMH. The project provides a unique opportunity to study the process of establishing a VGI system, including the organization of the project and development teams, the engagement of participants, and the mapping environment used. Further, it also provides an opportunity to evaluate the deliverables of the project now that it has wrapped up. The VGI systems framework will be applied in a retroactive reconstruction to report on the development and deployment of the Thought Spot project, which may in turn also support the continued refinement of the framework. 


\subsubsection{Crowdsourcing Air Quality Monitoring}

The Clean Air Partnership is a Toronto-based NGO that works to transform cities into sustainable, vibrant, and resilient communities, where the air is clean to breathe and greenhouse gas emissions are minimized. As a part of their mission, their applied research and community engagement efforts aim to broaden and improve access to public policy debates on air pollution and climate change issues. An integral part of this work is air quality monitoring. However, traditional equipment is expensive, stationary, temporally sparse, and does not provide continuous nor universally accessible data to the public. Recognizing the need for better availability, access, and engagement with air quality monitoring, the Clean Air Partnership is looking into participatory crowdsourcing of air quality data.

Currently, the Clean Air Partnership has created a forum to open the discussion about potential issues, solutions, and problems that crowdsourcing air quality can address, what issues may potentially arise, and how to mitigate those issues. These early meetings attracted over 30 organizations representing government, NGO, academic, and private interests, highlighting the interest of citizen science in tracking levels of pollutants. Collectively, these stakeholders recognize the potential of collaborative air quality monitoring to give voice to clean air advocates from all over the community, not only helping to bring together data but also serving as a forum for community engagement, revenue generation, and policy change support. The institutional support for crowdsourced air quality monitoring is further enabled by mobile monitoring advancements; the variety and availability of monitors is growing with many new technologies entering the market in just the last few months.

The shift away from government-led to community-driven air quality monitoring, however, is not without challenges. Out of all of the air quality stakeholders engaged, none have experience with a citizen science, crowdsourcing, or VGI approach. A key theme throughout the preliminary meetings was the growing need for an intermediary to support this transition. While this project is only in its early phases, a VGI systems approach could help facilitate the implementation by addressing the process required. Overall, if the Clean Air Partnership is able to successfully navigate the intersection of citizen science with 
governmental air quality monitoring, it could build a large community of clean air partners, leading to a greater understanding of how, when, and where poor air quality is of greatest concern.

While local food, mental health, and air quality monitoring are separate domains, they share the same goals of engaging the broader public while producing VGI. The studies highlighted here further highlight the importance of continued study into the systems that support the creation of VGI. What do these projects have in common? What can they teach us about future projects? How do they fit within the VGI systems framework? Understanding the process of establishing VGI systems will help scientists, researchers, and community organizations better design, implement, and study them in the future; moving us closer to using VGI systems as a framework to further engagement and inquiry.

\subsection{VGI and Ethics}

A dominant stream of research is the legal and ethical side of location information, which has become especially paramount in the Web 2.0 era. Leading the legal side of the VGI and open data research is Scassa $(2013,2014)$, who identified copyright, intellectual property, and privacy as the dominant issues within this type of work. Existing ethical, legal, and practical issues related to archiving qualitative research data (Parry \& Mauthner, 2004) are amplified when they are collected and then made open and available to the public. This project was mindful of these issues, and sought ethical review through the University Research Ethics Board (REB).

Overall, the university ethics process was both challenging and useful. The REB application proved to be a challenge because the process of establishing a VGI system did not adhere to the standard REB form-fillable application. Questions, such as the sample, timeframe, data type, were difficult to answer because the process of collecting user contributions is as controlled, as it is in experimental research. While the VGI systems framework imposed bounds on the process development, the sample was still largely unknown and dependent on 'volunteered' (rather than requested) contributions.

Interestingly, the process of completing the REB application prompted the research design to consider, and in some cases, adhere to more traditional data collection strategies 
early on in the process of establishing the VGI system. Arguably, this led to greater, yet not complete, control over the variables in the project. In fact, questions about sample on the REB application was one reason this project targeted local food stakeholders as the primary contributors. However, there were still gaps in the REB application that do not yet address emerging ethical and legal issues associated with novel and evolving Web-based, location-based, and crowdsourced research projects.

To supplement the REB approval, additional criteria were established to ensure the ethical operation during the design and implementation of the VGI system. First, an advisory board was sought and established to help make crucial decisions about scope of project, project management, and contribution vetting. It was also decided that no personal location information be released; e.g., the location of a home garden. As the project progressed, it became clear that there are tensions between citizens and the government that regulate and restrict vegetable growing outside of the traditional farm or backyard gardens. Given these tensions, contributor information was supressed to ensure the study did not put any contributor in conflict with existing bylaws or regulations. The selfimposed ethical guide highlight the need for all research ethic boards to consider updating their standard forms to be more accommodating of emerging sensitivities related to online, location, and crowdsourced research projects.

\subsection{Final Thoughts}

The dissertation presented here undertook novel research related to the phenomenon of VGI, combining both theoretical and applied contributions. Theoretically, this research established a framework to guide the process of creating VGI. It then applied that framework to Durham's food system. The Durham Food Map case study made a significant contribution to Durham's urban food system, filling information gaps for the Durham Food Policy Council and facilitating connections across the diverse and hyper-local food system stakeholders operating within Durham Region. Finally, this research concluded with lessons related to Geoweb development, democracy and the Geoweb, datadriven geography, VGI and citizen science, other applications of VGI systems, and VGI and 
ethics issues. It seems clear from this research and the lessons: VGI, the Geoweb, and related advancements are making a significant impact and appear to be here to stay.

VGI systems are not fixed; rather, they are constantly re-produced in their development, application, and adoption. Moving forward, it is important to continue to refine the VGI systems framework to harness volunteered geographic information for decision-making at various levels, meeting the needs of government, not-for-profit, and private communities alike. There is a nascent focus on the interoperability of multiple VGI projects, which will only be realized through iterative design. In a time when research on VGI is still in its infancy, the VGI systems framework is well positioned to facilitate further advancement. My hope is that other researchers will take the lessons from this body of work and use it to strengthen both food systems and VGI systems. 


\section{REFERENCE LIST}

Ahmed, S., Simiyu, E., Githiri, G., Acioly, A., Mbaka, S., Karanja, I., \& Kigen, L. (2014). Dining with less danger: mapping food and environmental hazards in Mathare, Nairobi. International Institute for Environment and Development, 1-4.

Angra, I., Cranmer-Byng, S., Gill, J., Guthrie, K., Hedley, M., Johnson, B., Kamphuis, K., MacFarlane, A., Needham, L., Papoff, K., Roberts, M., Senitt, H., and Vestula, K. (2014). Food Security in Guelph. Guelph: Guelph Wellbeing. Retrieved from http://guelphwellbeing.ca/sites/default/files/images/Food security report_x-1a.pdf

Arnstein, S. (1969). A ladder of citizen participation. Journal of the American Institute of Planners, 35(4), 216-224.

Baker, L., Campsie, P., \& Rabinowicz, K. (2010). Menu 2020: Ten good food ideas for Ontario. Toronto: Metcalf Food Solutions.

Ball, K., \& Thornton, L. (2013). Food environments: measuring, mapping, monitoring and modifying. Public Health Nutrition, 16(7), 1147-1150. doi:10.1017/S1368980013001304

Barilla Centre for Food and Nutrition Foundation. (2015). The Milan Protocol on Food and Nutrition, (April), 25. Retrieved from http://www.milanprotocol.com

Barth, D. (2009). The bright side of sitting in traffic: crowdsourcing road congestion data. Retrieved September 11, 2014, from http://googleblog.blogspot.ca/2009/08/brightside-of-sitting-in-traffic.html

Bartlett, R., \& Rivard, J. (2014). Online Mapping Tools. Retrieved May 1, 2015, from https://www.library.carleton.ca/help/online-mapping-tools

Batty, M., Hudson-Smith, A., Milton, R., \& Crooks, A. (2010). Map mashups, Web 2.0 and the GIS revolution. Annals of GIS, 16(1), 1-13. doi:10.1080/19475681003700831 
Beaubien, E. G., \& Hamann, A. (2011). Plant phenology networks of citizen scientists: recommendations from two decades of experience in Canada. International Journal of Biometeorology, 55(6), 833-41. doi:10.1007/s00484-011-0457-y

Beaudreau, P., Johnson, P. A., \& Sieber, R. E. (2012). Strategic choices in developing a geospatial web 2.0 application for rural economic development. Journal of Rural and Community Development, 7(3), 95-105.

Bertalanffy, L. von. (1968). General System Theory. New York: George Braziller.

Bill 36. Local Food Act, Pub. L. No. Bill 36; Chapter 7, Statutes of Ontario (2013). Canada: 2nd session, 40th Legislature, Ontario.

Bill, R., \& Fritsch, D. (1999). Grundlagen der Geoinformationssysteme. Band 1: Hardware, Software und Daten [translated from German "Fundamentals of GIS, Volume 1: Hardware, Software, and Data"]. Heidelberg.

Brabham, D. C. (2009). Crowdsourcing the Public Participation Process for Planning Projects. Planning Theory, 8(3), 242-262. doi:10.1177/1473095209104824

Brown, G. (2012). Public Participation GIS (PPGIS) for regional and environmental planning: reflections on a decade of empiricial research. URISA: Journal of the Urban and Regional Information Systems Association, 24(2), 7-18.

Burke, J., Estrin, D., Hansen, M., Parker, A., Ramanathan, N., Reddy, S., \& Srivastava, M. (2006). Participatory sensing. Centre for Embedded Network Sensing. Retrieved from http://escholarship.org/uc/item/19h777qd

Butt, M. A., \& Li, S. (2012). Developing a web-based, collaborative PPGIS prototype to support public participation. Applied Geomatics, 4, 197-215. doi:10.1007/s12518012-0085-1 
Chrisman, N. (2005). Full Circle: More than Just Social Implications of GIS. Cartographica: The International Journal for Geographic Information and Geovisualization, 40(4), 2335. doi:10.3138/8U64-K7M1-5XW3-2677

Chrisman, N. R. (1999). What does “GIS" mean? Transactions in GIS, 3(2), 175-186.

Cinnamon, J., \& Schuurman, N. (2012). Confronting the data-divide in a time of spatial turns and volunteered geographic information. GeoJournal, 78(4), 657-674. doi:10.1007/s10708-012-9458-6

City of Oshawa. (2012). Creating Our Sustainable Tomorrow: Oshawa Strategic Plan 20132018. Retrieved from www.oshawa.ca/strategic

Clancy, K., \& Ruhf, K. (2010). Is local enough? Some arguements for regional food systems. Choices: A Publication of Agricultural and Applied Economics Association, 25(1), 1-5.

Coleman, D. J. (2010). Volunteered geographic information in spatial data infrastructure: an early look at opportunities and constraints. In GSDI 12 World Conference (pp. 1-18). Retrieved from http://www.gsdi.org/gsdiconf/gsdi12/papers/905.pdf

Coleman, D. J., Georgiadou, Y., \& Labonte, J. (2009). Volunteered geographic information: the nature and motivation of produsers. International Journal of Spatial Data Infrastructures, 4, 332-358. doi:10.2902/1725-0463.2009.04.art16

Coleman, D. J., Sabone, B., \& Nkhwanana, N. (2010). Volunteering Geographic Information to Authorative Databases: Linking Contributor Motivations to Program Characteristics. Geomatica, 64(1), 2010.

Connors, J. P., Lei, S., \& Kelly, M. (2012). Citizen science in the age of neogeography: utilizing volunteered geographic information for environmental monitoring. Annals of the Association of American Geographers, 102(6), 1267-1289. doi:10.1080/00045608.2011.627058 
Contreras-Judge, P., Caneo, C., Drummond, M., Earle, B., Kinniburgh, J., \& Pacheco-Rye, A. (2013). Durham Food System Environmental Scan: A report of the Durham Food Policy Council. Community Development Council Durham, 50.

Crampton, J. W. (2009). Cartography: maps 2.0. Progress in Human Geography, 33(1), 91100. doi:10.1177/0309132508094074

Damyanov, N. N., Damon Matthews, H., \& Mysak, L. A. (2012). Observed decreases in the Canadian outdoor skating season due to recent winter warming. Environmental Research Letters, 7(014028). doi:10.1088/1748-9326/7/1/014028

Deloitte. (2013). Best practices in local food: a guide for municipalities. Ontario Municipal Knowledge Network and the Association of Municipalities Ontario. Retrieved from https://www.amo.on.ca/AMO-

PDFs/Reports/2013/2013BestPracticesinLocalFoodAGuideforMunicipalitie.aspx

Devillers, R., Stein, A., Bédard, Y., Chrisman, N., Fisher, P., \& Shi, W. (2010). Thirty Years of Research on Spatial Data Quality: Achievements, Failures, and Opportunities. Transactions in GIS, 14(4), 387-400. doi:10.1111/j.1467-9671.2010.01212.x

Dodge, M., \& Kitchin, R. (2013). Crowdsourced cartography: mapping experience and knowledge. Environment and Planning A, 45(1), 19-36. doi:10.1068/a44484

Dubbeling, M., Hoekstra, F., Renting, H., Carey, J., \& Wiskerke, H. (2015). City Region Food Systems. RUAF Foundation: Resource Centres on Urban Agriculture and Food Security, $29,1-72$.

Dunn, C. E. (2007). Participatory GIS: a people's GIS? Progress in Human Geography, 31(5), 616-637. doi:10.1177/0309132507081493

Durham Farm Fresh Map. (2015). Retrieved November 4, 2014, from http://durhamfarmfresh.ca/map/ 
Durham Region. (2012). From Vision to Action: Region of Durham Community Climate Change Local Action Plan, 1-60. Retrieved from http://www.durham.ca/climatechange

Edwards, R. (2014). The "citizens" in citizen science projects: educational and conceptual issues. International Journal of Science Education, Part B: Communication and Public Engagement, (September), 1-16. doi:10.1080/21548455.2014.953228

Edwards-Jones, G., Milà i Canals, L., Hounsome, N., Truninger, M., Koerber, G., Hounsome, B., ... Jones, D. L. (2008). Testing the assertion that "local food is best": the challenges of an evidence-based approach. Trends in Food Science and Technology, 19, 265-274. doi:10.1016/j.tifs.2008.01.008

Elwood, S. (2008). Volunteered geographic information: future research directions motivated by critical, participatory, and feminist GIS. GeoJournal, 72(3-4), 173-183. doi:10.1007/s10708-008-9186-0

Elwood, S. (2009a). Geographic information science: emerging research on the societal implications of the geospatial web. Progress in Human Geography, 34(3), 349-357. doi:10.1177/0309132509340711

Elwood, S. (2009b). Geographic Information Science: new geovisualization technologies -emerging questions and linkages with GIScience research. Progress in Human Geography, 33(2), 256-263. doi:10.1177/0309132508094076

Elwood, S. (2010). Geographic Information Science: Visualization, visual methods, and the geoweb. Progress in Human Geography, 35(3), 401-408. doi:10.1177/0309132510374250

Elwood, S., Goodchild, M. F., \& Sui, D. Z. (2012). Researching volunteered geographic information: spatial data, geographic research, and new social practice. Annals of the Association of American Geographers, 102(3), 571-590. doi:10.1080/00045608.2011.595657 
Elwood, S., \& Leszczynski, A. (2013). New spatial media, new knowledge politics. Transactions of the Institute of British Geographers, 38(4), 544-559. doi:10.1111/j.1475-5661.2012.00543.x

Fast, V. (2015). Durham's Food Story - YouTube. Retrieved from https://www.youtube.com/watch?v=U0g5GZLP__w

Fast, V., \& Rinner, C. (2014). A Systems Perspective on Volunteered Geographic Information. ISPRS International Journal of Geo-Information, 3(4), 1278-1292. doi:10.3390/ijgi3041278

Feagan, R. (2007). The place of food: mapping out the "local" in local food systems. Progress in Human Geography, 31(1), 23-42. doi:10.1177/0309132507073527

Feick, R., \& Robertson, C. (2014). A multi-scale approach to exploring urban places in geotagged photographs. Computers, Environment and Urban Systems. doi:10.1016/j.compenvurbsys.2013.11.006

Fischer, F. (2012). A new but delicate geographic data-source: VGI as big data. GeoInformatics, 15(3), 46-47.

Flanagin, A. J., \& Metzger, M. J. (2008). The credibility of volunteered geographic information. GeoJournal, 72(3-4), 137-148. doi:10.1007/s10708-008-9188-y

Francis, C. (2003). Agroecology: the ecology of food systems. Journal of Sustainable Agriculture, 22(13535), 99-118.

Fraser, D. (2014, August 13). Community Garden: St. Catharines could be on "cutting edge" of food security--Vegetables on menu for city hall lawn. St. Catharines Standard, p. A3. St. Catharines.

Garnett, T. (2012). Where are the best opportunities for reducing greenhouse gas emissions in the food system (including the food chain)? Food Policy, 37, 463-466. doi:10.1016/j.foodpol.2012.04.006 
Goodchild, M. F. (1992). Geographical information science. International Journal of Geographical Information Systems, 6(1), 31-45.

Goodchild, M. F. (2007). Citizens as sensors: the world of volunteered geography. GeoJournal, 69(4), 211-221. doi:10.1007/s10708-007-9111-y

Goodchild, M. F. (2008). Assertion and authority: the science of user-generated geographic content. In Proceedings of the Colloquium for Andrew U. Frank's 60th Birthday. GeoInfo 39. Department of Geoinformation and Cartography, Vienna University of Technology. (Vol. 39, pp. 1-18).

Goodchild, M. F. (2009). Neogeography and the nature of geographic expertise. Journal of Location Based Services, 3(2), 82-96. doi:10.1080/17489720902950374

Goodchild, M. F., \& Li, L. (2012). Assuring the quality of volunteered geographic information. Spatial Statistics, 1, 110-120. doi:10.1016/j.spasta.2012.03.002

Gouveia, C., \& Fonseca, A. (2008). New approaches to environmental monitoring: the use of ICT to explore volunteered geographic information. GeoJournal, 72(3-4), 185-197. doi:10.1007/s10708-008-9183-3

Graser, A. (2014). GIScience for dynamic transportation systems. In Scholarly, Research, and Creative Activity Talks. Toronto: Ryerson University.

Grira, J., Bédard, Y., \& Roche, S. (2009). Spatial data uncertainty in the VGI world: going from consumer to producer. Geomatica, 64(1), 61-71.

Haklay, M. (2010). How good is volunteered geographical information? A comparative study of OpenStreetMap and Ordnance Survey datasets. Environment and Planning B: Planning and Design, 37(4), 682-703. doi:10.1068/b35097

Haklay, M. (2013a). Citizen science and volunteered geographic information: overview and typology of participation. In D. Z. Sui, S. Elwood, \& M. F. Goodchild (Eds.), 
Crowdsourcing Geographic Knowledge: Volunteered Geographic Information (VGI) in Theory and Practice (pp. 105-122). Springer.

Haklay, M. (2013b). Neogeography and the delusion of democratisation. Environment and Planning A, 45(1), 55-69. doi:10.1068/a45184

Haklay, M. (2014). Volunteered Geographic Information and Citizen Science. In Vespucci Summer Institute - VGI and Citizen Science: Engaging, Creating, and Understanding. Fiesole, Italy.

Haklay, M., Antoniou, V., Basiouka, S., Soden, R., \& Mooney, P. (2014). Crowdsourced Geographic Information Use in Government. London. Retrieved from http://discovery.ucl.ac.uk/1433169/

Haklay, M., Singleton, A., \& Parker, C. (2008). Web Mapping 2.0: The Neogeography of the GeoWeb. Geography Compass, 2(6), 2011-2039. doi:10.1111/j.17498198.2008.00167.x

Haklay, M., \& Weber, P. (2008). Open StreetMap: User-Generated Street Maps. IEEE Pervasive Computing, 7(4), 12-18.

Hall, A. D., \& Fagen, R. E. (1956). Definition of system. In General Systems: Yearbook of the Society for General Systems Research, International Society for the Systems Sciences (Volume 1., pp. 18-28). Pocklington, UK.

Hall, B., Chipeniuk, R., Feick, R. D., Leahy, M. G., \& Deparday, V. (2010). Community-based production of geographic information using open source software and Web 2.0. International Journal of Geographical Information Science, 24(5), 761-781.

Hardy, D., Frew, J., \& Goodchild, M. F. (2012). Volunteered geographic information production as a spatial process. International Journal of Geographical Information Science, 26(7), 1191-1212. doi:10.1080/13658816.2011.629618 
Hart, H., \& Fast, V. (2015). Crowd mapping mental health promotion through the Thought Spot project. In Annual Meeting of the Association of American Geographers. Chicago.

Heywood, I., Cornelius, S., \& Carver, S. (2006). An Introduction to Geographical Information Systems (3rd ed.). Harlow: Pearson Prentice Hall.

Hickling Arthurs Low. (2012). Volunteered Geographic Information (VGI) Primer. Canadian Geospatial Data Infrastructure, Information Product 21e, 22 pages, doi http://dx.doi.org/10.4095/291948. Retrieved from http://ftp2.cits.rncan.gc.ca/pub/geott/ess_pubs/291/291948/cgdi_ip_21e.pdf

Hickling Arthurs Low. (2013). Canadian Geomatics Community Strategy "White Paper" and Scenarios. Canadian Geospatial Data Infrastructure, Information Product 31e, 64 pages, doi:10.4095/292903. Retrieved from http://ftp2.cits.rncan.gc.ca/pub/geott/ess_pubs/292/292903/cgdi_ip_31e.pdf

Hincrichs, C. C. (2003). The practice and politics of food system localization. Journal of Rural Studies, 19, 33-45. doi:10.1016/S0743-0167(02)00040-2

Hoffmann, U. (2013). Wake up before it is too late: make agriculture truly sustainable now for food security in a changing climate. United Nations Trade and Environment Review, ISSN:1810-5432, 341 pages.

Horner, J. (2013). GHFFA Media Release: Asset Mapping Completed for Golden Horseshoe Food and Farming.

Jarosz, L. (2008). The city in the country: Growing alternative food networks in Metropolitan areas. Journal of Rural Studies, 24, 231-244. doi:10.1016/j.jrurstud.2007.10.002

Jensen, D., \& Roy, M. (Eds.). (2013). Food: An Atlas. Guerrilla Cartography. Oakland, California: Guerrilla Cartography. Retrieved from http://www.ediblegeography.com/food-an-atlas/ 
Jensen, K. B., \& Glasmeier, A. K. (2010). Policy, research design and the socially situated researcher. In D. DeLyser, S. Herbert, S. Aitken, M. Crang, \& L. McDowell (Eds.), The Sage Handbook of Qualitative Geography (pp. 82-93). SAGE Publications.

Johnson, J., Avenarius, C., \& Weatherford, J. (2006). The Active Participant-Observer: Applying Social Role Analysis to Participant Observation. Field Methods, 18(2), 111134. doi: $10.1177 / 1525822 X 05285928$

Johnson, P. A., \& Robinson, P. (2014). Civic Hackathons: Innovation, procurement, or civic engagement? Review of Policy Research, 31(4), 349-357. doi:10.1111/ropr.12074

Johnson, P. A., \& Sieber, R. E. (2012a). Increasing access to and use of geospatial data by municipal government and citizens: the process of 'geomatization' in rural Quebec. URISA: Journal of the Urban and Regional Information Systems Association, 24(2), 5764.

Johnson, P. A., \& Sieber, R. E. (2012b). Motivations driving government adoption of the Geoweb. GeoJournal, 77(5), 667-680. doi:10.1007/s10708-011-9416-8

Johnson, P. A., Sieber, R. E., Magnien, N., \& Ariwi, J. (2012). Automated web harvesting to collect and analyse user-generated content for tourism. Current Issues in Tourism, 15(3), 293-299.

Johnson, S. (2006). The ghost map: the story of London's most terrifying epidemic--and how it changed science, cities, and the modern world. New York: Riverhead Books.

Kearns, R. (2005). Knowing Seeing? Undertaking Observational Research. In I. Hay (Ed.), Qualitative Research Methods in Human Geography (Second edi., pp. 192-206). New York: Oxford University Press.

Knapp, C. N., \& Trainor, S. F. (2013). Adapting science to a warming world. Global Environmental Change, 23(5), 1296-1306. doi:10.1016/j.gloenvcha.2013.07.007 
Kretzmann, J. P., \& McKnight, J. L. (1993). Building Communities from the Inside Out: A Path Toward Finding and Mobilizing a Community's Assets.

Kubursi, A., Cummings, H., MacRae, R., \& Kanaroglou, P. (2015). Dollars \& Sense: Opportunities to Strenghten Southern Ontario's Food System.

Kulla, B. (1979). Angewandte Systemwissenschaft [translated from German to "Applied Systems Science"]. Wuerzburg: Physica-Verlag.

Lauriault, T. P., \& Mooney, P. (2014). Crowdsourcing: A Geographic Approach to Public Engagement Keywords (No. Working paper 6).

Lawrence, H., Robertson, C., \& McLeman, R. (2013). VGI-based citizen science: a field report from the frontlines of the RinkWatch project. In ESRI GIS in Education Conference. Toronto, Ontario. Retrieved from http://www.esri.ca/en/content/gis-educationconference

Leal, J. (2015). Ontario's Local Food Report: 2014-15 Edition. Ontario Ministry of Agriculture, Food and Rural Affairs, (June), 24. Retrieved from http://www.omafra.gov.on.ca/english/about/local_food_rpt.htm

Leszczynski, A., \& Wilson, M. W. (2013). Guest editorial: theorizing the geoweb. GeoJournal, 78(6), 915-919. doi:10.1007/s10708-013-9489-7

Levkoe, C. Z. (2006). Learning Democracy Through Food Justice Movements. Agriculture and Human Values, 23(1), 89-98. doi:10.1007/s10460-005-5871-5

Levkoe, C. Z. (2011). Propagating the food movement: a uniquely decentralized and mighty $\begin{array}{llll}\text { movement. } & \text { Briarpatch } & \text { Magazine. } & \text { Retrieved }\end{array}$ http://briarpatchmagazine.com/articles/view/propagating-the-food-movement

Levkoe, C. Z., Bebee, M., Wakefield, S., Castel, E., \& Dávila, C. (2012). Propagating the Food Movement: Provincial Networks and Social Mobilization in Canada. Food Secure Canada, 40. Retrieved from 
http://foodsecurecanada.org/sites/foodsecurecanada.org/files/LEVKOE-ReportFINAL.pdf

Levkoe, C. Z., \& Dávila, C. (2010). Canadian Food Networks: Propagating the Food Movement, 2010.

Liang, S., Bermudez, L. E., Huang, C., Jazayeri, M., \& Khalafbeigi, T. (2013). Advances on Sensor Web for Internet of Things. American Geophysical Union. Retrieved from http://adsabs.harvard.edu/abs/2013AGUFMIN41C1615L

Lin, W. (2013). Volunteered geographic information and networked publics? Politics of everyday mapping and spatial narratives. GeoJournal, 78(6), 949-965. doi:10.1007/s10708-013-9490-1

Longley, P., Goodchild, M. F., Maguire, D., \& Rhind, D. (2011). Geographic Information Systems and Science. Hoboken: John Wiley \& Sons.

Macias, T. (2008). Working toward a just, equitable, and local food system: the social impact of community-based agriculture. Social Science Quarterly, 89(5), 1086-1101.

Martellozzo, F., Landry, J.-S., Plouffe, D., Seufert, V., Rowhani, P., \& Ramankutty, N. (2014). Urban agriculture: a global analysis of the space constraint to meet urban vegetable demand. Environmental Research Letters, 9(6), 064025. doi:10.1088/17489326/9/6/064025

Maryland Food System Map. (n.d.). Retrieved December 12, 2014, from http://mdfoodsystemmap.org/about-the-map/

McDougall, K. (2015). Growing Round Town. Retrieved May 2, 2015, from http://www.incredible-edible-todmorden.co.uk/projects/growing-round-town

McGarry, F., Cowan, D., \& Alencar, P. (2010). Geomatics for Collaborative Innovation. In Canadian Geomatics Conference. 
Méndez, E., Bacon, C., \& Cohen, R. (2013). Agroecology as a transdisciplinary, participatory, and action-oriented approach. Agroecology and Sustainable Food Systems, 37(1), 318. doi:10.1080/10440046.2012.736926

Miller, H. J. (2004). Tobler's First Law and Spatial Analysis. Annals of the Association of American Geographers, 94(2), 284-289.

Miller, H. J., \& Goodchild, M. F. (2014). Data-driven geography. GeoJournal. doi:10.1007/s10708-014-9602-6

Mohney, G. (2014). You Can Help the Red Cross Map the Ebola Zone and Fight the Outbreak. Retrieved October 21, 2014, from http://abcnews.go.com/Health/redcross-map-ebola-zone-fight-outbreak/story?id=24863778

Mooney, P., \& Cocoran, P. (2011). Can volunteered geographic information be a participant in eEnvironment and SDI? In J. Hřebíček, G. Schimak, \& R. Denzer (Eds.), Environmental Software Systems: Frameworks of EEnvironment (pp. 115-122). Hoboken: Springer.

Morrison, K. T., Nelson, T. a., \& Ostry, A. S. (2011). Methods for mapping local food production capacity from agricultural statistics. Agricultural Systems, 104(6), 491499. doi:10.1016/j.agsy.2011.03.006

Mount, P., \& Andrée, P. (2013). Visualising community-based food projects in Ontario. Local Environment, 18(5), 578-591.

Neis, P., \& Zielstra, D. (2014). Recent developments and future trends in volunteered geographic information research: the case of OpenStreetMap. Future Internet, 6(1), 76-106. doi:10.3390/fi6010076

Neis, P., \& Zipf, A. (2012). Analyzing the Contributor Activity of a Volunteered Geographic Information Project - The Case of OpenStreetMap. ISPRS International Journal of GeoInformation, 1(3), 146-165. doi:10.3390/ijgi1020146 
Neptis Foundation. (2015). Neptis Geoweb: Engagement by Visualization. Retrieved March 22, 2015, from http://www.neptis.org/neptis-geoweb-engagement-visualization

Neumann, W. P., Dixon, S. M., \& Ekman, M. (2012). Ergonomics action research I: shifting from hypothesis testing to experiential learning. Ergonomics, 55(10), 1127-1139. doi:10.1080/00140139.2012.700327

Newman, G., Zimmerman, D., Crall, A., Laituri, M., Graham, J., \& Stapel, L. (2010). Userfriendly web mapping: lessons from a citizen science website. International Journal of Geographical Information Science, 24(12), 1851-1869. doi:10.1080/13658816.2010.490532

Newman, L., \& Dale, A. (2009). Large footprints in a small world: toward a macroeconomics of scale. Sustainability: Science, Practice, \& Policy, 5(1), 9-19.

Nivala, A.-M., Brewster, S., \& Sarjakoski, T. L. (2008). Usability Evaluation of Web Mapping Sites. The Cartographic Journal, 45(2), 129-138. doi:10.1179/174327708X305120

Okolloh, 0. (2009). Ushahidi, or "testimony": Web 2.0 tools for crowdsourcing crisis information. Participatory Learning and Action, 59(1), 65-70. Retrieved from http://www.ingentaconnect.com/content/iiedpla/pla/2009/00000059/00000001/a rt00010

Parry, O., \& Mauthner, N. S. (2004). Whose Data Are They Anyway? Practical, Legal and Ethical Issues in Archiving Qualitative Research Data. Sociology: The Journal of the British Sociological Association, 38(1), 139-152. doi:10.1177/0038038504039366

Peng, Z., \& Tsou, M.-H. (2003). Internet GIS: distributed geographic information services for the Internet and wireless networks. New Jersey: John Wiley \& Sons.

Peters, C. J., Bills, N. L., Wilkins, J. L., \& Fick, G. W. (2008). Foodshed analysis and its relevance to sustainability. Renewable Agriculture and Food Systems, 24(01), 1-7. doi:10.1017/S1742170508002433 
Pickles, J. (Ed.). (1995). Ground Truth: The Social Implications of Geographic Information Systems. New York: Guilford Press.

Poore, B. S., \& Chrisman, N. R. (2006). Order from noise: toward a social theory of geographic information. Annals of the Association of American Geographers, 96(3), 508-523.

Pothukuchi, K., Joseph, H., Burton, H., \& Fisher, A. (2002). What's cooking in your food system? A guide to community food assessment. Community Food Security Coalition, 127.

Rabari, C., \& Storper, M. (2014). The digital skin of cities: urban theory and research in the age of the sensored and metered city, ubiquitous computing and big data. Cambridge Journal of Regions, Economy and Society, 8(1), 27-42. doi:10.1093/cjres/rsu021

Resch, B. (2013). People as Sensors and Collective Sensing- Contextual Observations Complementing Geo-Sensor Network Measurements. In J. M. Krisp (Ed.), Progress in Location-Based Services (pp. 391-406). Berlin, Heidelberg: Springer. doi:10.1007/978-3-642-34203-5

Rhind, D. (1977). Computer-aided cartography. Transactions of the Institute of British Geographers, 2(1), 71-97.

Rinner, C., \& Bird, M. (2009). Evaluating community engagement through argumentation maps-a public participation GIS case study. Environment and Planning B: Planning and Design, 36(4), 588-601. doi:10.1068/b34084

Rinner, C., \& Fast, V. (2015). A Classification of User Contributions on the Participatory Geoweb. In F. Harvey \& Y. Leung (Eds.), Advances in Spatial Data Handling and Analysis: Select Papers from the 16th IGU Spatial Data Handling Symposium (pp. 3549). Switzerland: Springer. doi:10.1007/978-3-319-19950-4 
Rinner, C., Keßler, C., \& Andrulis, S. (2008). The use of Web 2.0 concepts to support deliberation in spatial decision-making. Computers, Environment and Urban Systems, 32(5), 386-395. doi:10.1016/j.compenvurbsys.2008.08.004

Rinner, C., Kumari, J., \& Mavedati, S. (2011). A geospatial web application to map observations and opinions in environmental planning. In S. Li, S. Dragicevic, \& B. Veenendall (Eds.), Advances in Web-based GIS, Mapping Services and Applications (pp. 277-291). London: Taylor and Francis.

Roberts, S., Grosser, S., \& Swartley, B. D. (2012). Crowdsourcing to geocode development credit authority data: a case study. Retrieved from http://www.usaid.gov/sites/default/files/documents/2151/USAIDCrowdsourcingCas eStudy.pdf

Rural Economic Development Program. (2013). Local Food Fund, OIC 201/20. Retrieved from www.Ontario.ca/localfood

Sani, A. P., \& Rinner, C. (2011). A Scalable Geoweb Tool for Argumentation Mapping. Geomatica, 65(2), 145-156.

Scassa, T. (2013). Legal issues with volunteered geographic information. The Canadian Geographer, 57(1), 1-10. doi:10.1111/j.1541-0064.2012.00444.x

Scassa, T. (2014). Privacy and Open Government. Future Internet, 6(2), 397-413. doi:10.3390/fi6020397

Schaffer, J. (2007). Citizen Media: Fad or the Future of News? The rise and prospects of hyperlocal journalism. Baltimore, MD. Retrieved from http://www.jlab.org/_uploads/downloads/citizen_media-1.pdf

Scharf, K., Levkoe, C., \& Saul, N. (2010). In Every Community a Place for Food: The Role of the Community Food Centre in Building a Local, Sustainable, and Just Food System. Toronto: Metcalf Foundation. 
Schuurman, N. (2009). The new Brave New World: geography, GIS, and the emergence of ubiquitous mapping and data. Environment and Planning D: Society and Space, 27(4), 571-572. doi:10.1068/d3809

Schwartz, M. S., \& Schwartz, C. G. (1955). Problems in Participant Observation. Problems in Participant Observation, 60(4), 343-353.

Seeger, C. J. (2008). The role of facilitated volunteered geographic information in the landscape planning and site design process. GeoJournal, 72(3-4), 199-213. doi:10.1007/s10708-008-9184-2

Seymour, W. (2001). In the flesh or online? Exploring qualitative research methodologies. Qualitative Research, 1(2), 147-168.

Sieber, R. (2006). Public participation geographic information systems: A literature review and framework. Annals of the Association of American Geographers, 96(3), 491-507.

Sieber, R. E., \& Johnson, P. a. (2015). Civic open data at a crossroads: Dominant models and current challenges. Government Information Quarterly. doi:10.1016/j.giq.2015.05.003

Software/Desktop - OpenStreetMap Wiki. (n.d.). Retrieved September 12, 2014, from http://wiki.openstreetmap.org/wiki/Software/Desktop

Sonnino, R., \& Spade, J. J. (2014). The "new frontier"? Urban Strategies for Food Security and Sustainability. In T. Marsden \& A. Morley (Eds.), Sustainable Food Systems: Building a New Paradigm (pp. 166-185). Routledge.

Stefanidis, A., Crooks, A., \& Radzikowski, J. (2011). Harvesting ambient geospatial information from social media feeds. GeoJournal, 78(2), 319-338. doi:10.1007/s10708-011-9438-2

Sui, D. Z., Elwood, S., \& Goodchild, M. F. (Eds.) (2013). Crowdsourcing Geographic Knowledge: Volunteered Geographic Information (VGI) in Theory and Practice. Dordrecht: Springer Netherlands. doi:10.1007/978-94-007-4587-2 
Sui, D. Z., \& Goodchild, M. F. (2011). The convergence of GIS and social media: challenges for GIScience. International Journal of Geographical Information Science, 25(11), 1737-1748. doi:10.1080/13658816.2011.604636

Sullivan, T. O., Corneil, W., Kuziemsky, C., Louise, L., \& McCrann, L. (2013). The EnRiCH Community Intervention Collaborative Asset-Mapping to Enhance Resilience for High Risk Populations. Retrieved from http://enrichproject.ca/publications-andresources.html

Sustain, the alliance for better food and farming. (2013). Good Food For London (3rd ed.). London. Retrieved from http://www.london.gov.uk/sites/default/files/good_food_for_london_report_2013.pdf

Tacoli, C. (2014). Up in the air: Citizen scientists map food dangers in Nairobi. Retrieved December 12, 2014, from http://www.iied.org/air-citizen-scientists-map-fooddangers-nairobi

The Rainforest Foundation. (2014). Mapping for Rights: Putting Communities on the Map. Retrieved December 12, 2014, from http://map.mappingforrights.org/

Tomlinson, R. F. (1968). A geographic information system for regional planning. In G. A. Stewart (Ed.), Land Evaluation. (pp. 200-210). Melbourne, Australia: Macmillan.

Tomlinson, R. (2007). Thinking about GIS: geographic information system planning for managers (3rd ed.). Redlands: ESRI Press.

Townsend, A. M. (2013). Smart cities: big data, civic hackers, and the quest for a new utopia (1st ed.). New York: W.W. Norton \& Company, Inc.

Township of Uxbridge. (2014). Official Plan: Township of Uxbridge Office Consolidation $\begin{array}{llll}\text { January } & 2014 . & \text { Uxbridge. } & \text { Retrieved }\end{array}$ http://town.uxbridge.on.ca/sites/default/files/documents/Uxbridge Official Plan Consolidation Jan2014-Complete.pdf 
Tudge, P., Sieber, R., Wiersma, Y., Corbett, J., Chung, S., Allen, P., \& Robinson, P. J. (2012). Collaborating towards innovation: lessons from the participatory GeoWeb GEOIDE Network. In N. R. Chrisman \& M. Wachowicz (Eds.), The Added Value of Scientific Networking: Perspectives from the GEOIDE Network Members 1998-2012 (pp. 103118). Quebec City: GEOIDE Network.

Tulloch, D. L. (2008). Is VGI participation? From vernal pools to video games. GeoJournal, 72(3-4), 161-171. doi:10.1007/s10708-008-9185-1

Unwin, D. J. (1996). GIS, spatial analysis and spatial statistics. Progress in Human Geography, 20(4), 540-551.

Van Loenen, B., \& Onsrud, H. J. (2004). Geographic Data for Academic Research: Assessing Access Policies. Cartography and Geographic Information Science, 31(1), 3-17. doi:10.1559/152304004773112730

Vaz, E., \& Arsanjani, J. (2015). Crowdsourced mapping of land use in urban dense environments: An assessment of Toronto. The Canadian Geographer, 1-10. doi:10.1111/cag.12170

Vota, W. (2012). Dead Ushahidi: a stark reminder for sustainability planning in ICT4D. Retrieved September 10, 2014, from http://www.ictworks.org/2012/07/09/deadushahidi-stark-reminder-sustainability-planning-ict4d/

Walton, M. (2003). Agriculture in the Central Ontario Zone: Issue Paper No. 1M. Toronto, Ontario.

Walton, M. (2012). Golden Horseshoe Food and Farming Action Plan 2021. Planscape Inc., (January), 28. Retrieved from www.gtaaac.ca

Walton-Roberts, M., Beaujot, R., Hiebert, D., McDaniel, S., Rose, D., \& Wright, R. (2014). Why do we still need a census? Views from the age of "truthiness" and the "death of evidence." The Canadian Geographer, 58, 34-47. 
Weber, C. L., \& Matthews, H. S. (2008). Food-Miles and the Relative Climate Impacts of Food Choices in the United States. Environmental Science and Technology, 42(10), 35083513.

Werts, J. D., Mikhailova, E. a, Post, C. J., \& Sharp, J. L. (2012). An integrated WebGIS framework for volunteered geographic information and social media in soil and water conservation. Environmental Management, 49(4), 816-32. doi:10.1007/s00267-0129818-5

Wiener, N. (1961). Cybernetics or Control and Communication in the Animal and the Machine (2nd ed.). Cambridge: MIT Press.

Wiggins, A., \& Crowston, K. (2015). Surveying the citizen science landscape. First Monday, 20(1). doi:http://dx.doi.org/10.5210/fm.v20i1.5520

Williams, M. (2007). Avatar Watching: Participant Observation in Graphical Online Environments. Qualitative Research, 7(1), 5-24. doi:10.1177/1468794107071408

Williams, T., \& Hardison, P. (2013). Culture, law, risk and governance: contexts of traditional knowledge in climate change adaptation. Climatic Change, 120(3), 531544. doi:10.1007/s10584-013-0850-0

Wilson, B. A., \& Mckenzie, S. (2014). Mapping Food Desert Persistency in Thunder Bay, Ontario, 1996-2006. Canadian Social Science, 10(2), 9-18. doi:10.3968/4410

Wilson, M. W., \& Graham, M. (2013). Neogeography and volunteered geographic information: a conversation with Michael Goodchild and Andrew Turner. Environment and Planning A, 45(1), 10-18. doi:10.1068/a44483

Wood, D. (2010). Rethinking the Power of Maps. New York: Guilford Press.

Yu, J., Benatallah, B., Casati, F., \& Daniel, F. (2008). Understanding Mashup Development. IEEE Internet Computing, 12(5), 44-52. doi:10.1109/MIC.2008.114 
Zook, M., Graham, M., Shelton, T., \& Gorman, S. (2010). Volunteered geographic information and crowdsourcing disaster relief: a case study of the Haitian earthquake. World Medical and Health Policy, 2(2), 6-32. doi:10.2202/1948-4682.1069 


\section{GLOSSARY}

\section{List of Abbreviations and Acronyms}

API - application programming interface

APO - active participant observation

CAM - collaborative asset mapping

CAMH - Center for Addiction and Mental Health

CAP - Clean Air Partnership

DFF - Durham Farm Fresh

DIG - Durham Integrated Growers

DFPC - Durham Food Policy Council

DFSES - Durham Food System Environmental Scan

Geoweb - geospatial web 2.0

GHFFA - Golden Horseshoe Food and Farming Alliance

GIS - geographic information systems

GISci / GIScience - geographic information science

NGO - non government organization

PPGIS / PGIS - public participation GIS / participatory GIS

RSS Feed - rich site summary feed

SMS - simple text messages

UGC - user generated content

UGGC - user generated geographic content

VGI - volunteered geographic information

WGF - We Grow Food

\section{List of Software and Applications}

Argoomap - http://sourceforge.net/projects/argoomap/

CartoDB - https://cartodb.com

Crowdmap (Classic) - https://crowdmap.com

Durham Food Map (Crowdmap version) - https://durhamfood.crowdmap.com

Food Assets in Durham Region Map (CartoDB version) - http://cdb.io/1Ljjx18

GeoCommons - http://geocommons.com

GeoLive - http://www.geolive.ca

GeoKey - http://geokey.org.uk

Mapnik - http://mapnik.org

OpenStreetMap - https://www.openstreetmap.org

Plantwatch - https://www.naturewatch.ca/plantwatch/

RinkWatch - http://www.rinkwatch.org

Ushahidi - http://www.ushahidi.com

Wikimapia - http://wikimapia.org 


\section{Definitions}

Citizen science - engaging the public to contribute to various aspects of scientific study, which can include monitoring and reporting on the phenomena under investigation

Geographical citizen science - citizen science that has a location component; for example, using a GPS to track hikers

Crowdsourcing - a process where the community (a crowd) is engaged to contribution to a particular task, blending bottom-up openness and top-down management

Food deserts - lack of food availability

Food swaps - availability of primarily unhealthy food

GIS - Geographic information Systems

Attribute - information associated with a geographic feature; e.g., the building feature contains attributes on building size, age, and building height

Field - columns storing data about attributes; e.g., building size, age, and building height are individual fields in the attribute table

Geographic feature - the representation of an object on a map, which can be represented using points (e.g., building), lines (e.g., road), or polygons (e.g., park)

GIScientists - a person trained in the theory and application of GIS

Metadata - data about data, including details about creator, origins, and timestamp

Map mashup - mixing a variety of data sources, most often using Google API, in an online mapping application

Neogeography - the new geography where everyone (in theory) has access to geographic tools, including map making

VGI - Volunteered Geographic Information

Footprint VGI - unknown and unintentional contributions of spatial content

Passive VGI - known but unintentional contributions of spatial content

Active VGI - known and intentional contributions of spatial content 